\title{
WestVirginiaUniversity
}

THE RESEARCH REPOSITORY @ WVU

Graduate Theses, Dissertations, and Problem Reports

2006

\section{Forecasting truck traffic growth at West Virginia non-interstate highways}

\author{
Sundeep Gopisetty \\ West Virginia University
}

Follow this and additional works at: https://researchrepository.wvu.edu/etd

\section{Recommended Citation}

Gopisetty, Sundeep, "Forecasting truck traffic growth at West Virginia non-interstate highways" (2006). Graduate Theses, Dissertations, and Problem Reports. 1770.

https://researchrepository.wvu.edu/etd/1770

This Thesis is protected by copyright and/or related rights. It has been brought to you by the The Research Repository @WVU with permission from the rights-holder(s). You are free to use this Thesis in any way that is permitted by the copyright and related rights legislation that applies to your use. For other uses you must obtain permission from the rights-holder(s) directly, unless additional rights are indicated by a Creative Commons license in the record and/ or on the work itself. This Thesis has been accepted for inclusion in WVU Graduate Theses, Dissertations, and Problem Reports collection by an authorized administrator of The Research Repository @ WVU. For more information, please contact researchrepository@mail.wvu.edu. 


\title{
Forecasting Truck Traffic Growth at West Virginia Non-Interstate Highways
}

\author{
By \\ Sundeep Gopisetty
Thesis submitted to the
College of Engineering and Mineral Resources
at West Virginia University
in partial fulfillment of the requirements
for the degree of
Master of Science
in
Civil Engineering \\ Approved By \\ David R. Martinelli, Ph.D., Chair \\ Lloyd. J. French, Ph.D. \\ Ronald W. Eck, Ph.D. \\ Department of Civil and Environmental Engineering \\ Morgantown, West Virginia \\ 2006
}

Keywords: Highways, Analysis, Forecasting, Truck Traffic, Growth Rate 


\section{ABSTRACT \\ Forecasting Truck Traffic Growth at West Virginia Non-Interstate Highways \\ Sundeep Gopisetty}

Reliable estimates of truck volumes are important in transportation planning and design applications, such as pavement design and management. This study evaluates different statistical methods based on their accuracy and data requirements, to calculate the truck growth rates by developing statistical models. Nine years of data from 1995 to 2003 was used to develop these models for calculating the truck growth rates at non-interstate highways of West Virginia. The literature review and the current practices for the state DOT was conducted to better understand and select the different forecasting methods that could be applicable to the given data. As a result, the two techniques namely, the regression analysis and the growth factor method were used for the purpose. These techniques were applied to each site and for each truck classification. For a clear perspective of truck traffic patterns across the state, the sites were grouped based on the location of the counters, i.e., the rural and the urban, and trucks were grouped according to the number of axles. Precision test was then conducted to validate the models. All the results from the methods used for this study were compared and was concluded that the regression analysis is the best suited method for the given data, in West Virginia. The comprehensive approach to the evaluation can be used by the state DOT. 


\section{ACKNOWLEDGEMENTS}

I would like to thank, Dr. David R. Martinelli, who is responsible for helping me complete the writing of this thesis as well as the challenging research that lies behind it. He has not only been my advisor but also a mentor. Besides my advisor, I would also like to thank Dr. Lloyd J. French and Dr. Ronald W. Eck, for their guidance and insightful comments by reviewing my work on a very short notice and rescuing me from various red tape crises. The quality of this study was greatly enhanced by the gracious assistance of my committee.

Also, a word of thanks to West Virginia Division of Highways (WVDOH) and MidAtlantic Universities Transportation Center (MAUTC) for their financial support of this project. MAUTC is recognized as one of the ten original centers in the University Transportation Centers Program, which is established by the U.S. Department of Transportation (USDOT) in 1987.

The beautiful weather in Morgantown, West Virginia has kept me in good spirits. Also, thanks to the folks at West Virginia University for their encouragement and moral support all the way. Last but not the least; I thank my parents for their unconditional support and encouragement to pursue my interests, though the interests went beyond boundaries of language, field and geography. 


\title{
TABLE OF CONTENT
}

\begin{abstract}
..................................................................................................................................................... ii

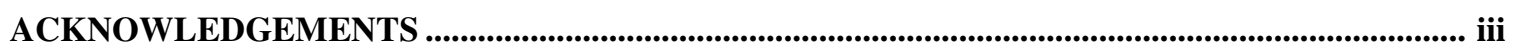

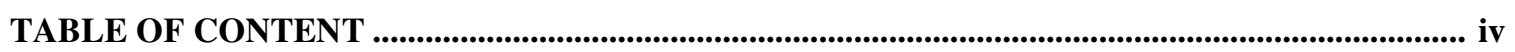

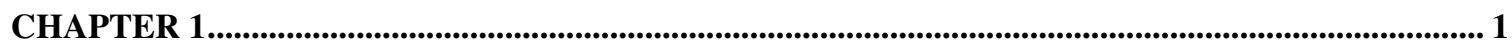

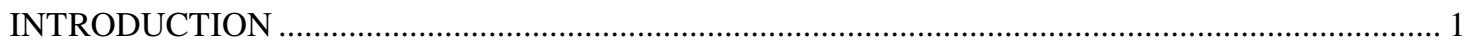

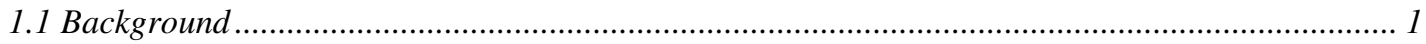

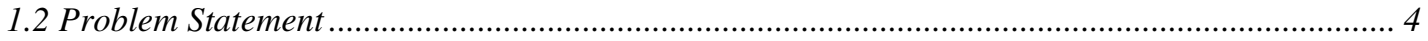

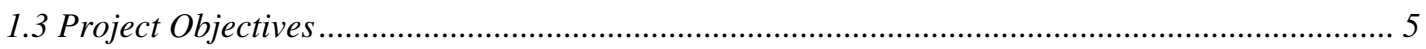

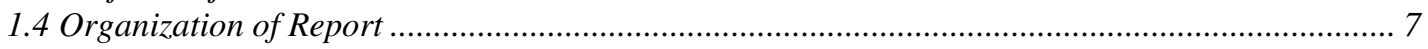

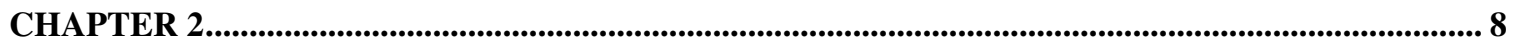

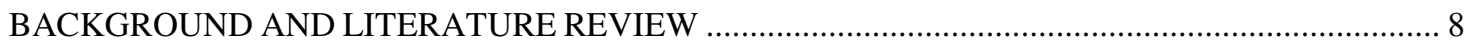

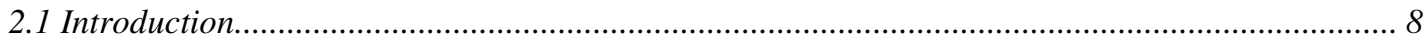

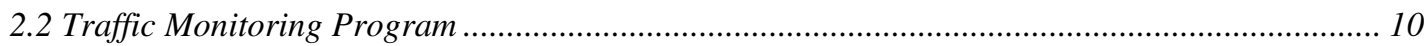

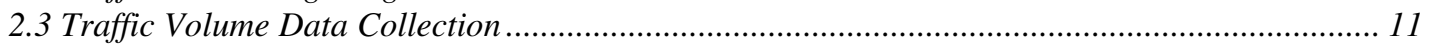

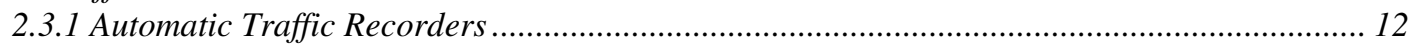

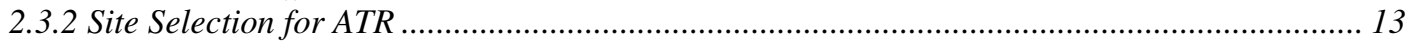

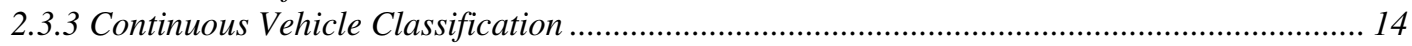

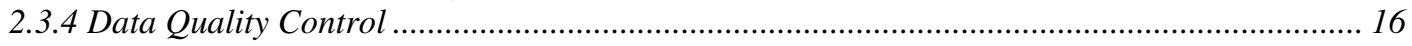

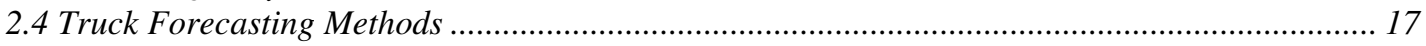

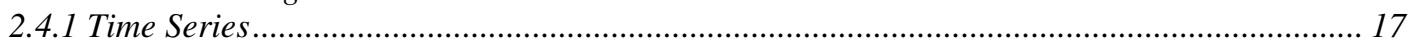

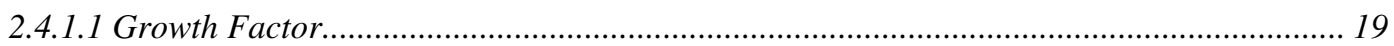

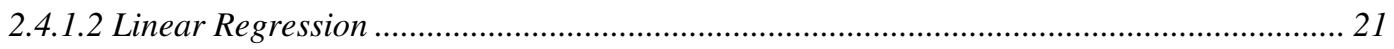

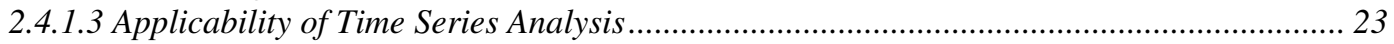

2.4.1.4 Forecasting AADTT Using a Variety of Independent Variables ......................................... 24

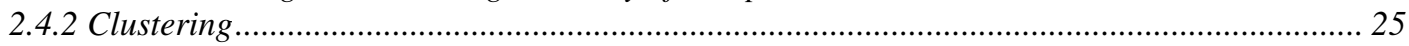

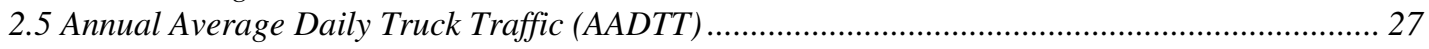

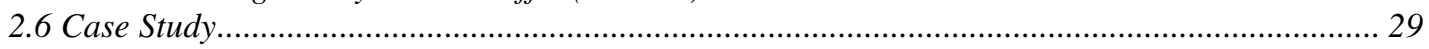

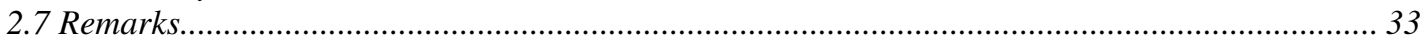

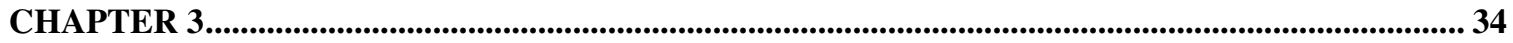

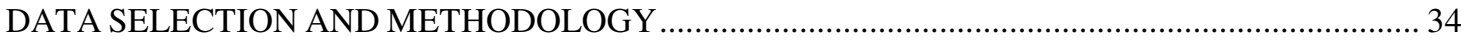

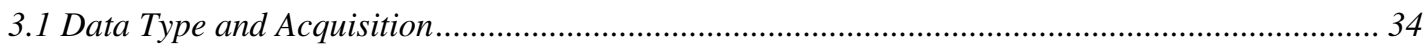

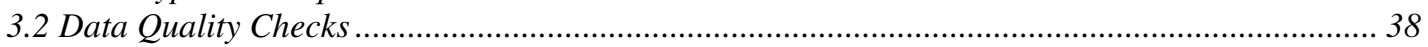

3.3 Estimation of Annual Average Daily Truck Traffic (AADTT) .................................................. 39

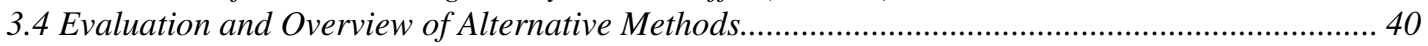

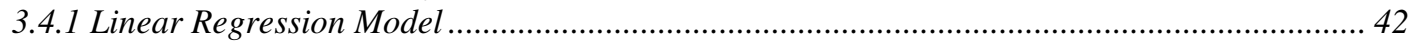

3.4.1.1 Statewide Growth Rate for Non-Interstate Highways ........................................................ 43

3.4.1.2 Regression Analysis for Each Truck Classification ............................................................ 43

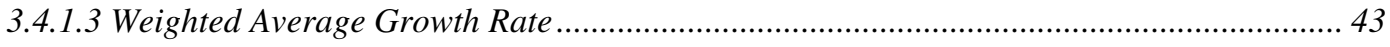

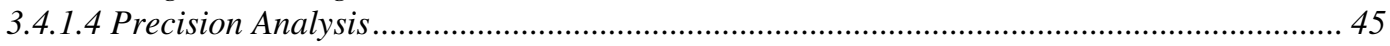

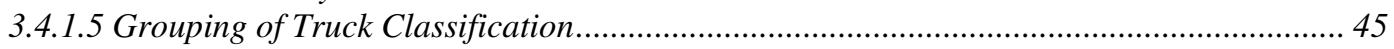

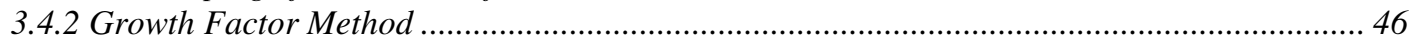

3.4.2.1 Statewide Growth Rate for Non-Interstate Highways ........................................................... 46

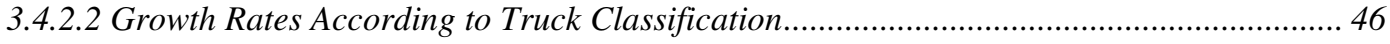

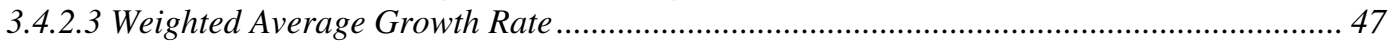

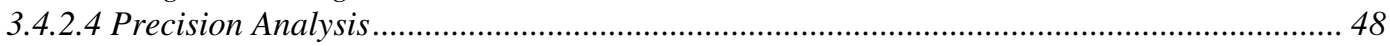

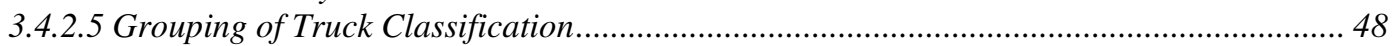

3.4.3 Calibration and Validation of the Models Selected ................................................................ 48 


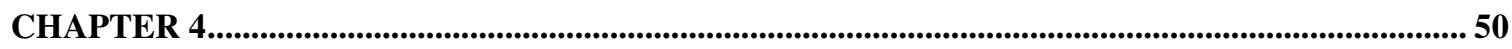

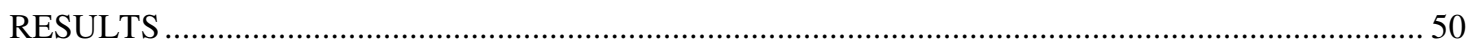

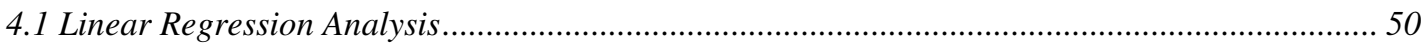

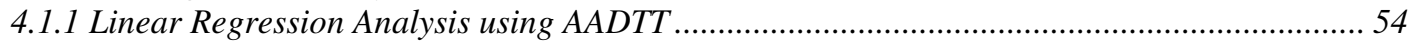

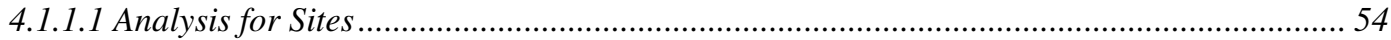

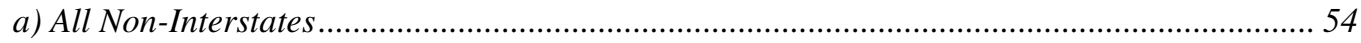

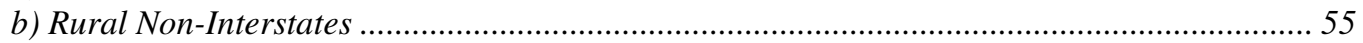

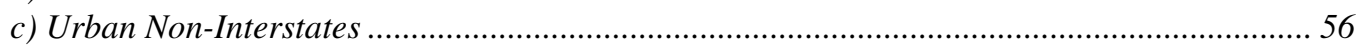

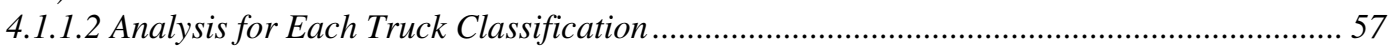

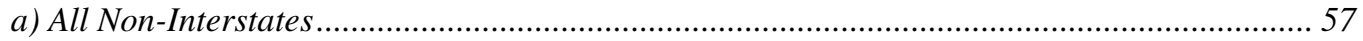

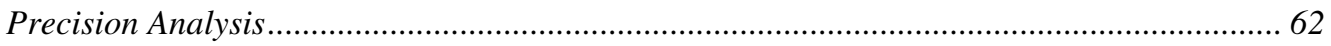

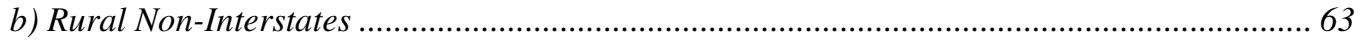

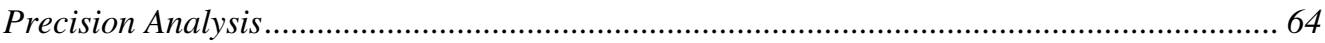

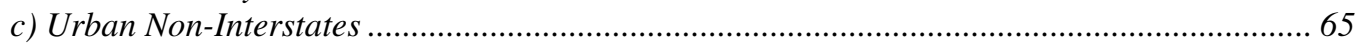

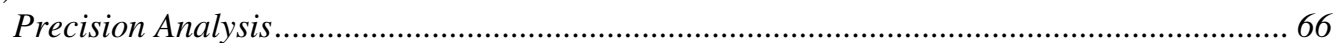

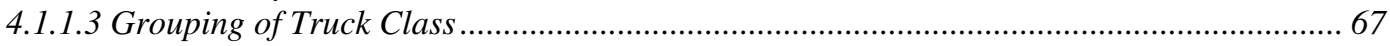

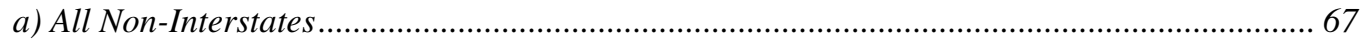

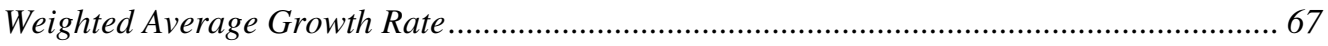

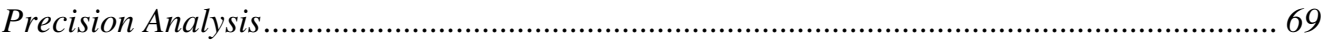

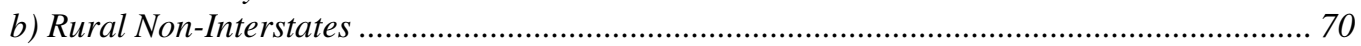

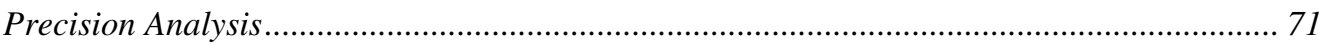

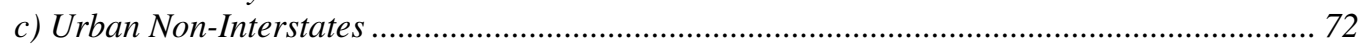

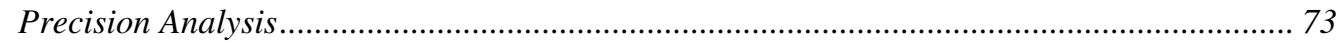

4.1.2 Linear Regression Analysis using Yearly Average of AADTT .............................................. 74

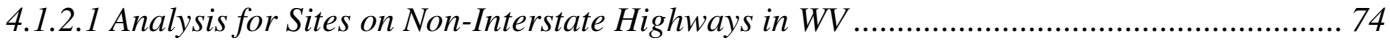

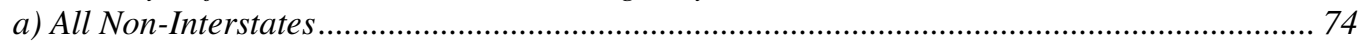

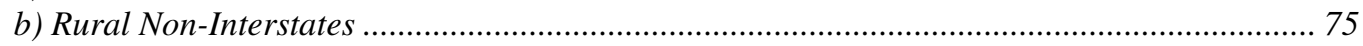

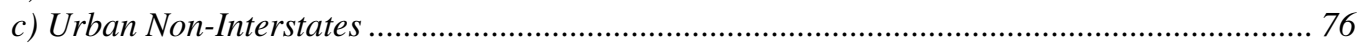

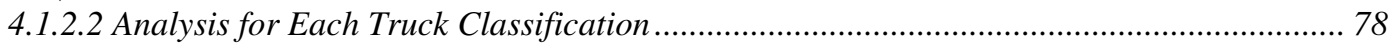

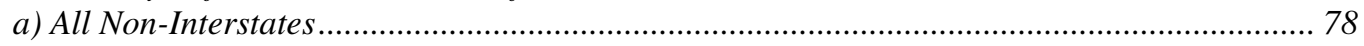

Analysis by Grouping Truck Classes................................................................................. 79

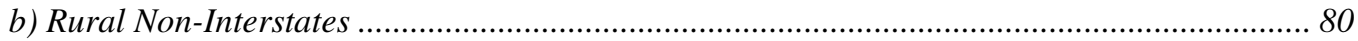

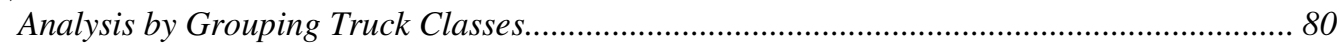

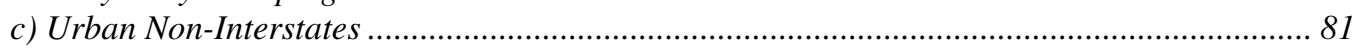

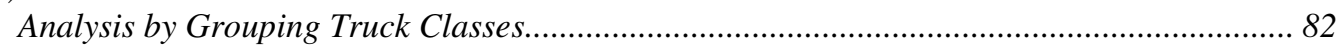

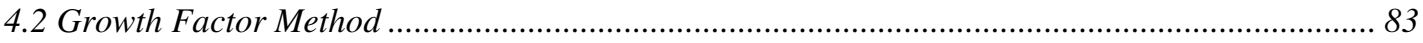

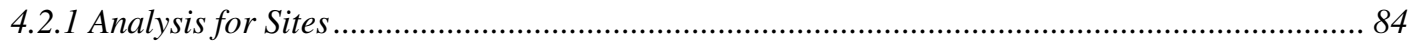

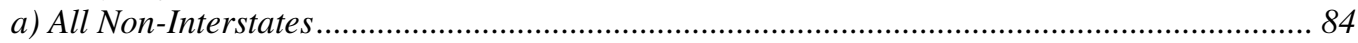

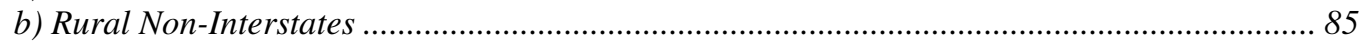

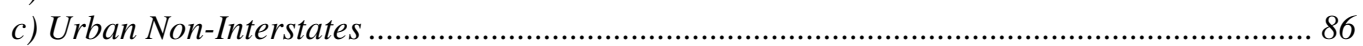

4.3 Comparison among the resulted Annual Average Growth Rates by different Methods................ 87

4.3.1 Annual Average Growth Rate for All, Rural and Urban Non-Interstate Highways.................. 87

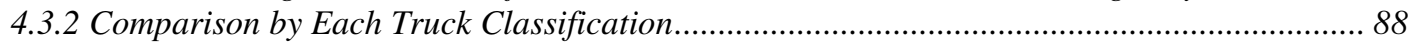

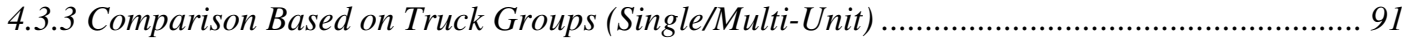

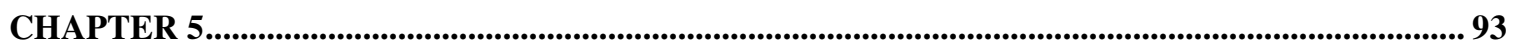

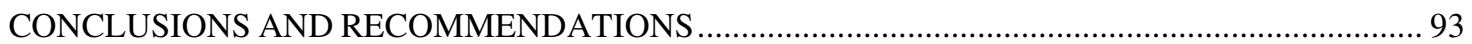

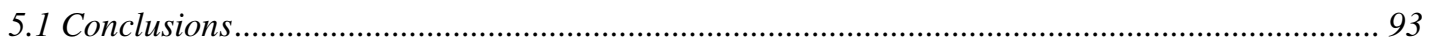

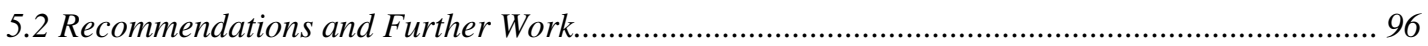

REFERENCES .................................................................................................................................................... 97

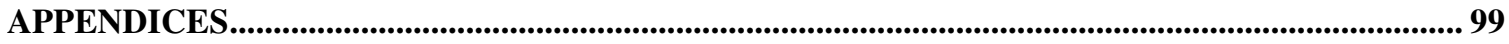

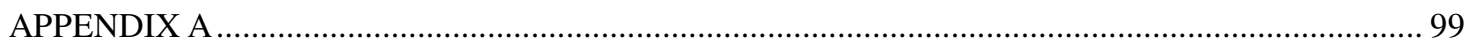

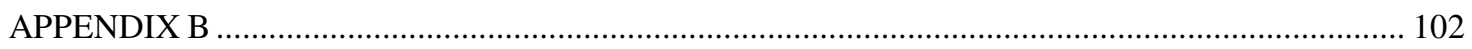

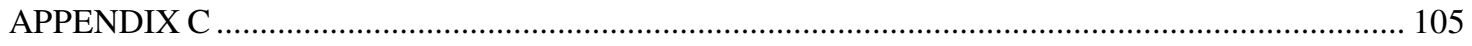




\section{LIST OF TABLES}

Table 2.1 - The Highway Performance Monitoring System Functional Classes …………………………………..... 25

Table 3.1 - List of Non-Interstate Permanent Traffic Count Stations in West Virginia ………………………….. 35

Table 3.2 - List of Traffic Count Stations used for this Project …………………………………………………………. 36

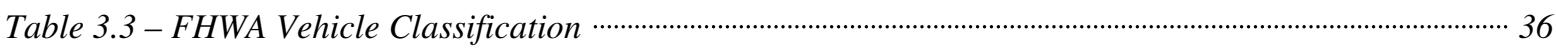

Table 3.4 - Annual Average Daily Truck Traffic (AADTT) at Non-Interstate Highways …………………….... 39

Table 4.1 - Linear Regression Models and Coefficient of Regression Values for Each Site ………………………. 50

Table 4.2 - Missing AADTT values Estimated using the Regression Models ………………………………………..... 51

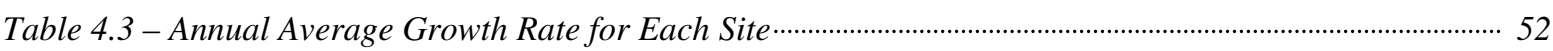

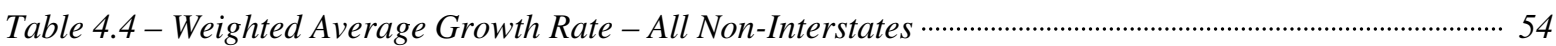

Table 4.5 - Weighted Average Growth Rate - Rural Non-Interstates ……………………………………………… 55

Table 4.6 - Weighted Average Growth Rate - Urban Non-Interstates ……………………………………………….. 56

Table 4.7 - Annual Average Growth Rate according to Truck Classification - All Non-Interstates.................... 58

Table 4.8 - AADTT from 1995 to 2003 for Each Truck Classification and Site - All Non-Interstates ............... 58

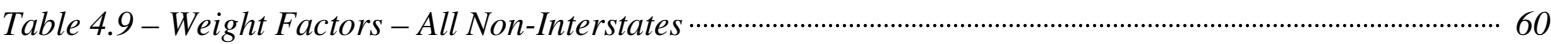

Table 4.10 - Weighted Average Growth Rate - All Non-Interstates ……………………………………………………... 61

Table 4.11 - Coefficient of Variation (CV) for Each Truck Class - All Non-Interstates …………………………… 62

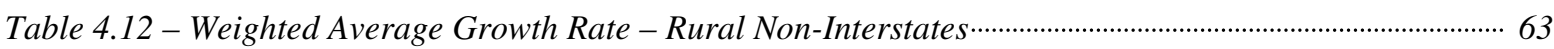

Table 4.13 - Coefficient of Variation (CV) for Each Truck Class - Rural Non-Interstates ………………………... 64

Table 4.14 - Weighted Average Growth Rate - Urban Non-Interstates ……………………………………………….... 65

Table 4.15 - Coefficient of Variation (CV) for Each Truck Class - Urban Non-Interstates .................................. 66

Table 4.16 - Annual Average Growth Rates for Single and Multi-Unit Truck Classes

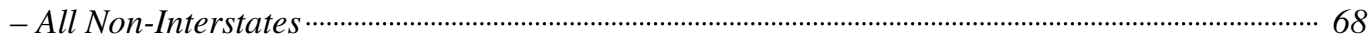

Table 4.17 - Weight Factors for Single and Multi-Unit Truck Classes - All Non-Interstates …………........... 68

Table 4.18 - Weighted Average Growth Rate (all non-Interstates) …………………………………………………...... 68

Table 4.19 - Coefficient of Variation (CV) for analysis in Each Truck Group (Single/Multi-Unit)

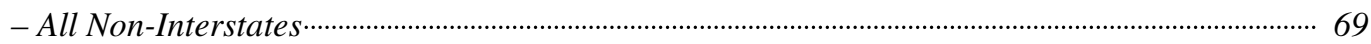

Table 4.20 - Weight Factors for Single and Multi-Unit Truck Classes - Rural Non-Interstates ……………….... 70

Table 4.21 - Weighted Average Growth Rate (rural non-intestates) ……………………………………………….. 70

Table 4.22 - Coefficient of Variation (CV) for analysis in Each Truck Group (Single/Multi-Unit)

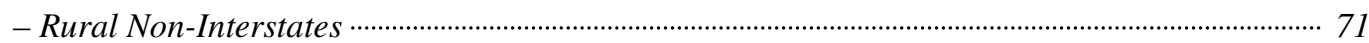

Table 4.23 - Weight Factors for Single and Multi-Unit Truck Classes - Urban Non-Interstates ........................ 72

Table 4.24 - Weighted Average Growth Rate (urban non-intestates) ……………………………………………………..... 72

Table 4.25 - Coefficient of Variation (CV) for analysis in Each Truck Group (Single/Multi-Unit)

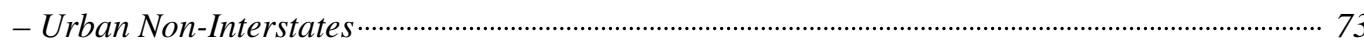


Table 4.26 - Linear Regression Models, Growth Rates and Coefficients of Regression $\left(R^{2}\right)$ Values for Each Truck Classification - All Non-Interstate Highways ……………………………………….... 78

Table 4.27 - Linear Regression Models, Growth Rates and Coefficients of Regression $\left(R^{2}\right)$ Values for Each Truck Classification - (single and multi-unit) All Non-Interstates ……………………………..... 79

Table 4.28 - Linear Regression Models, Growth Rates and Coefficients of Regression $\left(R^{2}\right)$ Values for Each Truck Classification - Rural Non-Interstate Highways …………………………………….... 80

Table 4.29 - Linear Regression Models, Growth Rates and Coefficients of Regression $\left(R^{2}\right)$ Values for Each Truck Classification - (single and multi-unit) Rural Non-Interstates ………....................... 81

Table 4.30 - Linear Regression Models, Growth Rates and Coefficients of Regression $\left(R^{2}\right)$ Values for Each Truck Classification - Urban Non-Interstate Highways ………………………………….... 81

Table 4.31 - Linear Regression Models, Growth Rates and Coefficients of Regression $\left(R^{2}\right)$ Values for Each Truck Classification - (single and multi-unit) Urban Non-Interstates.………………………... 82

Table 4.32 - Weighted Average Growth Rate - All Non-Interstates ……………………………………………………… 84

Table 4.33 - Weighted Average Growth Rate - Rural Non-Interstates ………………………………………….. 85

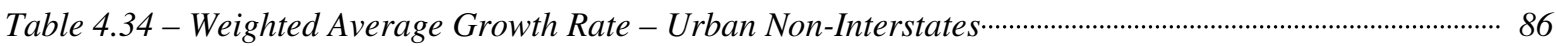

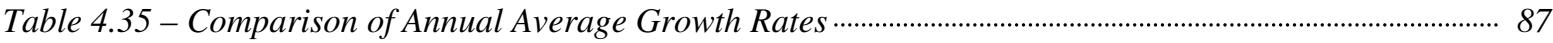

Table 4.36 - Comparison of Annual Average Growth Rates - All Non-Interstate Highways ……………………. 88

Table 4.37 - Comparison of Annual Average Growth Rates - Rural Non-Interstates ……………………….... 89

Table 4.38 - Comparison of Annual Average Growth Rates - Urban Non-Interstates ……………………...... 90

Table 4.39 - Comparison of Annual Average Growth Rates - All Non-Interstate Highways …………………….. 91

Table 4.40 - Comparison of Annual Average Growth Rates - Rural Non-Interstates ……………………………... 91

Table 4.41 - Comparison of Annual Average Growth Rates - Urban Non-Interstates …………………………... 92

Table 5.1 - Comparing Different Forecasting Methods ………………………………………………………….... 94 


\section{LIST OF FIGURES}

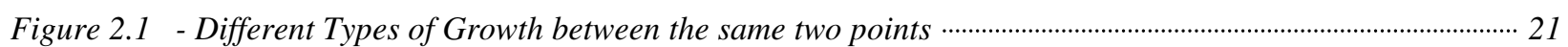

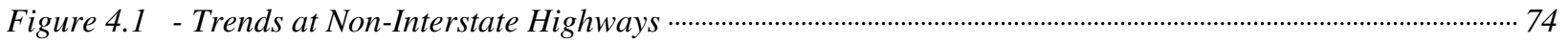

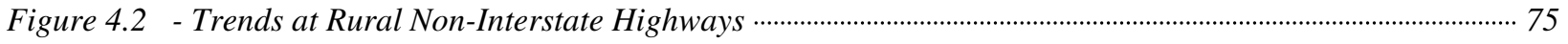

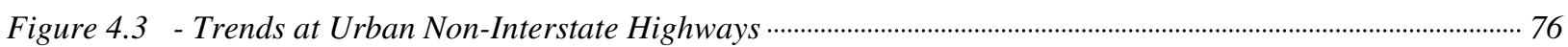




\section{CHAPTER 1}

\section{INTRODUCTION}

\subsection{Background}

West Virginia's 38,281 miles of roads and streets are grouped into functional classes according to the type of service they provide. For the purposes of this study, a non-Interstate highway was considered "out of standard" if it does not have the following:

- Full control of access with no traffic signals, pedestrian crossings, at-grade intersections.

- A minimum of two traffic lanes in each direction, separated by a median.

- A minimum of 2' shoulder or clearance on each side of the travelway.

Non-Interstate highway systems are generally constructed to Interstate standards, but are not required to. This is generally up to the state or local entity responsible for the highway. According to the West Virginia classification system for highways, the nonInterstate highway system accounted for 1,292 miles in length whereas, the interstate highway system accounted for just 555 miles in length (As of June 30, 2000). This implies that non-Interstate highways also share a major portion of the entire highway system.

Travel on the state's non-Interstate highways, by both passenger cars and large commercial trucks, has increased significantly since 1990. Trucks are the mode of choice 
for the majority of local and regional distribution and delivery activity across the U.S. Trucks, especially large or heavy trucks, because of their size, weight, and subsequent operating characteristics can disrupt traffic flows, exacerbating already congested roadways. They have a large influence on various engineering designs including pavement design, alignment and intersection design.

Efficient transport is indispensable for economic growth and prosperity. Intermodal transport is a necessary component of an efficient transport network, at both the national and international levels. The U.S. freight transportation network moves a staggering volume of goods each year. Over 15 billion tons of goods, worth over $\$ 9$ trillion, were moved in 1998 (USDOT FHWA 2002a). The movement of bulk goods, such as grains, coal, and ores, still comprises a large share of the tonnage moved on the U.S. freight network. One of the principal modes of freight transportation is by trucks.

In 1998, excluding commodities transported by pipeline, trucks moved 71 percent of total tonnage and 80 percent of the total value of U.S. shipments. By 2020, trucks are expected to haul about three quarters of total tonnage, followed by rail (14 percent), water (7 percent), and air (less than 1 percent). As the demand for goods and services grows, so does the amount of truck traffic on the nation's highways. Transportation is becoming an even more critical segment of the food distribution network as food distribution is the most dispersed segment of the economy. The nation's food distribution system is becoming increasingly reliant on truck travel to move agricultural products. The United States Department of Agriculture (USDA) reports that 90 percent of refrigerated 
perishables, such as fruits and vegetables, are delivered by truck. A recent report found that it was likely that market changes and changes in consumer preferences were likely to further increase the reliance on trucking to move U.S. agricultural products (Growing Traffic in Rural America: Safety, Mobility and Economic Challenges in America's Heartland, March 2005).

Information about truck traffic volumes is necessary to meet federal reporting requirements and to assist state and local agencies in assessing system performance and needs. Effective management of truck traffic is a common goal throughout the nations of the world, and unsurprisingly, across most urbanized areas of the U.S. Therefore, traffic forecasting is one of the most basic functions of highway planning and management. Traffic monitoring counts provide the most commonly employed measure of roadway usage and are needed for the majority of traffic engineering analysis. The Traffic Monitoring and Forecasting Program concentrates on the collection of traffic volume, vehicle classification and truck weight data. This program will affect the truck travel patterns at highway systems and may be applied to project planning, design of new roadways, safety analysis, and air quality assessment. 


\subsection{Problem Statement}

Over the last two decades, the volume of trucks has grown dramatically, and the mix of goods and the way they are moved have changed. Commercial trucking is projected to increase $51 \%$ in West Virginia by 2020 (USDOT: Office of Freight Management and Operations). But the system improvements have not kept pace with the growth in truck transportation demand. Understanding the dynamics of truck transportation now and in the future, it is important for assessing potential investment, operational strategies, prioritizing investments and matching infrastructure supply to demand.

The truck traffic growth on the nation's highway system has been studied for more than 25 years. It is very likely that changing travel patterns of trucks and changing demographics in West Virginia have reduced the validity of the results of these studies for use in the traffic analyses of the present day and the planning horizon. The patterns for non-Interstate highways are associated with the geographical location of the site and the socioeconomic variables that change with time. These truck travel patterns are different from commuter travel patterns, it is necessary to determine the effects of truck traffic on capacity requirements.

On the West Virginia Interstate System, traffic counts are made every year on the segments between interchanges, and sometimes on ramps. On non-Interstate system routes, traffic counts are made on a three-year cycle (according to WVDOH Districts). Because of database differences, it is not possible to analyze non-Interstate highways in 
the same manner and to the same level of detail as Interstate highways. The pavements at non-Interstate highways are designed to last for a fairly long time. But, the pavement life measure is dependent on the amount of traffic using the highway and, more specifically, truck traffic. The projected growth in traffic will also affect the measure of performance. So this work is dedicated to assessing and evaluating potential forecasting methodologies that can be applied to forecast truck traffic volumes across all non-Interstate highway classifications in West Virginia. More specifically, a detailed study of the science and application of truck forecasting to support future planning efforts to develop truck forecasting procedures in West Virginia is performed.

\subsection{Project Objectives}

This research evaluates the theory and practice of current truck forecasting methodologies to estimate the truck traffic growth rate on West Virginia non-Interstate highways. The evaluation developed in this research presents a systematic format that can be easily transferred for use by the transportation professionals and the state DOT, which is supported by the PATR data. This research is limited to the West Virginia nonInterstate highways and a separate study is conducted for the interstate highways. This is due to the reason that they have different travel patterns and the volume of truck traffic is considered to be more on the interstate highways than on the non-Interstate highways. Also, because of database differences, it is not possible to analyze non-Interstate highways in the same manner and to the same level of detail as interstate highways. Further refinement is that socioeconomic data are used to estimate differences in the vehicle fleet by geographic area as the truck traffic volume on the non-Interstate 
highways is associated with these socioeconomic variables like population, employment, and geographic location of the site.

Several objectives for the forecasting study are as follows:

1. To perform a literature review that documents the state of art models and procedures and which might be relevant to the forecasting of truck traffic on West Virginia non-Interstate highways.

2. To convert the traffic count data (raw data), into the user interface using the software "REPORTER".

3. To generate a final sample of truck traffic data from the converted data by eliminating the outliers.

4. To systematically develop the traffic growth rates at individual sites of the nonInterstate highways based on the functional classification, using the alternative forecasting methods.

5. To document the methodology and the results and make recommendations on the method for future truck travel forecasting on West Virginia non-Interstate highway system. 


\subsection{Organization of Report}

This report is divided into five chapters. Chapter 1 presents the background on traffic growth on the highway system, identifies the problem and the project objectives. Chapter 2 presents the finding of the comprehensive literature review related to the similar forecasting analysis used in other states. Chapter 3 presents the methodology in which the truck travel forecasting analysis was conducted for West Virginia's non-

Interstate highway system. Chapter 4 shows the results and the related diagrams and graphs. Chapter 5 discusses about project conclusions and recommendations including limitations and suggestions for implementation. 


\section{CHAPTER 2}

\section{BACKGROUND AND LITERATURE REVIEW}

\subsection{Introduction}

This chapter discusses the literature relating to various types of truck forecasting methods that may be relevant to the non-Interstate highway system in West Virginia. The major scope of the literature review that relates to the WVDOH program was limited to the examination of the Statewide Traffic Forecasting (FHWA, 1999); Traffic Monitoring Guide (TMG) (FHWA, 2001) and Guidelines for Traffic Data Programs (AASHTO, 1992) since these serve as guidelines for states' traffic monitoring programs. They are also used as guides by all other states while performing traffic counts and interpreting the flow forecasts. Therefore, this chapter also documents the literature related to the previous and the most recent forecasting methodologies of other states.

Estimation of Annual Average Daily Truck Traffic (AADTT) is extremely important in traffic planning and operations for the state departments of transportation, because it provides information for the planning of new road construction, determination of roadway geometry, congestion management, safety considerations and pavement design. Accurate data is crucial for the calibration and validation of truck travel demand models. Inaccuracies in traffic volume forecasts are responsible for additional costs associated with over and under design. Also, AADTT is used to estimate state-wide truck vehicle miles traveled on all roads and is used by local governments and the environmental protection agencies to determine compliance with the 1990 Clean Air Act 
Amendment. Additionally, this data is reported annually by state departments of transportation to the Federal Highway Administration. Usually, the AADTT data is obtained from or is a part of the Annual Average Daily Traffic (AADT) and the general methods for collecting the AADT data are traffic count based and non-traffic count based. Permanent Automatic Traffic Recorders (ATR) and the portable short-term counts are the two types of traffic-based counts recommended by the TMG. The non-traffic count based method for estimating AADT uses non-traffic data such as socio-economic data, including fuel sales, trip-making behavior, household size, household income, population, number of licensed drivers, and employment (Hallmark and Lamptey, 2004). While state governments collect traffic counts, due to budgetary constraints, the data coverage is often limited, especially for local roads or in rural areas. Typically, when count data are unavailable, estimates are made based on comparisons to roads that are considered to be similar. Such comparisons are inherently subject to large errors. 


\subsection{Traffic Monitoring Program}

Traffic monitoring in the USA dates back nearly one hundred years. Traffic monitoring is the process of collecting data on the existing number and characteristics of vehicles using roadway system. Statistics on current and historical traffic provide the foundation on which to evaluate the transportation system and plan for future transportation needs. Various programs are dependent on the availability of high quality, consistent, and reliable data. The data is used by environmental and project planners as well as traffic and design engineers to evaluate the transportation system and to plan for future transportation needs. It is also used to observe the traffic flow variations (monthly, daily and hourly) and characteristics; AADT and annual growth; vehicle classification and occupancy; vehicle flow and passenger movements. Some of the following objectives of the traffic monitoring program are as follows:

- Collect data needed by users as efficiently as possible.

- Provide a mechanism for collecting data needed, as efficiently as possible.

- Ensure that all reliable traffic data collected within the State highway agency are made available to users.

Traffic monitoring programs differ substantially from state to state. Traffic monitoring has a long tradition and each agency has an established legacy program. The TMG is designed to help States improve their traffic monitoring programs and ensure that data is available to meet the needs with a view towards the future of traffic monitoring. 


\subsection{Traffic Volume Data Collection}

For many years, the traditional approach to monitor traffic at the statewide level consisted of,

- a modest number of permanent, continuously operating, data collection sites, and

- a large number of short duration data collection efforts.

The permanent data collection sites provide knowledge of seasonal and day-ofweek trends. The summarization of the continuously collected data allows the development of adjustment factors needed to convert short count data into estimates of "annual average" or "design" conditions. Continuous count summaries also provide very precise measurements of changes in travel volumes and characteristics at a limited number of locations.

The short duration counts provide the geographic coverage needed to understand traffic characteristics on individual roadways, as well as on specific segments of those roadways. Traffic volumes tend to vary dramatically from one location to another. Because permanent counters are expensive to install, operate, and maintain; short duration counts are needed on roads throughout the State to provide accurate measurements of traffic conditions on individual roadway sections. These short duration counts are then adjusted to represent annual or design conditions given the patterns measured at the continuous count locations. 


\subsubsection{Automatic Traffic Recorders}

The WVDOH uses permanent counters, which count vehicles by means of imbedded pavement induction loops, are located at various sites throughout the State. On the Interstate System, traffic counts are made every year on the segments between interchanges, and sometimes on ramps. On non-Interstate System routes, traffic counts are made on a three-year cycle (according to WVDOH Districts), covering all Highway Performance Monitoring System (HPMS) sample sections and other segments. For those segments not in the current counting cycle, an estimate of average daily traffic is made, based on historical trends and growth factors relating to the National Highway Functional Classification and the county in which the segment is located. Though there are many types of traffic collector devices, the most common traffic monitoring data collection program in use today is permanent automatic traffic recorders (ATRs).

Permanent ATR stations are located throughout the state that constantly record traffic and are considered the most accurate type of AADT data. Equipped with loop detectors, these ATR stations count the number of vehicles passing each location, continuously, throughout the year, and transmit the recorded data via telemetry to the traffic monitoring computers at the central location. At the central location, the data are checked for quality, summarized, and stored for later use. The summary and raw values are then made available to data users within the Department. The ATR stations are installed throughout the Road Inventory network covering all functional classifications of highways except Urban Local Streets. 
The most common errors possible in collecting and analyzing traffic data are 1) errors in collection, and 2) errors in editing (FHWA, 2001). Also, malfunction of the recorder, malfunction of the detector and power failure are sources of invalid and missing data from the permanent counters. These errors result in missing days, missing hours of data, negative numbers included in the figures, and vehicle classification errors. If no correction could be made the only manual step in editing permanent counter data is to review the data set for completeness and to exclude data that has been rendered invalid. The data reported from the ATRs is used to analyze and establish the traffic patterns at highway system and predict the future traffic growth rates.

\subsubsection{Site Selection for ATR}

Most of the states have already placed many continuous ATR counters. As these counters are expensive to move, the primary issue is not where to locate them but how best to use the data that come from these counters for the specific purpose. Also the TMG states that the initial ATR sites which are in existence from the past may no longer be reliable or applicable for data collection, but the fact that the historical data exists at these sites provides a reason for the continuing efforts to collect data at those locations.

The TMG recommends the following steps for selecting continuous count locations:

- To determine the "statewide" objectives for the continuous count program which includes the number and distribution of count locations to develop seasonal and day- 
of-week factors, statewide trend reports, preparation of reports that use permanent recorder data, etc.

- To determine what continuous data collection is needed for specific projects and what continuous data collection exists or is planned for operational purposes like traffic management and place the counters at that specific project locations.

- To determine the available funding that support continuous counter operation that can serve statewide purposes.

- To prioritize the "specific" project locations.

- To use the existing count locations as much as possible and if needed to determine and prioritize the number of additional continuous count locations.

\subsubsection{Continuous Vehicle Classification}

With the importance given to the study of truck traffic volume and due to the development of affordable equipment, continuous count programs are now included by continuous vehicle classifiers by most of the states. The results of many traffic analyses are more dependent on truck volumes (AADTT data) than they are on total traffic volumes (AADT data). Given the importance of truck information, the need for continuous vehicle classifiers becomes clear with the realization that truck traffic often follows different seasonal and day-of-week trends than do total volumes, which tend to be dominated by automobile traffic. This will allow the monitoring of changes in truck volumes and changes in vehicle fleet mix. If truck movement patterns are to be understood and accounted for in the traffic monitoring and data analysis efforts, then monitoring volumes by vehicle classification becomes necessary (FHWA, 2001). 
The important analyses needed for this study which is supported by continuous classification equipment include the following:

- The seasonal fluctuations in truck travel on roads.

- Trends in annual truck volumes on specific roadways (because truck travel has grown faster than car travel)

- Day-of-week traffic patterns for trucks as opposed to cars

- The lane distribution patterns of trucks.

Continuously operating vehicle classifiers use a variety of technologies. The two most common are axle classifiers and length classifiers. Axle classifiers record the number of vehicles in various categories. The vehicle classification categories are defined by the number and location of axles for each vehicle. Length classifiers usually use dual inductance loops to measure the total length of passing vehicles, which is then used to classify each passing vehicle. The FHWA standard classification uses the axle-based classifiers to categorize vehicles into 13 classes. These classifiers can also be used to monitor vehicle speeds as well as to track the changes in commodity movements. Therefore, vehicle classifiers also provide the same data as ATRs. That is, by simply combining all vehicle categories, a continuous classifier provides continuous total volume estimates. 


\subsubsection{Data Quality Control}

Traffic recorders may not always work as intended. Sensors may fail, come loose, improperly installed, or the settings themselves may be inappropriate. Also the equipment may not be properly calibrated or the calibration may drift over time as environmental conditions change. The operating conditions also may not allow the equipment to function as designed.

Data collected from such equipment yield inaccurate results. Quality control programs are intended to identify the poorly calibrated or malfunctioning equipment and to remove data collected by that equipment from the analysis process. This removed data may be replaced by the additional data collected. Performing quality checks quickly allows repair or recalibration efforts to be undertaken quickly, which in turn prevents loss of large volume of data. A key to quality assurance is to make sure the known values against which collected data are compared are accurate measures of the expected traffic patterns. If unexpected patterns are observed, additional work is required and, in some cases, it is readily apparent that equipment or sensors have failed. For permanent data collection sites, such failures indicate that repairs are needed as quickly as practical. In the case of short duration data collection, the affected data must be discarded and may be replaced by new data. In cases where the unexpected data is plausible, additional data should be collected to confirm or invalidate the unusual data. 


\subsection{Truck Forecasting Methods}

The methodology of forecasting truck traffic completely relies on the available data from the ATRs. But there are several factors (land developments, climatic conditions, etc.) that affect the method of forecasting. Also all these factors change from time to time, therefore each method has its own importance, based on the available resources and the influential factors during that time. Even the State DOTs do not establish a single methodology for forecasting traffic. So the best way to forecast truck traffic is to use all the available resources and methods from several perspectives. Some of the different methods used for forecasting truck traffic on non-Interstate highways are described in this section.

\subsubsection{Time Series}

Time-series forecasting is a forecasting method that uses a set of historical values to predict an outcome. These historic values, often referred to as a "time series", are spaced equally over time and can represent anything from monthly data to daily volumes. Time series analysis is a means of understanding data variability over time. Because a time series model exclusively represents past events and relationships, it can be used to forecast the future as long as the future is expected to behave like the past. Some of the more elementary time series methods require only readily available historical data, so they provide quick answers. Given more time and a broader set of data, rather sophisticated time series models can be built. This model can handle more than simple trends (growth and decline). They can also consider cycles in the data (annual, weekly, daily), discrete changes to some important influential factors and trends in important 
factors. Because the time series model uses past data, it cannot anticipate unpredictable or random events that could substantially affect traffic volumes. Time-series forecasting assumes that a time series is a combination of a pattern and some random error. The goal is to separate the pattern from the error by understanding the pattern's trend, its long-term increase or decrease, and its seasonality, the change caused by seasonal factors such as fluctuations in use and demand.

Many DOTs use some sort of a time series model for forecasting and implies that most could be providing more accurate forecasts by using a statewide model (Horowitz and Farmer, 1999). Separate study is conducted for traffic on non-Interstate highways and Interstate highways. This is due to the fact that the different travel patterns and the impacts of socioeconomic variables, exists at individual highways. These variables have greater effect on the forecasting analysis of truck traffic for non-Interstate highways than for Interstate highways. Therefore, the trend analysis method incorporates socioeconomic factors into the forecast. Thus, this method is the most flexible and simplistic approach to forecast truck traffic on non-Interstate highways compared to other forecasting methods. Growth factor analysis and linear regression analysis are the two techniques for this method. 


\subsubsection{Growth Factor}

This trend analysis assumes a constant growth rate over time. This method assumes that there is an increase in the percentage of truck traffic volume each year and that this will continue in the future. Any number of years of past data can be used to find a growth factor and using plenty of historical data usually minimizes the effects of spikes in the data (Memmott, 1983).

Many methods exist for developing growth rates or factors and not all are as simple as the one specified below.

$$
g=\sqrt[n]{\frac{A A D T T_{t}}{A A D T T_{t-n}}}-1
$$

(Dixon, 2004)

where,

$$
\begin{aligned}
& A A D T T_{t}=\text { AADTT volume recorded during the most recent year } \mathrm{t} \text {; } \\
& A A D T T_{t-n}=\text { AADTT volume recorded n years prior to the year } \mathrm{t} \text {; } \\
& g=\text { annual growth rate; and } \\
& n=\text { number of years between the most recent }\left(\mathrm{AADTT}_{\mathrm{t}}\right) \text { and past }\left(\mathrm{AADTT}_{\mathrm{n}}\right) \text { volumes. }
\end{aligned}
$$


The Guidebook to Statewide Travel Forecasting (FHWA, 1999) uses the calculated annual growth rate to forecast the AADTT volumes from the calculated annual growth rate

$$
A A D T T_{t+n}=A A D T T_{t}(1+g)^{n}
$$

where,

$$
\begin{aligned}
A A D T T_{t+n} & =\text { AADTT value forecasted } \mathrm{n} \text { years in the future; } \\
\text { AADTT }_{t} & =\text { base year AADTT value observed during year } \mathrm{t} \\
g & =\text { annual growth rate; and } \\
n & =\text { number of years into the future for which a forecast is being made. }
\end{aligned}
$$

If the annual growth rates are not updated on a regular basis, the accuracy of the forecasts would be questionable. The errors in forecasting affect design and planning applications when deciding the required accuracy for such forecasts.

The growth factors can also be obtained by finding the curve that best fits the historical data. But this can produce large errors in the volume estimates if the future trend is not consistent with the past. Figure 2.1 shows that growth can even take many forms between the base year and the projection year and have identical beginning and ending points. 


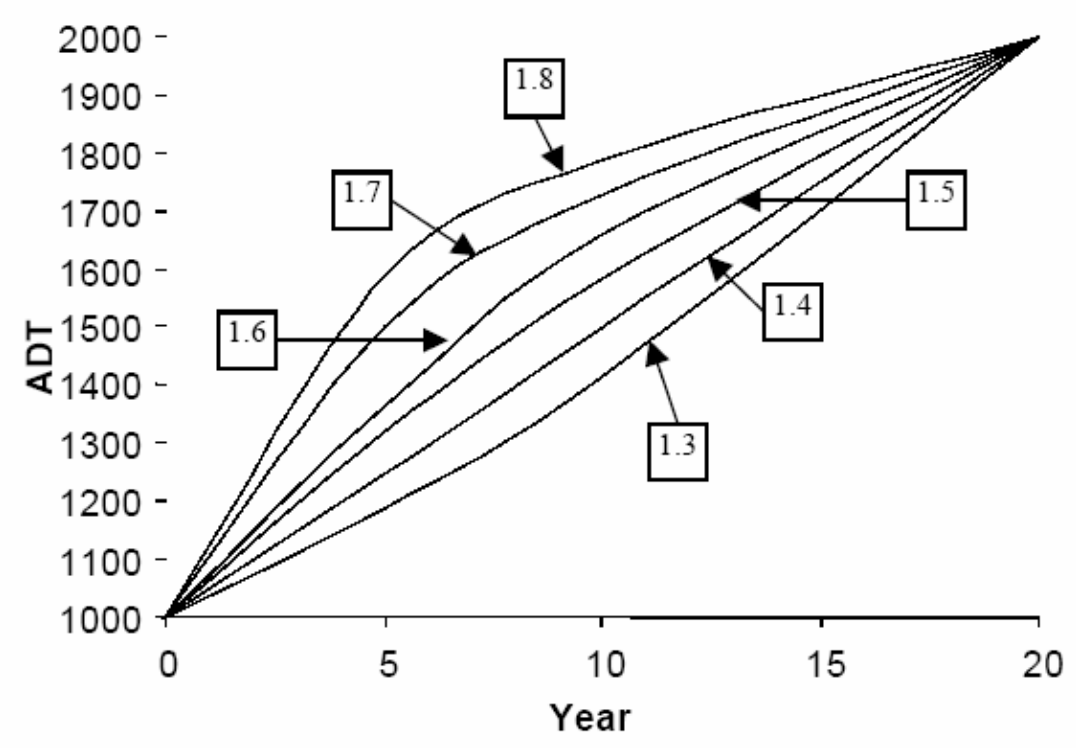

Figure 2.1 Different Types of Growth between the same two points

The average error could be 28.7 percent though there is a perfect fit of the historical data (Memmott, 1983). The WVDOH is using 9 years $(1995-2003)$ of past data, to forecast current AADTT volumes to a design year in the future. AADTT volumes are calculated using the AADT volumes collected from the ATR stations. The advantage of this technique is that, it is relatively facile.

\subsubsection{Linear Regression}

Linear regression analysis is the most often used technique among the time series methods based on statistical theory. It is the simplest method that forecasts future truck volumes based on the historical AADTT, thus developing a trend line of volumes into the future. It is the method of applying the best fit to the data which has both the dependent variable (volume) and the independent variable (time). Depending upon the nature of the data and the future use of the forecasts, the choice of formulation is selected. The outputs 
of a regression model should not only include the best-fit but also should include measures of goodness-of-fit, including standard error for each variable along the R-square values for the equation (FHWA, 1999). The National Cooperative Highway Research Program (NCHRP, 2005) uses a simple formula for linear regression analysis.

$$
V_{i}=a+b . Y_{i}+\varepsilon_{i}
$$

where,

\footnotetext{
$V_{i}$ is the $i$ th observation of the dependent variable (to be predicted);

$Y_{i}$ is the $i$ th observation of the independent variable (explanatory); and

$a$ and $b$ are the parameters to be estimated by the linear regression in the manner that minimizes $\varepsilon_{i}$ (the error term). The error term is sometimes neglected in the equation.
}

This method also incorporates socioeconomic factors into the forecast which are referred to as independent variables in this regression analysis. There are many sophisticated methods which allow the use of multiple independent variables. This approach is used if there are multiple independent factors which exists and are supposed to cause growth or fluctuations in truck traffic. The growth rate could be then defined as the function of the traffic volume as well as the independent variables so called socioeconomic variables. For example, the size of the harvest is one such factor in the agricultural areas because the effects of growth in agricultural production can influence the fluctuations in total truck volume and also in the individual functional class itself. Other independent factors are population, number of lanes, employment, and functional 
classification that are generally correlated with each other. The reliability of the analysis also increases with the incorporation of these variables. It should be remembered that not all the variables that are to be incorporated, generate accurate predictions of the truck traffic growth. This is due to the reason that the variables change over the time period and so care must be taken in selecting the variables that are to be used for forecasting.

\subsubsection{Applicability of Time Series Analysis}

Guide Book on Statewide Travel Forecasting (FHWA, 1999) discusses the various applications of time series analysis.

Modal Considerations: Time series can be used to analyze all types of modes though the approaches may differ. The analysis is helpful for short-term forecasts where behavioral models have not been calibrated or input data are unavailable.

Policy Considerations: The analysis can be used to forecast data which is needed for policy analysis and it also includes,

- Attributes of traffic, such as vehicle occupancy, vehicle weight and vehicle classes;

- Enforcement needs;

- Economic trends;

- Environmental conditions; and

- Growth in competing modes. 
Data Considerations: For a multimodal forecast on a network, time series are useful for,

- Forecasting inputs to trip generation;

- Forecasting comparatively minor modes (e.g., air freight, barges) when data limitations or time constraints prohibit application of a behavioral model;

- Forecasting external travel;

- Placing bounds on the reasonableness of forecasts; and

- Determining seasonal, monthly or day of week adjustment factors for postprocessing results from a behavioral model.

Cautions: Great care must be taken for forecasting traffic volumes. There is always a limited ability for anticipating changes in future conditions. Also events that have not occurred cannot be modeled. Also it is not possible to model an existing factor that has not changed appreciably in the past. Like any other model, time series cannot anticipate rare future conditions or events.

\subsubsection{Forecasting AADTT Using a Variety of Independent Variables}

A study on "Annual Average Daily Traffic Prediction Model for County Roads," (Sinha and Kuczek, 1998), used linear regression analysis to predict AADT volumes on county roads in Indiana using demographic and economic variables. This analysis can be applied in the similar fashion for predicting AADTT values on non-Interstate highways in West Virginia. The predictor variables that can be explored are:

- County population,

- County vehicle registration,

- Presence of Interstate highways nearby,
- County employment,

- Location (urban or rural),

- Access to state highway system. 
As the variables are not normally distributed, the independent variables are to be standardized. A full model containing all of the available significant variables can generate a reasonable level of accuracy. Forecasts could be performed with these models if the future year predictions of the variables are used. This method could be effective because of the model's efficiency, cost effectiveness and simplicity.

\subsubsection{Clustering}

The statistical method of clustering was developed back in early 1980s. Clustering traffic counts of different roads is based on the similar functional and geographical characteristics. Many of the times this is the initial step in performing regression analysis. The functional classes (Table 2.1) have been set up by the FHWA for different types of roadways and these are documented in the HPMS Field Book (FHWA, May 2005).

Table 2.1 The Highway Performance Monitoring System Functional Classes

\begin{tabular}{|l|ll|}
\hline \multicolumn{2}{|c|}{ Rural Functional Systems } & \multicolumn{1}{c|}{ Urban Functional Systems } \\
\hline - Interstate & $\bullet$ & Interstate \\
- Other Principle Arterials & $\bullet$ & Other Freeway and Expressway \\
$\bullet \quad$ Minor Arterial & $\bullet$ & Other Principle Arterials \\
$\bullet \quad$ Minor Collector & $\bullet$ & Minor Arterial \\
$\bullet \quad$ Local Roads & $\bullet$ & Collector \\
\hline
\end{tabular}


The grouping is required for AADT at each section of roadway. The AADT volume is not measured at the stations without ATR counters. Therefore Garber and Bayat-Mokhtari, (1981) developed a method for predicting the AADT value for the current year which does not require a known or measured AADT value. This method has three steps:

1. Dividing roadways into sections that have a homogenous traffic volume;

2. Identifying variables that significantly predict AADT (type of terrain, population of the county, land use, functional use and functional class); and

3. Grouping the data by similar characteristics.

After the step three, the clusters of data are run for regression analysis, but the observed fact is that the coefficients of variation of the AADT values for each cluster were lower than that recommended by the FHWA and did not require the initial step. FHWA recommends that the absolute precision of estimates be within 10 percent.

This part of the research is limited to the coefficient of variation as the sites and the related data were limited. Though not included, the result from a cluster analysis is a larger and more statistically valid collection of traffic count data available for use in travel forecasting.

The cluster analysis is observed to have two major weaknesses. The first one is the lack of theoretical guidelines for developing the optimal number of groups. It is difficult to determine the number of groups to be formed. The cluster analysis process 
starts with all ATRs in a single group, and proceeds until each ATR is in an individual group.

The second weakness in the approach is that the groups that are formed cannot be defined properly, since the procedure considers only variability at the ATRs and is not applicable to the short counts. Plotting the sites on a map that fall within a specific cluster group is sometimes helpful when attempting to define a given group output.

The two advantages of cluster analysis are

1. The independent determination of "similarity" between groups is allowed, thus making the groups less subject to bias; and

2. It can identify travel patterns that may not be perceived by the analyst.

\subsection{Annual Average Daily Truck Traffic (AADTT)}

The TMG provides two basic procedures to calculate AADTT on the consciously collected truck traffic volume on the road segments. They are:

1. The simple average; and

2. Average of averages method developed by AASHTO.

The first method calculates the AADTT by simply taking the average of all available daily truck traffic volumes in a year. Its simplicity makes it more easy to program. However, it will cause bias in AADTT estimation if there are considerable numbers of missing days in the collected volumes due to several reasons like the equipment malfunctions. 
The second method is developed by the AASHTO and is adopted by many of the state DOTs (Wang and Dr. Teng, Aug 2004). It is expressed by the following formula:

$$
A A D T T=\frac{1}{84} \sum_{i=1}^{12} \sum_{j=1}^{7} M A D W_{i, j}
$$

where,

$i=$ twelve months in a year $(i=1,2 \ldots 12)$;

$j=$ seven days in a week $(j=1,2 \ldots 7)$; and

$M A D W=$ monthly average days of the week truck traffic.

This method is known as the average of averages method. This method accounts for missing data by giving the same weight to each day of the week in each month. This method provides more reliable results than the first procedure if the counts have missing data.

The first step in this method is to calculate an average daily truck traffic volume for MADW. For one complete month, MADW is the average value of the truck volumes for each day of the week in a month. Therefore, there are seven values of MADW for a month; each refers to each day of the week. After MADW computation, Monthly Average Daily Truck Traffic (MADTT) for a given month can be computed by averaging the seven MADW values for that month. The final AADTT of one segment for a specific year is the average of the 12 MADTT values in that year. For one complete year, there 
are 84 MADW values. Therefore, for this method, the equation of AADTT takes the average of 84 average values.

The results from the two methods could be almost the same if the counts have very few missing data points. If so, the difference between the results from the two methods could be neglected. For the purpose of this research the first method namely the simple average method was adopted due to its simplicity.

\subsection{Case Study}

Many State DOTs have been conducting research for years to predict reliable traffic growth rates for non-Interstate and Interstate highways. Also predicting what traffic would be like into the future is the ambition motivating the design of intelligent transportation systems (ITS). The estimation of truck growth rates had been of great concern in particular because of potential lack of accuracy in the estimated methods and data. There is rapidly growing truck movement into and out of West Virginia. Therefore, this project focuses on truck AADT or AADTT. Several methods have been established to date. A literature search provided several reports and documents as reference material on this project. These reports were reviewed to determine the possible different methods for forecasting truck traffic on non-Interstate highways. Some of the following reports are listed and summarized below. 
Minnesota DOT has conducted the research on the "Estimation of Truck Vehicle Miles Traveled (VMT)" (Hallmark and Lamptey, Dec 2004). VMT for trucks is usually the product of the roadway section length in miles (centerline mileage) and AADTT. In order to obtain reliable VMT estimates, accurate AADTT estimates must be developed from traffic monitoring programs. About $70 \%$ of the state DOTs, including Minnesota DOT, use a traffic-count-based method for estimating truck VMT. All the quickly growing jurisdictions are counted on a two-year cycle and the relatively slow growing jurisdictions are counted on a four-year cycle. The active ATRs have their importance to the department in the following areas:

- Location of the monitors provides the traffic pattern and when clustered statistically they provide the basis for determining adjustment factors. These factors are used to expand short counts to AADT or AADTT.

- Values from these ATRs are used to constrain the annual statewide VMT every year.

- Traffic volumes and patterns on the non-Interstate and Interstate highways of the state are necessary for number of applications.

- Speed monitoring capability could be presented.

- Continuous vehicle classification using traffic volumes and patterns is a stronger emphasis in MnDOTs traffic monitoring program.

MnDOT has 78 continuous ATRs and 14 of which are classification capable. MnDOT does not count weekends, holidays and events. Counts are made 
between noon on Monday and noon on Friday. The two methods used by the department for truck VMT estimation are: (1) Truck VMT is estimated by multiplying the AADTT by the length of the segment and (2) Truck VMT is estimated by multiplying total aggregate truck VMT by average truck percentages. MnDOT is trying to develop separate adjustment factors for trucks. Since the department has census-based estimating system, Heavy Commercial Annual Daily Traffic (HCADT) is used to estimate Truck VMT.

* Kentucky Transportation Center conducted a study to determine patterns of traffic flow in "Analysis of Traffic Growth Rates", (Barrett, et al., Aug 2001). In this study, they developed traffic growth rates by traffic composition and highway type for Kentucky's system of highways. These were based on procedures to estimate trends in VMT and ADT. The models to predict VMT were developed individually for Interstate and non-Interstate routes. These models used socioeconomic data such as income, employment, etc. Also, regression and logarithmic methods were used to estimate the county-level growth rates and these were analyzed by linear regression analysis to estimate growth rates by functional class. The growth rates for Interstate highways were determined from historical data as the cause and effect of the socioeconomic variables was neglected. But the effect was considered while estimating growth rates for nonInterstate highways. This also proved that the available socioeconomic data had the potential to predict non-Interstate VMT, however, more data refinement was 
needed to develop more reliable models. Promising results were produced to minimize the level of effort required to estimate traffic volumes on local roads and the following were observed:

- In many cases, the growth rate for VMT was more than $6 \%$ at nonInterstates; and

- The increase of VMT on Interstate highways was $1 \%$ more than increase on non-Interstate roadways.

* "Estimation of Annual Average Daily Traffic on Non-State Roads in Florida County” (Quig, Xia, et al., 1999).

The estimation of AADT for non-state roads had been of great concern to Florida DOT because of the potential lack of accuracy in the estimated data. For this study, a multiple regression model was developed for estimating AADT on nonstate roads in Florida. A large sample size of 450 counts was used and 12 independent variables were analyzed. The study also used Geographic Information Systems (GIS) to aggregate the data for use of statistical analysis. Results after performing the statistical analysis indicated that the most important contributing predictors were roadway characteristics, like number of lanes, functional classification and land use. Also socioeconomic variables, such as population, automobile ownership, school enrollment, number of dwelling units and employment statistics had significant impact on AADT. Additional analysis 
revealed deficiencies in traditional roadway functional classifications and a need to improve or revise the classification procedures.

\subsection{Remarks}

In summary, both the Traffic Monitoring Guide (FHWA, 2001) and the State DOTs emphasize the need to forecast Annual Average Daily Truck Traffic (AADTT) in particular. The forecast analysis is performed individually for non-Interstate and Interstate highways. Once the data is collected, it is recommended to group the sites by similar characteristics such as urban/rural characteristics, functional class, time-of-day, day-of-week, seasonality, geographical characteristics, axles and single/multi-unit truck vehicles. Also, traffic on non-Interstate highways is more influenced by demographic variables than traffic on Interstate highways. Therefore, forecasting for non-Interstate highways should incorporate demographic variables. And, these factors need to be updated over time period to validate the results that are obtained in the forecasting analysis. 


\section{CHAPTER 3}

\section{DATA SELECTION AND METHODOLOGY}

\subsection{Data Type and Acquisition}

Nine years of data, 1995 to 2003, was used for the forecasting analysis in this project. The traffic data was collected by the West Virginia Department of Transportation from the 52 permanent count stations located throughout the state. There are 24 counters located on non-Interstate highways. The characteristics of these counter locations are described in Table 3.1. The counters record the traffic volumes and the classification data every hour of the year for every lane at every station. However, not all of the 24 sites were used for this project due to the insufficient data. During this process only 19 sites were selected for this project and these are presented in Table 3.2.

The data provided by the West Virginia Department of Transportation consisted of raw data files. The very first step of this project was to convert this raw data into usable spreadsheets by a DOS program called "Reporter" provided by the WVDOT. The converted data is saved into a Microsoft Excel format. Part of the data generated garbage values and some data was not useful for this study, such as weight and travel speed characteristics which were removed and not considered in the spreadsheets. To separate this unusable data, a small tool called 'macro' was used in MS Excel. It also helped in organizing the useful data, 'by lane', 'by direction', 'by hour', 'by day', and 'by month.' The data created 'by day' was used to estimate the Annual Average Daily Truck Traffic (AADTT). Also the vehicle classification between 4 and 13 (truck classes) was required 
for this project which was reported by the stations itself. Table 3.3 shows the FHWA vehicle classification scheme of 13 categories based on the number of axles, weight, length, etc.

Table 3.1 - List of Non-Interstate Permanent Traffic Count Stations in West Virginia

\begin{tabular}{|c|c|c|c|c|}
\hline Site Number & Location & Description & Functional Class & Number of Lanes \\
\hline 10 & US 60 & 0.5 miles west of $\mathrm{CO} 60 / 4$ & 2 & 2 \\
\hline 13 & WV 152 & 0.3 miles north of $\mathrm{CO} 52 / 1$ & 6 & 2 \\
\hline 14 & US 33 & 1.1 miles east of $\mathrm{CO} 13$ & 6 & 2 \\
\hline 15 & US 35 & 1.0 miles north of $\mathrm{CO} 27$ & 6 & 2 \\
\hline 16 & US 52 & 0.5 miles east of $\mathrm{CO} 52 / 17$ & 6 & 2 \\
\hline 17 & US 119 & 1.1 miles south of CO $119 / 90$ & 6 & 2 \\
\hline 19 & $\mathrm{CO} 21$ & 0.4 miles north of $\mathrm{CO} 33 / 12$ & 7 & 2 \\
\hline 20 & US 220 & 1.5 miles south of CO $220 / 4$ & 7 & 2 \\
\hline 22 & US 19 & 1.5 miles north of CO $19 / 36$ & 7 & 2 \\
\hline 23 & US 19 & 0.4 miles south of $\mathrm{CO} 40 / 2$ & 7 & 2 \\
\hline 25 & US 60 & 0.1 miles west of $\mathrm{CO} 25 / 1$ & 7 & 2 \\
\hline 34 & WV 25 & 1.0 miles west of WV 622 & 14 & 2 \\
\hline 36 & US 60 & 0.1 miles west of $\mathrm{CO} 85$ & 14 & 4 \\
\hline 37 & US 11 & 1.0 miles south of WV 45 & 16 & 2 \\
\hline 38 & WV 61 & 1.4 miles south of I-77 KC & 17 & 2 \\
\hline 40 & WV 114 & 0.2 miles north of $\mathrm{CO} 114 / 1$ & 16 & 2 \\
\hline 41 & US 119 & 0.1 miles north of CO $119 / 16$ & 16 & 2 \\
\hline 43 & WV 44 & 0.5 miles south of US 119 & 7 & 2 \\
\hline 44 & WV 94 & 0.5 miles north of WV 3 & 6 & 2 \\
\hline 45 & WV 7 & 0.2 miles east of WV 2 & 7 & 2 \\
\hline 48 & WV 20 & 0.1 miles west of $\mathrm{CO} 20 / 12$ & 6 & 2 \\
\hline 49 & WV 92 & 2.5 miles south of WV 39 & 6 & 2 \\
\hline 351 & US $52 \mathrm{WB}$ & 0.7 miles west of CO 29 & 14 & 2 \\
\hline 352 & US $52 \mathrm{~EB}$ & 0.7 miles west of CO 29 & 14 & 2 \\
\hline
\end{tabular}


Table 3.2 - List of Traffic Count Stations used for this Project

\begin{tabular}{|c|c|l|c|c|}
\hline Site Number & Location & \multicolumn{1}{|c|}{ Description } & Functional Class & Number of Lanes \\
\hline \hline & & & & \\
\hline 10 & US 60 & 0.5 miles west of CO 60/4 & 2 & 2 \\
\hline 13 & WV 152 & 0.3 miles north of CO 52/1 & 6 & 2 \\
\hline 14 & US 33 & 1.1 miles east of CO 13 & 6 & 2 \\
\hline 15 & US 35 & 1.0 miles north of CO 27 & 6 & 2 \\
\hline 16 & US 52 & 0.5 miles east of CO 52/17 & 6 & 2 \\
\hline 17 & US 119 & 1.1 miles south of CO 119/90 & 6 & 2 \\
\hline 19 & CO 21 & 0.4 miles north of CO 33/12 & 7 & 2 \\
\hline 20 & US 220 & 1.5 miles south of CO 220/4 & 7 & 2 \\
\hline 22 & US 19 & 1.5 miles north of CO 19/36 & 7 & 2 \\
\hline 23 & US 19 & 0.4 miles south of CO 40/2 & 7 & 4 \\
\hline 25 & US 60 & 0.1 miles west of CO 25/1 & 7 & 2 \\
\hline 34 & WV 25 & 1.0 miles west of WV 622 & 14 & 2 \\
\hline 36 & US 60 & 0.1 miles west of CO 85 & 14 & 2 \\
\hline 37 & US 11 & 1.0 miles south of WV 45 & 16 & 2 \\
\hline 38 & WV 61 & 1.4 miles south of I-77 KC & 17 & 2 \\
\hline 40 & WV 114 & 0.2 miles north of CO 114/1 & 16 & 2 \\
\hline 44 & WV 94 & 0.5 miles north of WV 3 & 6 & 7 \\
\hline 45 & WV 7 & 0.2 miles east of WV 2 & 6 & 2 \\
\hline 48 & WV 20 & 0.1 miles west of CO 20/12 & &
\end{tabular}

Table 3.3 - FHWA Vehicle Classification

\begin{tabular}{|l|l|l|c|}
\hline \multicolumn{2}{|c|}{ Class Group } & \multicolumn{1}{c|}{ Description } & No. of Axles \\
\hline 1 & & Motorcycles & 2 \\
\hline 2 & & All Cars & 2 \\
& & Cars W/ 1-Axle Trailer & 3 \\
\hline 3 & & Cars W/ 2-Axle Trailer & 4 \\
\hline
\end{tabular}




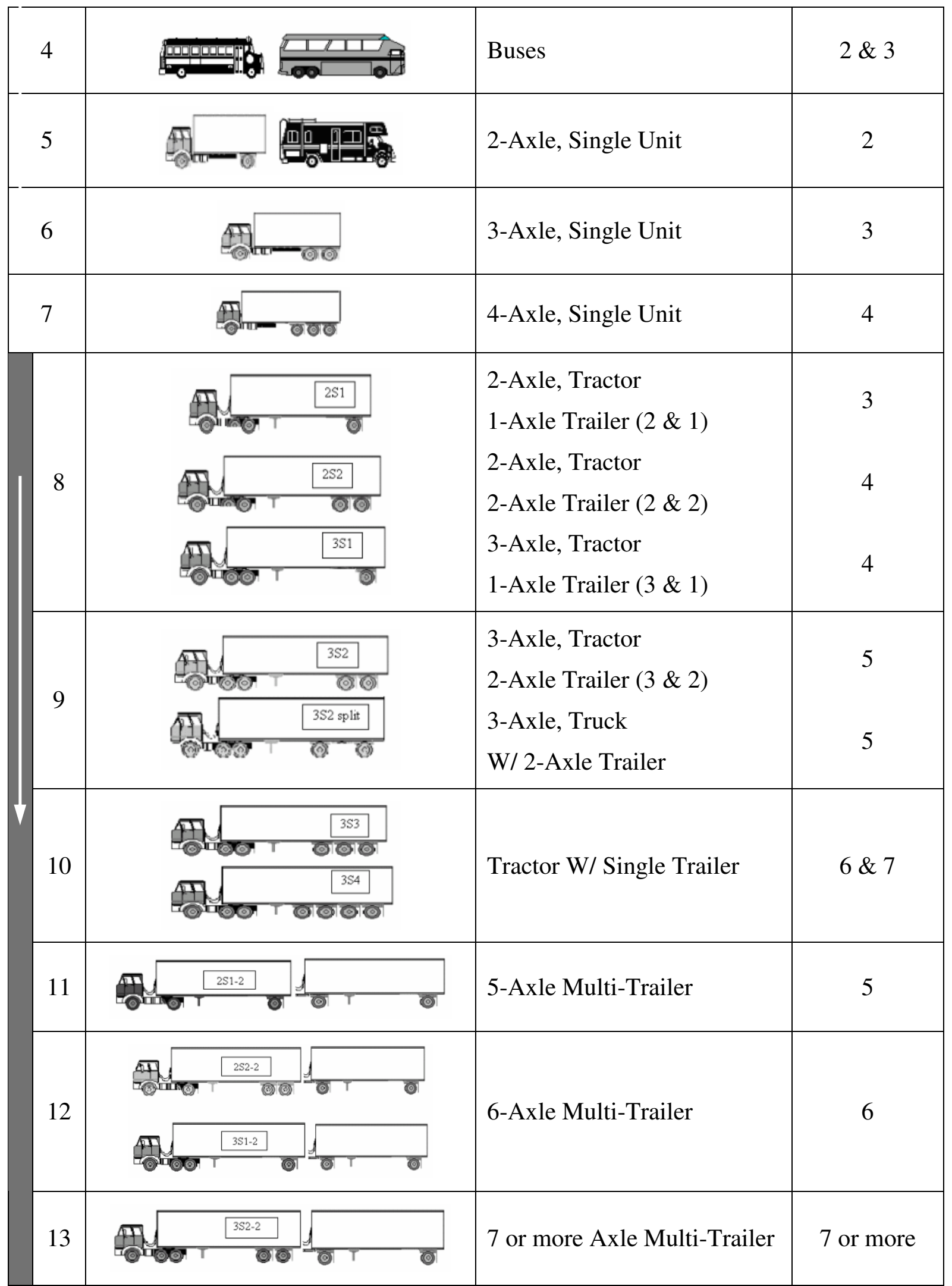




\subsection{Data Quality Checks}

The very next step of this project was to identify the types of errors or outliers contained in the data obtained from the first step. The errors were identified manually at the data organization stage. The types of errors identified during this observation are (i) missing data; (ii) zero values and (iii) extremely large or small numbers which are unusual. These data points were eliminated from the further analysis based on the recommended guidelines provided by AASHTO and the TMG.

Another technique was used for further identification of outliers. In this technique, the mean and the standard deviation were calculated from the simulated values and were compared against the mean plus or minus two times the standard deviation $\quad(\mu \pm 2 \sigma)$ and the data within these bounds were reported and the remaining data was dropped from further analysis. If the values were normally distributed, $95 \%$ of the observations fall within the range. As this was not possible, Chebyshev's theorem was adapted. According to this theorem, "If a probability distribution has a mean 'mu' and standard deviation 'sd', then the probability of getting a value which deviates from 'mu' by at least $k$ *sd is at

most $1 / k^{2}$." In this case $\mathrm{k}=2$, so it was assumed that at most $25 \%$ of the values should be outside the calculated interval and $75 \%$ of the values are expected to be inside the interval (Enhancements, Calibration and Validation: Intelligent Transportation Systems Program, MIT). After the data quality check, AADTT was calculated from the filtered data for each site in each particular year. The truck forecasting analysis was then performed for the calculated AADTTs. 


\subsection{Estimation of Annual Average Daily Truck Traffic (AADTT)}

The AADTT for each site was calculated after removing the outliers from the data.

Two methods to estimate the AADTT were described by the FHWA in the TMG (2001). They are the 'simple average method' and the 'average of the averages method (AASHTO method).' These are briefly described in the Literature Review. For the purpose of this study, the 'simple average method' was used to estimate the AADTT for non-Interstate highways. This is because of its simplicity and insignificant differences in results between the two methods. The final result of AADTT for each site is shown below in Table 3.4.

Table 3.4 -Annual Average Daily Truck Traffic (AADTT) at Non-Interstate Highways

\begin{tabular}{|c|c|c|c|c|c|c|c|c|c|c|c|c||}
\hline ROUTE & SITE & CLASS & $\begin{array}{c}\text { Number } \\
\text { of lanes }\end{array}$ & $\mathbf{1 9 9 5}$ & $\mathbf{1 9 9 6}$ & $\mathbf{1 9 9 7}$ & $\mathbf{1 9 9 8}$ & $\mathbf{1 9 9 9}$ & $\mathbf{2 0 0 0}$ & $\mathbf{2 0 0 1}$ & $\mathbf{2 0 0 2}$ & $\mathbf{2 0 0 3}$ \\
\hline \hline US-60 & $\mathbf{1 0}$ & Rural & $\mathbf{2}$ & 645 & 768 & 880 & 787 & 853 & 924 & 896 & 954 & 956 \\
\hline WV-152 & $\mathbf{1 3}$ & Rural & $\mathbf{2}$ & 266 & 270 & 245 & 293 & 310 & 318 & 312 & 323 & \\
\hline US-33 & $\mathbf{1 4}$ & Rural & $\mathbf{4}$ & 907 & & 1185 & & & 1475 & & 1114 & 1447 \\
\hline US-35 & $\mathbf{1 5}$ & Rural & $\mathbf{2}$ & 1828 & 1826 & 1506 & 1710 & 2551 & 2498 & 2163 & 2469 & 2582 \\
\hline US-52 & $\mathbf{1 6}$ & Rural & $\mathbf{2}$ & 417 & 477 & 513 & 487 & 501 & 511 & 509 & 534 & 547 \\
\hline US-119 & $\mathbf{1 7}$ & Rural & $\mathbf{2}$ & 207 & 206 & 186 & & & 218 & 237 & 228 & 227 \\
\hline CO-21 & $\mathbf{1 9}$ & Rural & $\mathbf{2}$ & 67 & 64 & 64 & 122 & 135 & 103 & 138 & & 164 \\
\hline US-220 & $\mathbf{2 0}$ & Rural & $\mathbf{2}$ & 151 & 189 & 150 & 165 & 176 & 179 & 191 & 190 & 205 \\
\hline US-19 & $\mathbf{2 2}$ & Rural & $\mathbf{2}$ & 219 & 221 & & & & & & 431 & 405 \\
\hline US-19 & $\mathbf{2 3}$ & Rural & $\mathbf{2}$ & 265 & 280 & & 330 & 314 & 418 & 409 & 435 & 432 \\
\hline US-60 & $\mathbf{2 5}$ & Rural & $\mathbf{2}$ & 392 & 361 & 395 & & 372 & & & 459 & 415 \\
\hline WV-25 & $\mathbf{3 4}$ & Urban & $\mathbf{2}$ & 681 & 665 & 760 & 784 & 843 & 809 & 875 & 748 & 871 \\
\hline US-60 & $\mathbf{3 6}$ & Urban & $\mathbf{4}$ & 736 & 717 & 745 & 776 & 776 & 770 & 762 & 786 & 793 \\
\hline US-11 & $\mathbf{3 7}$ & Urban & $\mathbf{2}$ & 314 & 224 & 409 & 345 & 362 & & & & 418 \\
\hline WV-61 & $\mathbf{3 8}$ & Urban & $\mathbf{2}$ & 163 & 162 & 168 & & 167 & 171 & 168 & 175 & 178 \\
\hline WV-114 & $\mathbf{4 0}$ & Urban & $\mathbf{2}$ & 219 & 263 & 265 & 248 & 297 & 249 & 282 & 293 & 314 \\
\hline WV-94 & $\mathbf{4 4}$ & Rural & $\mathbf{2}$ & 536 & 566 & 680 & 539 & 614 & 605 & 743 & 893 & 840 \\
\hline WV-7 & $\mathbf{4 5}$ & Rural & $\mathbf{2}$ & 249 & 257 & 240 & 302 & 281 & 298 & & & 331 \\
\hline WV-20 & $\mathbf{4 8}$ & Rural & $\mathbf{2}$ & 202 & 197 & 215 & & 266 & 210 & 235 & 246 & 252 \\
\hline \hline
\end{tabular}


Using the Table 3.4, the models were developed and evaluated by the two techniques namely the Regression Analysis and the Growth Factor Method.

\subsection{Evaluation and Overview of Alternative Methods}

The approach to develop alternative analysis was based on performance criteria. Different methods are evaluated and the most reliable method is recommended for use to forecast truck traffic on West Virginia non-Interstate highways. The key to the approach is criteria that reflect the capabilities and limitations of these methods. It is also based upon the availability and reliability of the data. Also, an important consideration in the evaluation of various models is whether they have some theoretical basis that relates to the parameter being forecast.

The initial approach towards forecasting AADTT was performed using regression analysis. Both the linear and exponential regression analysis was performed for the available data. The time period was set as a unique independent variable throughout the analysis. This analysis allows better account for socioeconomic factors to remove some of the limitations associated with time-series analysis. However, it should be seen that the socioeconomic factors introduced will be relatively basic and may not yield robust modeling capabilities. Another advantage of using this analysis is its simplicity in using the data available to produce rapid results for forecasting. But this method lacks the ability to account for changing socioeconomic conditions. The results proved that the linear analysis was better compared to the exponential analysis as the value for coefficient of regression $\left(\mathrm{R}^{2}\right)$ was higher for the linear analysis. Linear regression 
analysis was performed to forecast statewide truck traffic on non-Interstate highways for both rural and urban areas and also for each truck classification. The prediction of the model was further improved by performing weighted analysis according to the number of trucks passing per day, in each group. Precision analysis was also performed on the sample size.

The next approach was using the growth factor technique to forecast truck traffic on non-Interstate highways in West Virginia. This technique represents the increase in percentage of AADTT per year. This technique is simple. However, there should be a good reason to believe that the future growth rate for truck traffic will differ from the past. The point to be remembered is that not more than two years of AADTT data can be used as an input though data over the years is available. The analysis by grouping truck classes and weighted annual average truck traffic growth rates was preformed similar to the one in linear regression analysis.

Finally, after the two approaches, a comparison was made between the two techniques and a decision was made that the linear regression analysis is a stronger approach than the growth factor technique. This was based on the coefficient of regression values and also the availability of data. Therefore, based on the available data and the results, it was concluded that the linear regression analysis is a well-suited method to predict truck traffic on non-Interstate highways in West Virginia. 


\subsubsection{Linear Regression Model}

Linear regression analysis is the simplest form of trend analysis that forecasts future truck volumes. The straight line equation is used for the linear regression analysis and is represented below.

$$
V_{i}=a+b . Y_{i}
$$

where,

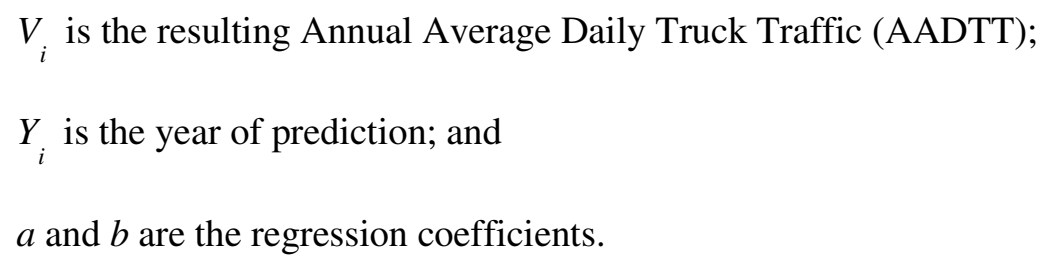

" $b$ " is the slope of the trend line which represents the average change in AADTT between each year at a particular count station and, therefore, it may be used to calculate the growth rate. The formula used to calculate growth rates for the purpose of this project is presented below.

$$
\text { Growth Rate }(\%)=\frac{\text { Slope }(b)}{A A D T T(\text { year } 2003)} \times 100
$$

The regression output also contains statistical variables like $R^{2}$ that indicate how well the observed data is being explained. The analysis was performed using Table 3.4 to develop a model for every site. The missing values were then predicted from the result obtained and are shown in the Table 4.2. The next step was to estimate the overall 
growth rates for all urban and rural, non-Interstate highways. The analysis was also performed individually for the rural and urban sites and also according to the truck classification.

\subsubsection{Statewide Growth Rate for Non-Interstate Highways}

The average growth rate was calculated for the provided WV non-Interstate sites. Initially, the AADTT's of all sites in a particular year were summed up and a graph was plotted between the calculated AADTT and the respective Year. Also the growth rate was calculated according to WV rural and urban non-Interstate classification system.

\subsubsection{Regression Analysis for Each Truck Classification}

Linear regression analysis was performed for every single truck class. According to the Federal Highway Administration vehicle classification scheme, the trucks are grouped between class 4 and class 13 . The growth rate was calculated based on the classification system and $\mathrm{R}^{2}$ was determined.

\subsubsection{Weighted Average Growth Rate}

Before estimating the weighted average growth rate, the growth rates were calculated by using the regression analysis. Once the growth rates were calculated, the weighted average growth rate was estimated by adding the products obtained by multiplying the growth rate by their weight factor for each site. The weight factors were calculated for each site and is given by the formula, 


$$
\text { Weight Factor }_{(X)}=\operatorname{AADTT}_{(X)} / \operatorname{AADTT}_{(T)}
$$

where,

$$
\begin{aligned}
& \operatorname{AADTT}_{(\mathrm{X})}=\text { sum of AADTT for all the years in that particular site(x); } \\
& \mathrm{AADTT}_{(\mathrm{T})}=\sum_{X=a}^{b} \operatorname{AADTT}_{(X)}, \text { 'a' is the initial site and ' } \mathrm{b} \text { ' is the final site. }
\end{aligned}
$$

Also, the formula for the total weighted average growth rate is as shown below:

Weighted Average Growth Rate $=\sum$ Growth Rate $(\%)_{(X)} * A A D T T_{(X)} / \operatorname{AADTT}_{(T)}$

The growth rates and the weighted average growth rates were calculated based on each truck classification and, the rural and urban characteristics. It is important to note that the weight factors estimated according to the truck classification were determined in the same manner, except for the fact that the average of AADTT is used instead of the sum for all the years. This is due to the presence of missing data at various sites, which makes the results impossible to validate if sum of the AADTT is considered as this will not count for the missing data. 


\subsubsection{Precision Analysis}

The precision analysis was executed on every site by determining the coefficient of variation for each group and site. The coefficient of variation is obtained by dividing the standard deviation by the mean of the AADTT for the groups used in the analysis. For the purpose of this project, a coefficient of variation of $50 \%$ was considered acceptable. The coefficient of variation measures the precision of the factors and tells how precisely the analysis was executed. The higher the percentage of variation, the lower is the precision and, therefore, in hypothetical terms the data collected should have a coefficient of variation equal to $0 \%$. This may not always be true as it also depends on the accuracy of the available data and hence collecting plenty of data could help eliminate the outliers or errors.

\subsubsection{Grouping of Truck Classification}

Apart from classifying the data according to the rural and urban non-Interstate classification system, it was also classified according to the number of axles to calculate the growth rate. During the analysis, the results may not be impressive due to the reason that the truck count in each classification may vary considerably. Large numbers may be found for groups 4 to 7 when compared to the group of heavy trucks from 8 to 13 . Therefore, the vehicle classification between 4 and 7 was grouped under one category and between 8 and 13 into another. This helps in better understanding of the growth rates for non-Interstate highways. 


\subsubsection{Growth Factor Method}

Two types of growth rates, the historical and current were estimated for the purpose of this project. The historical growth rate uses the AADTT from the first and the last year available whereas, the current growth rate uses the AADTT from the last two years. But due to the presence of missing data the current growth rate for this project uses the AADTT from the two most recent years available with one year as the optimum gap between them. The following equation is used to calculate the historical growth rate using the AADTT from the beginning and the ending years.

$$
\text { Historic Growth Rate }=\left(\frac{\text { Ending Year }}{\text { BeginTT }}\right)^{\frac{1}{\text { No.of Years }}}-1
$$

\subsubsection{Statewide Growth Rate for Non-Interstate Highways}

The statewide growth rate for non-Interstate highways was determined similar to the one in linear regression analysis. The current growth rate calculated from the two most recent years is used in this analysis. Also the growth rate according to rural and urban characteristics is estimated in percentages.

\subsubsection{Growth Rates According to Truck Classification}

Similar to the linear regression analysis, growth rates for each truck classification was estimated. 


\subsubsection{Weighted Average Growth Rate}

The weighted average growth rate was estimated by summing the products obtained by multiplying the growth rate by their weight factor for each site. The weight factors were calculated for each site which is slightly different from the way it was calculated during the regression analysis. The weight for each site is the sum of the AADTT divided by the total sum of AADTT for the two years under consideration.

$$
\text { Weight Factor }_{(X)}=\operatorname{AADTT}_{(X)} / \operatorname{AADTT}_{(T)}
$$

where,

$\operatorname{AADTT}_{(\mathrm{X})}=$ sum of AADTT for the two years considered in that particular site(x); $\operatorname{AADTT}_{(\mathrm{T})}=\sum_{X=a}^{b} A A D T T_{(X)} \quad$, 'a' is the initial site and ' $\mathrm{b}$ ' is the final site.

Also the formula for the total weighted average growth rate is as shown below:

Weighted Average Growth Rate $=\sum$ Growth Rate $(\%)_{(X)} * A A D T T_{(X)} / A A D T T_{(T)}$

The growth rates, weight factors and the weighted average growth rates were calculated based on each truck classification in the same manner. 


\subsubsection{Precision Analysis}

It was similar to the one performed in the regression analysis, except for the fact that this analysis used the AADTT that determines the growth rate in each site instead of using the growth rates directly.

\subsubsection{Grouping of Truck Classification}

The growth factor method was also performed based on the grouping of truck classification similar to the one in regression analysis. Two separate groups, one from 4 to 7 and another from 8 to 13 were formed for this analysis.

\subsubsection{Calibration and Validation of the Models Selected}

Once the model parameters have been estimated, the process of calibration and validation begins. Calibrating the models will adjust the parameter values until the predicted count matches the observed count within the region for the base year. Validation helps in testing the ability of the model to predict the future behavior. Validation is typically an iterative process linked to calibration. Linear regression, maximum likelihood estimation and analysis of variation are some of the statistical methods used in the calibration techniques. But the most common used is the linear regression method which is otherwise known as the "least squares method," in which the sum of the squares of the residuals is minimized by finding the best fit or the curve through the data (FHWA, 1999). The linear equation model for this study to estimate AADTT is

$$
A A D T T=a_{0}+a_{1} \cdot x_{1}
$$


The time period ' $x_{1}$ ' is the year of prediction and is used as the unique independent variable in all models. Also the parameters ' $\mathrm{a}_{0}$ ' and ' $\mathrm{a}_{1}$ ' are developed in order to minimize the error which is the difference between the observed and the predicted AADTT's for a specific year, i.e., the vertical deviations between the observed points and the predicted line. Finally, the forecasted models should be evaluated for reasonableness to achieve the degree of accuracy and consistency. Either the trend volumes or the model may not be appropriate to use if the accuracy is not determined. 


\section{CHAPTER 4}

\section{RESULTS}

\subsection{Linear Regression Analysis}

Linear regression analysis was performed for the available sites on non-Interstate highways in West Virginia. The models were developed using time period as the independent variable and the AADTT as the dependent variable. Coefficient of regression $\left(\mathrm{R}^{2}\right)$ was then obtained for each site. The regression models and their respective $\mathrm{R}^{2}$ values for each site are shown in Table 4.1.

Table 4.1 - Linear Regression Models and Coefficient of Regression Values for Each Site

\begin{tabular}{||c|c|c|c|c|c||}
\hline \hline Route & Class & SITE & $\begin{array}{c}\text { Number of } \\
\text { Lanes }\end{array}$ & Model & $\mathbf{R}^{2}$ \\
\hline \hline US 60 & Rural & 10 & 2 & $\mathrm{y}=33 \mathrm{x}-64816$ & 0.78 \\
\hline WV 152 & Rural & 13 & 2 & $\mathrm{y}=10 \mathrm{x}-19893$ & 0.81 \\
\hline US 33 & Rural & 14 & 2 & $\mathrm{y}=48 \mathrm{x}-94112$ & 0.52 \\
\hline US 35 & Rural & 15 & 2 & $\mathrm{y}=117 \mathrm{x}-232657$ & 0.60 \\
\hline US 52 & Rural & 16 & 2 & $\mathrm{y}=12 \mathrm{x}-23055$ & 0.74 \\
\hline US 119 & Rural & 17 & 2 & $\mathrm{y}=4 \mathrm{x}-8314.3$ & 0.60 \\
\hline CO 21 & Rural & 19 & 2 & $\mathrm{y}=13 \mathrm{x}-25808$ & 0.82 \\
\hline US 220 & Rural & 20 & 2 & $\mathrm{y}=5 \mathrm{x}-10317$ & 0.58 \\
\hline US 19 & Rural & 22 & 2 & $\mathrm{y}=27 \mathrm{x}-54554$ & 0.96 \\
\hline US 19 & Rural & 23 & 2 & $\mathrm{y}=24 \mathrm{x}-47122$ & 0.90 \\
\hline US 60 & Rural & 25 & 2 & $\mathrm{y}=7 \mathrm{x}-14358$ & 0.51 \\
\hline WV 25 & Urban & 34 & 2 & $\mathrm{y}=21 \mathrm{x}-41330$ & 0.57 \\
\hline US 60 & Urban & 36 & 4 & $\mathrm{y}=8 \mathrm{x}-14663$ & 0.72 \\
\hline US 11 & Urban & 37 & 2 & $\mathrm{y}=16 \mathrm{x}-32189$ & 0.52 \\
\hline WV 61 & Urban & 38 & 2 & $\mathrm{y}=2 \mathrm{x}-3329.7$ & 0.81 \\
\hline WV 114 & Urban & 40 & 2 & $\mathrm{y}=8 \mathrm{x}-16555$ & 0.61 \\
\hline WV 94 & Rural & 44 & 2 & $\mathrm{y}=40 \mathrm{x}-78925$ & 0.69 \\
\hline WV 7 & Rural & 45 & 2 & $\mathrm{y}=11 \mathrm{x}-21302$ & 0.84 \\
\hline WV 20 & Rural & 48 & 2 & $\mathrm{y}=6 \mathrm{x}-12300$ & 0.52 \\
\hline \hline
\end{tabular}


The coefficients of regression for all sites were greater than 0.5 . The respective models were used to estimate the missing values of AADTT in Table 3.4. In addition to this, the models were used to predict the growth rate for each site by dividing the slope of the regression model by the year 2003 estimate.

Table 4.2 shows the estimated AADTT's by using the regression models and Table 4.3 shows the predicted growth rates for each site.

Table 4.2 - Missing AADTT values Estimated using the Regression Models

\begin{tabular}{||c|c|c|c|c|c|c|c|c|c|c|c|c||}
\hline ROUTE & SITE & CLASS & $\begin{array}{c}\text { Number } \\
\text { of lanes }\end{array}$ & $\mathbf{1 9 9 5}$ & $\mathbf{1 9 9 6}$ & $\mathbf{1 9 9 7}$ & $\mathbf{1 9 9 8}$ & $\mathbf{1 9 9 9}$ & $\mathbf{2 0 0 0}$ & $\mathbf{2 0 0 1}$ & $\mathbf{2 0 0 2}$ & $\mathbf{2 0 0 3}$ \\
\hline \hline US-60 & 10 & Rural & 2 & 645 & 768 & 880 & 787 & 853 & 924 & 896 & 954 & 956 \\
\hline WV-152 & 13 & Rural & 2 & 266 & 270 & 245 & 293 & 310 & 318 & 312 & 323 & 338 \\
\hline US-33 & 14 & Rural & 4 & 907 & 1064 & 1185 & 1160 & 1207 & 1475 & 1303 & 1114 & 1447 \\
\hline US-35 & 15 & Rural & 2 & 1828 & 1826 & 1506 & 1710 & 2551 & 2498 & 2163 & 2469 & 2582 \\
\hline US-52 & 16 & Rural & 2 & 417 & 477 & 513 & 487 & 501 & 511 & 509 & 534 & 547 \\
\hline US-119 & 17 & Rural & 2 & 207 & 206 & 186 & 210 & 214 & 218 & 237 & 228 & 227 \\
\hline CO-21 & 19 & Rural & 2 & 67 & 64 & 64 & 122 & 135 & 103 & 138 & 151 & 164 \\
\hline US-220 & 20 & Rural & 2 & 151 & 189 & 150 & 165 & 176 & 179 & 191 & 190 & 205 \\
\hline US-19 & 22 & Rural & 2 & 219 & 221 & 264 & 291 & 319 & 346 & 373 & 431 & 405 \\
\hline US-19 & 23 & Rural & 2 & 265 & 280 & 307 & 330 & 314 & 418 & 409 & 435 & 432 \\
\hline US-60 & 25 & Rural & 2 & 392 & 361 & 395 & 394 & 372 & 409 & 416 & 459 & 415 \\
\hline WV-25 & 34 & Urban & 2 & 681 & 665 & 760 & 784 & 843 & 809 & 875 & 748 & 871 \\
\hline US-60 & 36 & Urban & 4 & 736 & 717 & 745 & 776 & 776 & 770 & 762 & 786 & 793 \\
\hline US-11 & 37 & Urban & 2 & 314 & 224 & 409 & 345 & 362 & 378 & 394 & 410 & 418 \\
\hline WV-61 & 38 & Urban & 2 & 163 & 162 & 168 & 165 & 167 & 171 & 168 & 175 & 178 \\
\hline WV-114 & 40 & Urban & 2 & 219 & 263 & 265 & 248 & 297 & 249 & 282 & 293 & 314 \\
\hline WV-94 & 44 & Rural & 2 & 536 & 566 & 680 & 539 & 614 & 605 & 743 & 893 & 840 \\
\hline WV-7 & 45 & Rural & 2 & 249 & 257 & 240 & 302 & 281 & 298 & 309 & 319 & 331 \\
\hline WV-20 & 48 & Rural & 2 & 202 & 197 & 215 & 221 & 266 & 210 & 235 & 246 & 252 \\
\hline \hline
\end{tabular}

The values in the shaded boxes represent the AADTT estimated using the regression models 
Table 4.3 - Annual Average Growth Rate for Each Site

\begin{tabular}{||c|c|c|c|c|c|c||}
\hline Route & Class & SITE & $\begin{array}{c}\text { Number of } \\
\text { Lanes }\end{array}$ & $\mathbf{2 0 0 3}$ & Slope & $\begin{array}{c}\text { Annual Average } \\
\text { Growth Rate }\end{array}$ \\
\hline \hline US 60 & Rural & 10 & 2 & 956 & 33 & $3.45 \%$ \\
\hline WV 152 & Rural & 13 & 2 & 338 & 10 & $2.96 \%$ \\
\hline US 33 & Rural & 14 & 2 & 1447 & 48 & $3.32 \%$ \\
\hline US 35 & Rural & 15 & 2 & 2582 & 117 & $4.53 \%$ \\
\hline US 52 & Rural & 16 & 2 & 547 & 12 & $2.19 \%$ \\
\hline US 119 & Rural & 17 & 2 & 227 & 4 & $1.76 \%$ \\
\hline CO 21 & Rural & 19 & 2 & 164 & 13 & $7.93 \%$ \\
\hline US 220 & Rural & 20 & 2 & 205 & 5 & $2.44 \%$ \\
\hline US 19 & Rural & 22 & 2 & 405 & 27 & $6.67 \%$ \\
\hline US 19 & Rural & 23 & 2 & 432 & 24 & $5.56 \%$ \\
\hline US 60 & Rural & 25 & 2 & 415 & 7 & $1.69 \%$ \\
\hline WV 25 & Urban & 34 & 2 & 871 & 21 & $2.41 \%$ \\
\hline US 60 & Urban & 36 & 4 & 793 & 8 & $1.01 \%$ \\
\hline US 11 & Urban & 37 & 2 & 418 & 16 & $3.83 \%$ \\
\hline WV 61 & Urban & 38 & 2 & 178 & 2 & $1.12 \%$ \\
\hline WV 114 & Urban & 40 & 2 & 314 & 8 & $2.55 \%$ \\
\hline WV 94 & Rural & 44 & 2 & 840 & 40 & $4.76 \%$ \\
\hline WV 7 & Rural & 45 & 2 & 331 & 11 & $3.32 \%$ \\
\hline WV 20 & Rural & 48 & 2 & 252 & 6 & $2.38 \%$ \\
\hline \hline
\end{tabular}

The growth rates in the above table vary for each site, ranging between $1.01 \%$ for Site 36 and $7.93 \%$ for Site 19 . Due to this reason, the sites were grouped under similar category of rural and urban sites in order to improve the regression coefficient and the growth rates for better understanding the traffic patterns at non-Interstate highways of West Virginia. 
Linear regression analysis was performed to predict truck traffic volumes and growth rates on non-Interstate highways in West Virginia. Models were developed based on two methods as described below:

- The first method uses AADTT for calculating Annual Average Growth Rates and Weighted Average Growth Rates at each site and for each truck classification.

- The second method uses the average of AADTT in every year. Regression models and growth rates were developed using these values for each site as well as for each truck classification. 


\subsubsection{Linear Regression Analysis using AADTT}

\subsubsection{Analysis for Sites}

\section{a) All Non-Interstates}

The first step was to estimate the annual average growth rates at each site using the linear regression analysis. The weight factors were then estimated based on the truck traffic count. Finally the weighted average growth rate was found by adding all of the products obtained by multiplying the weight factor by the annual average growth rate. The results obtained are displayed in the Table 4.4 .

Table 4.4 - Weighted Average Growth Rate - All Non-Interstates

\begin{tabular}{||c|c|c|c|c|c||}
\hline Route & Class & SITE & $\begin{array}{c}\text { Sum of trucks } \\
\text { during years }\end{array}$ & $\begin{array}{c}\text { Annual Average } \\
\text { Growth Rate }\end{array}$ & Weight/Site \\
\hline \hline US 60 & Rural & 10 & 7663 & $3.45 \%$ & 0.084 \\
\hline WV 152 & Rural & 13 & 2675 & $2.96 \%$ & 0.029 \\
\hline US 33 & Rural & 14 & 10862 & $3.32 \%$ & 0.120 \\
\hline US 35 & Rural & 15 & 19133 & $4.53 \%$ & 0.211 \\
\hline US 52 & Rural & 16 & 4496 & $2.19 \%$ & 0.050 \\
\hline US 119 & Rural & 17 & 1933 & $1.76 \%$ & 0.021 \\
\hline CO 21 & Rural & 19 & 1008 & $7.93 \%$ & 0.011 \\
\hline US 220 & Rural & 20 & 1596 & $2.44 \%$ & 0.018 \\
\hline US 19 & Rural & 22 & 2869 & $6.67 \%$ & 0.032 \\
\hline US 19 & Rural & 23 & 3190 & $5.56 \%$ & 0.035 \\
\hline US 60 & Rural & 25 & 3613 & $1.69 \%$ & 0.040 \\
\hline WV 25 & Urban & 34 & 7036 & $2.41 \%$ & 0.078 \\
\hline US 60 & Urban & 36 & 6861 & $1.01 \%$ & 0.076 \\
\hline US 11 & Urban & 37 & 3254 & $3.83 \%$ & 0.036 \\
\hline WV 61 & Urban & 38 & 1517 & $1.12 \%$ & 0.017 \\
\hline WV 114 & Urban & 40 & 2430 & $2.55 \%$ & 0.027 \\
\hline WV 94 & Rural & 44 & 6016 & $4.76 \%$ & 0.066 \\
\hline WV 7 & Rural & 45 & 2586 & $3.32 \%$ & 0.028 \\
\hline WV 20 & Rural & 48 & 2044 & $2.38 \%$ & 0.023 \\
\hline \hline
\end{tabular}

\begin{tabular}{|l|c||}
\hline \hline Mean & $3.36 \%$ \\
\hline Standard Deviation & $1.84 \%$ \\
\hline Coefficient of Variation & $54.77 \%$ \\
\hline
\end{tabular}

Weighted Average Growth Rate
$3.44 \%$ 
In fact, the lower the coefficient of variation the better is the result. But, in traffic analyses it is merely possible to see lower values for coefficient of variation. This may be due to the existence of different traffic patterns and the effects of socioeconomic variables. The coefficient of variation in the Table 4.4 is lower but it could be further reduced if more data is available to better estimate the growth rates.

\section{b) Rural Non-Interstates}

The growth rates on rural non-Interstate highways were calculated in a similar way to the ones for all non-Interstate highways. Out of total 19 sites, 14 sites are categorized as rural non-Interstate highways; the results are shown in Table 4.5.

Table 4.5 - Weighted Average Growth Rate - Rural Non-Interstates

\begin{tabular}{|c|c|c|c|c|c||}
\hline Route & Class & SITE & $\begin{array}{c}\text { Sum of trucks } \\
\text { during years }\end{array}$ & $\begin{array}{c}\text { Annual Average } \\
\text { Growth Rate }\end{array}$ & Weight/Site \\
\hline \hline US 60 & Rural & 10 & 7663 & $3.45 \%$ & 0.110 \\
\hline WV 152 & Rural & 13 & 2675 & $2.96 \%$ & 0.038 \\
\hline US 33 & Rural & 14 & 10862 & $3.32 \%$ & 0.156 \\
\hline US 35 & Rural & 15 & 19133 & $4.53 \%$ & 0.275 \\
\hline US 52 & Rural & 16 & 4496 & $2.19 \%$ & 0.065 \\
\hline US 119 & Rural & 17 & 1933 & $1.76 \%$ & 0.028 \\
\hline CO 21 & Rural & 19 & 1008 & $7.93 \%$ & 0.014 \\
\hline US 220 & Rural & 20 & 1596 & $2.44 \%$ & 0.023 \\
\hline US 19 & Rural & 22 & 2869 & $6.67 \%$ & 0.041 \\
\hline US 19 & Rural & 23 & 3190 & $5.56 \%$ & 0.046 \\
\hline US 60 & Rural & 25 & 3613 & $1.69 \%$ & 0.052 \\
\hline WV 94 & Rural & 44 & 6016 & $4.76 \%$ & 0.086 \\
\hline WV 7 & Rural & 45 & 2586 & $3.32 \%$ & 0.037 \\
\hline WV 20 & Rural & 48 & 2044 & $2.38 \%$ & 0.029 \\
\hline
\end{tabular}

\begin{tabular}{|l|c|}
\hline Mean & $3.78 \%$ \\
\hline Standard Deviation & $1.89 \%$ \\
\hline Coefficient of Variation & $49.96 \%$ \\
\hline
\end{tabular}

\begin{tabular}{|l|c|}
\hline $\begin{array}{l}\text { Weighted Average } \\
\text { Growth Rate }\end{array}$ & $3.84 \%$ \\
\hline
\end{tabular}




\section{c) Urban Non-Interstates}

The analysis here is similar to the one performed for all non-Interstate highways.

The available five sites were analyzed under this category and the results are displayed in Table 4.6.

Table 4.6 - Weighted Average Growth Rate - Urban Non-Interstates

\begin{tabular}{|c|c|c|c|c|c||}
\hline Route & Class & SITE & $\begin{array}{c}\text { Sum of trucks } \\
\text { during years }\end{array}$ & $\begin{array}{c}\text { Annual Average } \\
\text { Growth Rate }\end{array}$ & Weight/Site \\
\hline \hline WV 25 & Urban & 34 & 7036 & $2.41 \%$ & 0.333 \\
\hline US 60 & Urban & 36 & 6861 & $1.01 \%$ & 0.325 \\
\hline US 11 & Urban & 37 & 3254 & $3.83 \%$ & 0.154 \\
\hline WV 61 & Urban & 38 & 1517 & $1.12 \%$ & 0.072 \\
\hline WV 114 & Urban & 40 & 2430 & $2.55 \%$ & 0.115 \\
\hline
\end{tabular}

\begin{tabular}{|l|c|}
\hline Mean & $2.18 \%$ \\
\hline Standard Deviation & $1.16 \%$ \\
\hline Coefficient of Variation & $53.11 \%$ \\
\hline
\end{tabular}

\begin{tabular}{|l|c|}
\hline $\begin{array}{l}\text { Weighted Average } \\
\text { Growth Rate }\end{array}$ & $2.09 \%$ \\
\hline
\end{tabular}

The coefficients of variation for both the rural and urban categories also tend to be high which could be reduced if more reliable sample data is available. Of the above three categories, the best estimated growth rate was obtained at rural non-Interstate highways with $3.84 \%$ and having a coefficient of variation as $49.96 \%$. The reason for lower coefficient of variation could be due to the irregular traffic patterns that are observed usually at urban non-Interstate highways. 


\subsubsection{Analysis for Each Truck Classification}

\section{a) All Non-Interstates}

Models were developed for every truck classification at all sites during the course of nine years. Using these models, annual average growth rates were developed. The weight factors and the corresponding weighted average growth rates were then estimated by the same method used in the analysis for each site. The models for each truck classification are shown in the Appendix (A) and the annual average growth rates are shown in Table 4.7.

Table 4.7 shows better growth rates for most of the truck classifications at all sites. The sites showing no value indicate either that there were no trucks of that particular class observed at that site or that the value of slope over 2003 estimate is imaginary. Negative growth rates were also seen at some of the sites for particular truck classification. There may be several reasons for this decline in growth rate. One such reason may be decline in mineral and coal production which in turn has impacted over truck travel. Another reason may be due to the changes in traffic patterns. The influence of different socioeconomic variables can result in decrease or increase of truck traffic growth rates. Due to the limited source of data, the confirmable reasons are difficult to provide. Further study on forecasting truck traffic may explain the reasons for changes in growth rates. 
Table 4.7 - Annual Average Growth Rate according to Truck Classification - All Non-Interstates

\begin{tabular}{|c|c|c|c|c|c|c|c|c|c|c|c|c|c|c|c|c|c|c|c|}
\hline $\begin{array}{l}\text { Truck } \\
\text { Class }\end{array}$ & Site10 & Site13 & Site14 & Site15 & Site16 & Site17 & Site19 & Site20 & Site22 & Site23 & Site25 & Site34 & Site36 & Site37 & Site38 & Site40 & Site44 & Site45 & Site48 \\
\hline TC4 & $3.89 \%$ & $7.54 \%$ & $2.80 \%$ & $-2.65 \%$ & $11.03 \%$ & $7.60 \%$ & $8.71 \%$ & $-31.00 \%$ & $9.33 \%$ & $9.63 \%$ & $1.67 \%$ & $4.29 \%$ & $6.27 \%$ & $6.78 \%$ & $-13.00 \%$ & $2.53 \%$ & $2.67 \%$ & $2.08 \%$ & $3.00 \%$ \\
\hline TC5 & $2.98 \%$ & $2.41 \%$ & $1.42 \%$ & $1.55 \%$ & $5.13 \%$ & $1.90 \%$ & $9.80 \%$ & $2.52 \%$ & $0.73 \%$ & $2.77 \%$ & $0.88 \%$ & $7.61 \%$ & $-0.42 \%$ & $1.95 \%$ & $-1.82 \%$ & $2.58 \%$ & $1.26 \%$ & $0.11 \%$ & $-3.58 \%$ \\
\hline TC6 & $-9.27 \%$ & $2.68 \%$ & $1.32 \%$ & $4.97 \%$ & $-19.67 \%$ & $2.12 \%$ & $0.60 \%$ & $1.10 \%$ & $1.71 \%$ & $0.29 \%$ & $2.49 \%$ & $2.35 \%$ & $1.65 \%$ & $4.63 \%$ & $-3.23 \%$ & $3.39 \%$ & $8.85 \%$ & $3.02 \%$ & $0.95 \%$ \\
\hline TC7 & $-26.15 \%$ & $6.40 \%$ & $2.28 \%$ & $-9.33 \%$ & $-13.29 \%$ & $8.40 \%$ & $-2.00 \%$ & $-16.67 \%$ & $3.40 \%$ & $2.78 \%$ & $6.00 \%$ & $6.60 \%$ & $3.81 \%$ & $8.33 \%$ & - & $-3.00 \%$ & $5.22 \%$ & $2.43 \%$ & $-15.00 \%$ \\
\hline TC8 & $1.18 \%$ & $-3.61 \%$ & $1.18 \%$ & $-15.75 \%$ & $7.77 \%$ & $5.06 \%$ & $6.38 \%$ & $2.50 \%$ & $5.88 \%$ & $-0.56 \%$ & $2.71 \%$ & $5.76 \%$ & $4.76 \%$ & $3.13 \%$ & $4.67 \%$ & $4.04 \%$ & $8.98 \%$ & $2.79 \%$ & $1.18 \%$ \\
\hline TC9 & $0.23 \%$ & $1.58 \%$ & $3.86 \%$ & $7.86 \%$ & $0.95 \%$ & $1.59 \%$ & $0.40 \%$ & $0.86 \%$ & $11.90 \%$ & $-0.56 \%$ & $6.19 \%$ & $2.32 \%$ & $-1.43 \%$ & $5.09 \%$ & $1.79 \%$ & $1.00 \%$ & $4.90 \%$ & $-2.16 \%$ & $1.54 \%$ \\
\hline TC10 & $1.60 \%$ & $0.71 \%$ & $2.75 \%$ & $12.87 \%$ & $9.55 \%$ & $4.50 \%$ & - & - & $15.00 \%$ & $-12.00 \%$ & $13.33 \%$ & $-22.33 \%$ & $8.73 \%$ & $2.00 \%$ & $12.83 \%$ & $5.00 \%$ & $10.53 \%$ & $3.00 \%$ & $1.00 \%$ \\
\hline TC11 & - & - & - & - & - & - & - & - & - & - & - & - & - & - & - & - & - & - & - \\
\hline TC12 & - & - & - & - & - & - & - & - & - & - & - & - & - & - & - & - & - & - & - \\
\hline TC13 & $10.50 \%$ & $10.67 \%$ & $24.00 \%$ & $13.77 \%$ & $34.29 \%$ & $9.25 \%$ & - & $8.75 \%$ & $22.00 \%$ & $23.50 \%$ & $14.00 \%$ & $8.75 \%$ & $-7.00 \%$ & $-5.00 \%$ & $15.00 \%$ & $1.00 \%$ & $9.13 \%$ & $13.50 \%$ & $4.00 \%$ \\
\hline
\end{tabular}

Table 4.8 - AADTT from 1995 to 2003 for Each Truck Classification and Site - All Non-Interstates

\begin{tabular}{|c|c|c|c|c|c|c|c|c|c|c|c|c|c|c|c|c|c|c|c|}
\hline Truck & Site10 & Site13 & Site14 & Site15 & Site16 & Site17 & Site19 & Site20 & Site22 & Site23 & Site25 & Site34 & Site36 & Site37 & Site38 & Site40 & Site44 & Site45 & Site48 \\
\hline TC4 & 47 & 82 & 79 & 184 & 270 & 23 & 140 & 35 & 20 & 217 & 17 & 201 & 310 & 130 & 12 & 129 & 103 & 110 & 75 \\
\hline TC5 & 646 & 739 & 1481 & 870 & 777 & 488 & 665 & 216 & 269 & 518 & 817 & 1886 & 900 & 944 & 679 & 917 & 512 & 383 & 494 \\
\hline TC6 & 771 & 320 & 1426 & 820 & 809 & 266 & 42 & 167 & 353 & 418 & 428 & 1204 & 800 & 248 & 123 & 222 & 361 & 268 & 378 \\
\hline TC7 & 319 & 34 & 406 & 33 & 81 & 24 & 10 & 42 & 141 & 65 & 36 & 31 & 198 & 34 & - & 19 & 62 & 40 & 49 \\
\hline TC8 & 252 & 373 & 807 & 1254 & 523 & 234 & 101 & 101 & 163 & 270 & 389 & 563 & 466 & 224 & 151 & 184 & 403 & 241 & 200 \\
\hline TC9 & 2823 & 321 & 3866 & 13329 & 554 & 145 & 41 & 265 & 997 & 495 & 768 & 1088 & 1218 & 180 & 117 & 75 & 808 & 421 & 311 \\
\hline TC10 & 28 & 62 & 83 & 258 & 99 & 125 & 6 & - & 16 & 13 & 25 & 33 & 544 & 9 & 24 & 7 & 1119 & 11 & 16 \\
\hline TC11 & - & - & - & - & - & - & - & - & - & - & - & - & - & - & - & - & - & - & - \\
\hline TC12 & - & - & - & - & - & - & - & - & - & - & - & - & - & - & - & - & - & - & - \\
\hline TC13 & 38 & 17 & 79 & 145 & 66 & 19 & 3 & 6 & 12 & 20 & 26 & 37 & 19 & 11 & 5 & 17 & 105 & 25 & 36 \\
\hline
\end{tabular}


After annual growth rates were calculated, the weighted average growth rate for each classification was calculated by multiplying the weight factor by its corresponding annual growth rate from Table 4.7. The yearly values for each classification were added to obtain the weighted average growth rate for each truck classification. Table 4.8 shows the sum of AADTT at every site for each truck classification during the years of the study, 1995 to 2003. The following characteristics were observed for truck traffic on nonInterstate highways in West Virginia.

$>$ Maximum truck volumes were observed at Site15 (US 35), which is a north-south route in West Virginia. It begins at US 60, Kanawha County, at St. Albans. This route is heavily traveled, especially by trucks, as it is a part of thru route from Charleston to Cincinnati, Dayton and Columbus.

$>$ Based on the AADTT values, more number of trucks on non-Interstate highways in West Virginia belongs to class 9, which are the five-axle single trailer trucks.

About $75 \%$ of the truck traffic on non-Interstate highways in WV falls into the category of heavy truck vehicles or multi unit trucks. 
Table 4.9 - Weight Factors - All Non-Interstates

\begin{tabular}{|c|c|c|c|c|c|c|c|c|c|c|c|c|c|c|c|c|c|c|c|}
\hline $\begin{array}{l}\text { Truck } \\
\text { Class }\end{array}$ & Site10 & Site13 & Site14 & Site15 & Site16 & Site17 & Site19 & Site20 & Site22 & Site23 & Site25 & Site34 & Site36 & Site37 & Site38 & Site40 & Site44 & Site45 & Site48 \\
\hline TC4 & 0.022 & 0.038 & 0.036 & 0.084 & 0.124 & 0.011 & 0.064 & 0.016 & 0.009 & 0.099 & 0.008 & 0.092 & 0.142 & 0.06 & 0.005 & 0.059 & 0.047 & 0.05 & 0.034 \\
\hline TC5 & 0.045 & 0.052 & 0.104 & 0.061 & 0.055 & 0.034 & 0.047 & 0.015 & 0.019 & 0.036 & 0.058 & 0.133 & 0.063 & 0.066 & 0.048 & 0.065 & 0.036 & 0.027 & 0.035 \\
\hline TC6 & 0.082 & 0.034 & 0.151 & 0.087 & 0.086 & 0.028 & 0.004 & 0.018 & 0.037 & 0.044 & 0.045 & 0.128 & 0.085 & 0.026 & 0.013 & 0.024 & 0.038 & 0.028 & 0.04 \\
\hline TC7 & 0.196 & 0.021 & 0.25 & 0.02 & 0.05 & 0.015 & 0.006 & 0.026 & 0.087 & 0.04 & 0.022 & 0.019 & 0.122 & 0.021 & - & 0.012 & 0.038 & 0.025 & 0.03 \\
\hline TC8 & 0.037 & 0.054 & 0.117 & 0.182 & 0.076 & 0.034 & 0.015 & 0.015 & 0.024 & 0.039 & 0.056 & 0.082 & 0.068 & 0.032 & 0.022 & 0.027 & 0.058 & 0.035 & 0.029 \\
\hline TC9 & 0.101 & 0.012 & 0.139 & 0.479 & 0.02 & 0.005 & 0.001 & 0.01 & 0.036 & 0.018 & 0.028 & 0.039 & 0.044 & 0.006 & 0.004 & 0.003 & 0.029 & 0.015 & 0.011 \\
\hline TC10 & 0.011 & 0.025 & 0.033 & 0.104 & 0.04 & 0.05 & 0.002 & - & 0.006 & 0.005 & 0.01 & 0.013 & 0.22 & 0.004 & 0.01 & 0.003 & 0.452 & 0.004 & 0.006 \\
\hline TC11 & - & - & - & - & - & - & - & - & - & - & - & - & - & - & - & - & - & - & - \\
\hline TC12 & - & - & - & - & - & - & - & - & - & - & - & - & - & - & - & - & - & - & \\
\hline TC13 & 0.055 & 0.025 & 0.115 & 0.211 & 0.096 & 0.028 & 0.004 & 0.009 & 0.017 & 0.029 & 0.038 & 0.054 & 0.028 & 0.016 & 0.007 & 0.025 & 0.153 & 0.036 & 0.052 \\
\hline
\end{tabular}


The weight factors and the weighted average growth rates are displayed in Table 4.9 and Table 4.10 , respectively.

Table 4.10 - Weighted Average Growth Rate - All Non-Interstates

\begin{tabular}{||c||c||}
\hline $\begin{array}{c}\text { Truck } \\
\text { Class }\end{array}$ & $\begin{array}{c}\text { Weighted Average Growth Rate } \\
- \text { (all non-Interstates) }\end{array}$ \\
\hline \hline TC4 & $4.92 \%$ \\
\hline TC5 & $2.63 \%$ \\
\hline TC6 & $-0.40 \%$ \\
\hline TC7 & $-4.52 \%$ \\
\hline TC8 & $0.05 \%$ \\
\hline TC9 & $5.17 \%$ \\
\hline TC10 & $8.85 \%$ \\
\hline TC11 & - \\
\hline TC12 & - \\
\hline TC13 & $14.37 \%$ \\
\hline
\end{tabular}

Table 4.10 shows the results for the weighted average growth rate for each truck classification which represents the percent growth or decline of truck traffic volume per year. In the above table, there is no growth rate observed for the truck classification TC11 and TC12, for the reason either no trucks or very few trucks of that class are seen at observed sites. Also, the decline in growth rates for truck classes TC6 and TC7 is due to the abatement of coal mining activity in certain areas of West Virginia, for which these truck classes are the primary method of transportation. 


\section{Precision Analysis}

The annual average growth rate in Table 4.7 was tested for precision analysis. It is based on calculating coefficients of variation for each truck classification. The results are shown in Table 4.11.

Table 4.11 - Coefficient of Variation (CV) for Each Truck Class - All Non-Interstates

\begin{tabular}{||c||c|c|c||}
\hline \hline $\begin{array}{c}\text { Truck } \\
\text { Class }\end{array}$ & Mean & Standard Deviation & Coefficient Of Variation \\
\hline \hline TC4 & 2.27 & 9.68 & $426.00 \%$ \\
\hline TC5 & 2.09 & 3.01 & $144.00 \%$ \\
\hline TC6 & 0.52 & 6.04 & $1162.00 \%$ \\
\hline TC7 & -1.66 & 10.14 & $-611.00 \%$ \\
\hline TC8 & 2.53 & 5.33 & $211.00 \%$ \\
\hline TC9 & 2.52 & 3.43 & $136.00 \%$ \\
\hline TC10 & 4.59 & 9.57 & $208.00 \%$ \\
\hline TC11 & - & - & - \\
\hline TC12 & - & - & $81.00 \%$ \\
\hline TC13 & 12.17 & 9.85 & - \\
\hline \hline
\end{tabular}

The above table shows high coefficients of variation for all truck classes. This is due to large values of standard deviation that are associated with gaps between growth rates. The negative coefficient is a result of negative mean as the standard deviation is always positive as is based on the sum of squares. The presence of outliers could be another reason for higher coefficients. The Class TC13 has comparatively lower coefficient of variation than other truck classes. Therefore, it is more reliable to estimate the future truck traffic for this truck class. 


\section{b) Rural Non-Interstates}

A similar analysis was performed for rural sites on non-Interstate highways. Table 4.12 shows the results for fourteen sites under this category. The weight factors are reported in Appendix (B).

Table 4.12 - Weighted Average Growth Rate - Rural Non-Interstates

\begin{tabular}{||c||c||}
\hline $\begin{array}{c}\text { Truck } \\
\text { Class }\end{array}$ & $\begin{array}{c}\text { Weighted Average Growth Rate } \\
- \text { (rural non-Interstates) }\end{array}$ \\
\hline \hline TC4 & $4.89 \%$ \\
\hline TC5 & $2.30 \%$ \\
\hline TC6 & $-1.38 \%$ \\
\hline TC7 & $-6.37 \%$ \\
\hline TC8 & $-1.38 \%$ \\
\hline TC9 & $5.64 \%$ \\
\hline TC10 & $9.43 \%$ \\
\hline TC11 & - \\
\hline TC12 & - \\
\hline TC13 & $15.94 \%$ \\
\hline
\end{tabular}

Even under this category, there is a decline in growth rate for truck classes TC6 and TC7. The decline is also seen for the truck class TC8 and the reason could be same as mentioned in the previous analysis under 'all non-Interstate' category. 


\section{Precision Analysis}

A check for precision analysis was performed using the annual average growth rates for each truck class. The values for mean, standard deviation and coefficient of variation for each truck class are displayed in Table 4.13.

Table 4.13 - Coefficient of Variation (CV) for Each Truck Class - Rural Non-Interstates

\begin{tabular}{||c||c|c|c||}
\hline \hline $\begin{array}{c}\text { Truck } \\
\text { Class }\end{array}$ & Mean & Standard Deviation & Coefficient Of Variation \\
\hline \hline TC4 & 2.59 & 10.42 & $402.00 \%$ \\
\hline TC5 & 2.13 & 2.92 & $137.00 \%$ \\
\hline TC6 & 0.08 & 6.85 & $8563.00 \%$ \\
\hline TC7 & -3.25 & 10.78 & $-332.00 \%$ \\
\hline TC8 & 1.84 & 6.09 & $331.00 \%$ \\
\hline TC9 & 2.8 & 3.78 & $135.00 \%$ \\
\hline TC10 & 5.99 & 7.53 & $126.00 \%$ \\
\hline TC11 & - & - & - \\
\hline TC12 & - & - & $55.00 \%$ \\
\hline TC13 & 15.18 & 8.39 & - \\
\hline \hline
\end{tabular}

The more stable growth rate for rural non-Interstate highways is seen for class TC13 because it has low CV value compared to all other truck classes. 


\section{c) Urban Non-Interstates}

The analysis under urban category is similar to the one performed for rural nonInterstates. The weighted average growth rates are displayed in the Table 4.14.

Table 4.14 - Weighted Average Growth Rate - Urban Non-Interstates

\begin{tabular}{||c||c||}
\hline $\begin{array}{c}\text { Truck } \\
\text { Class }\end{array}$ & $\begin{array}{c}\text { Weighted Average Growth Rate } \\
-(\text { urban non-Interstates) }\end{array}$ \\
\hline \hline TC4 & $4.93 \%$ \\
\hline TC5 & $3.18 \%$ \\
\hline TC6 & $2.17 \%$ \\
\hline TC7 & $4.21 \%$ \\
\hline TC8 & $4.79 \%$ \\
\hline TC9 & $0.74 \%$ \\
\hline TC10 & $7.10 \%$ \\
\hline TC11 & - \\
\hline TC12 & - \\
\hline TC13 & $4.28 \%$ \\
\hline
\end{tabular}

The above table shows that there is no decline in the growth rate but the growth rate for truck class TC9 is very low. This may be due to several socioeconomic variables as mentioned previously. 


\section{$\underline{\text { Precision Analysis }}$}

This is based on the annual average growth rates for each truck classification under urban category. The values obtained are shown in Table 4.15.

Table 4.15 - Coefficient of Variation (CV) for Each Truck Class - Urban Non-Interstates

\begin{tabular}{||c||c|c|c||}
\hline $\begin{array}{c}\text { Truck } \\
\text { Class }\end{array}$ & Mean & Standard Deviation & Coefficient Of Variation \\
\hline \hline TC4 & 1.37 & 8.21 & $599.00 \%$ \\
\hline TC5 & 1.98 & 3.61 & $182.00 \%$ \\
\hline TC6 & 1.76 & 3.01 & $171.00 \%$ \\
\hline TC7 & 3.94 & 4.98 & $126.00 \%$ \\
\hline TC8 & 4.47 & 0.97 & $22.00 \%$ \\
\hline TC9 & 1.75 & 2.35 & $134.00 \%$ \\
\hline TC10 & 1.25 & 13.79 & $1103.00 \%$ \\
\hline TC11 & - & - & - \\
\hline TC12 & - & - & $224.00 \%$ \\
\hline TC13 & 4.35 & 9.76 & - \\
\hline
\end{tabular}

The coefficient of variation for truck class TC8 is the lowest among all and therefore, has the more stable growth rate for urban non-Interstate highways in WV. 


\subsubsection{Grouping of Truck Class}

To achieve precision in the analyses and to better understand truck travel patterns on non-Interstate highways in WV, truck classes were grouped into two based on the number of axles. Truck classes 4-7 were grouped as single unit and classes 8-13 were grouped as multi-unit. Another reason for performing this analysis was to achieve lower coefficients of variation.

\section{a) All Non-Interstates}

The growth rates were calculated by adding every class AADTT within a group for every year. After calculating AADTT for every year, linear regression was performed to obtain the models from which the growth rates were calculated. Table 4.16 shows the results for two groups of truck classification.

The results show negative growth rate in group TC4-TC7 at Site 10, Site 16, Site 20, Site 38, and Site 48; and in group TC8-TC13 at Site 13, and Site 23. The variation in growth rates in both groups is found between $-5 \%$ and $11 \%$.

\section{Weighted Average Growth Rate}

The weighted average growth rates for each site were derived by multiplying the weight factors obtained by using the AADTT and the Annual Average Growth Rates from Table 4.16. The weight factors are shown in Table 4.17; Table 4.18 shows the Weighted Average Growth Rate for each classified group of trucks. 
Table 4.16 - Annual Average Growth Rates for Table 4.17 - Weight Factors for Single and MultiSingle and Multi-Unit Truck Classes - All Non- Unit Truck Classes - All Non-Interstates Interstates

\begin{tabular}{|c|c|c|}
\hline \multirow{2}{*}{ Site } & \multicolumn{2}{|c|}{ Truck Class } \\
\hline & TC4 - TC7 & TC8 - TC13 \\
\hline 10 & $-5.16 \%$ & $0.47 \%$ \\
\hline 13 & $3.03 \%$ & $-0.39 \%$ \\
\hline 14 & $1.53 \%$ & $3.65 \%$ \\
\hline 15 & $2.04 \%$ & $7.02 \%$ \\
\hline 16 & $-0.36 \%$ & $6.66 \%$ \\
\hline 17 & $2.55 \%$ & $4.23 \%$ \\
\hline 19 & $9.33 \%$ & $5.11 \%$ \\
\hline 20 & $-0.42 \%$ & $1.83 \%$ \\
\hline 22 & $2.00 \%$ & $11.28 \%$ \\
\hline 23 & $3.34 \%$ & $-0.18 \%$ \\
\hline 25 & $1.55 \%$ & $5.16 \%$ \\
\hline 34 & $5.36 \%$ & $2.46 \%$ \\
\hline 36 & $2.41 \%$ & $3.56 \%$ \\
\hline 37 & $3.33 \%$ & $3.99 \%$ \\
\hline 38 & $-2.07 \%$ & $5.12 \%$ \\
\hline 40 & $2.66 \%$ & $3.79 \%$ \\
\hline 44 & $4.63 \%$ & $7.90 \%$ \\
\hline 45 & $1.65 \%$ & $0.04 \%$ \\
\hline 48 & $-1.64 \%$ & $1.78 \%$ \\
\hline
\end{tabular}

\begin{tabular}{|c|c|c|}
\hline \multirow{2}{*}{ Site } & \multicolumn{2}{|c|}{ Truck Class } \\
\hline & TC4 - TC7 & TC8 - TC13 \\
\hline 10 & 0.065 & 0.079 \\
\hline 13 & 0.043 & 0.019 \\
\hline 14 & 0.124 & 0.121 \\
\hline 15 & 0.070 & 0.424 \\
\hline 16 & 0.071 & 0.031 \\
\hline 17 & 0.029 & 0.013 \\
\hline 19 & 0.031 & 0.004 \\
\hline 20 & 0.017 & 0.009 \\
\hline 22 & 0.029 & 0.030 \\
\hline 23 & 0.044 & 0.020 \\
\hline 25 & 0.047 & 0.031 \\
\hline 34 & 0.121 & 0.044 \\
\hline 36 & 0.080 & 0.056 \\
\hline 37 & 0.049 & 0.011 \\
\hline 38 & 0.030 & 0.007 \\
\hline 40 & 0.047 & 0.007 \\
\hline 44 & 0.038 & 0.061 \\
\hline 45 & 0.029 & 0.018 \\
\hline 48 & 0.036 & 0.014 \\
\hline
\end{tabular}

Table 4.18 Weighted Average Growth Rate (all non-Interstates)

\begin{tabular}{|c|c|}
\hline Truck Class & Weighted Average Growth Rate \\
\hline \hline TC4 - TC7 & $1.98 \%$ \\
\hline TC8 - TC13 & $5.17 \%$ \\
\hline
\end{tabular}


The weighted average growth rates shown in the Table 4.18 are smaller for classification group TC4 - TC7 and higher for classification group TC8 - TC13, than those obtained in the previous analyses that were ranging between $2 \%$ and $4 \%$.

\section{Precision Analysis}

The annual average growth rates from Table 4.16 were checked for precision analysis. The values for mean, standard deviation and coefficient of variation are shown in Table 4.19.

Table 4.19 - Coefficient of Variation (CV) for analysis in Each Truck Group (Single/Multi-Unit) - All Non-Interstates

\begin{tabular}{||c||c|c|c||}
\hline Truck Class & Mean & Standard Deviation & Coefficient Of Variation \\
\hline \hline TC4 - TC7 & 1.88 & 3.08 & $164.00 \%$ \\
\hline TC8 - TC13 & 3.87 & 3.03 & $78.00 \%$ \\
\hline
\end{tabular}

From the above table, high $\mathrm{CV}$ value is observed for the truck classification group TC4 - TC7. This is due to large variation in the growth rate from $-5 \%$ to $9 \%$ and also there are 5 sites in this group that have negative growth rates. The $\mathrm{CV}$ value for the classification group TC8 - TC13 is smaller than the other group, but this value is also considered to be high. One reason for this could be due to very large difference observed between the growth rate at Site 22 and all other sites. 


\section{b) Rural Non-Interstates}

The analysis for rural non-Interstate highways was conducted similar to the previous analysis for all non-Interstate highways. Table 4.20 shows the weight factors for each classification group for rural non-Interstates and Table 4.21 shows the weighted average growth rate for the respective groups.

Table 4.20 - Weight Factors for Single and Multi-Unit Truck Classes - Rural Non-Interstates

\begin{tabular}{|c|c|c|}
\hline \multirow{2}{*}{ Site } & \multicolumn{2}{|c|}{ Truck Class } \\
\cline { 2 - 3 } & TC4- TC7 & TC8 - TC13 \\
\hline $\mathbf{1 0}$ & 0.097 & 0.090 \\
\hline $\mathbf{1 3}$ & 0.064 & 0.022 \\
\hline $\mathbf{1 4}$ & 0.184 & 0.139 \\
\hline $\mathbf{1 5}$ & 0.103 & 0.485 \\
\hline $\mathbf{1 6}$ & 0.105 & 0.036 \\
\hline $\mathbf{1 7}$ & 0.043 & 0.015 \\
\hline $\mathbf{1 9}$ & 0.046 & 0.004 \\
\hline $\mathbf{2 0}$ & 0.025 & 0.011 \\
\hline $\mathbf{2 2}$ & 0.042 & 0.034 \\
\hline $\mathbf{2 3}$ & 0.066 & 0.023 \\
\hline $\mathbf{2 5}$ & 0.070 & 0.035 \\
\hline $\mathbf{4 4}$ & 0.056 & 0.070 \\
\hline $\mathbf{4 5}$ & 0.043 & 0.020 \\
\hline $\mathbf{4 8}$ & 0.054 & 0.016 \\
\hline
\end{tabular}

Table 4.21 Weighted Average Growth Rate (rural non-intestates)

\begin{tabular}{|c||c|}
\hline Truck Class & Weighted Average Growth Rate \\
\hline \hline TC4 - TC7 & $1.32 \%$ \\
\hline TC8 - TC13 & $5.42 \%$ \\
\hline
\end{tabular}


The growth rates observed in the Table 4.21 are similar to those obtained for all non-Interstates classification group with smaller rates for group TC4 - TC7 and higher rates for group TC8 - TC13.

\section{Precision Analysis}

Precision analysis was conducted based on the annual average growth rates for rural sites on non-Interstate highways from Table 4.16. The results for coefficient of variation are displayed in Table 4.22. Coefficients of variation are high due to the large variation of growth rates from $-5 \%$ to $11 \%$.

Table 4.22 - Coefficient of Variation (CV) for analysis in Each Truck Group (Single/Multi-Unit) - Rural Non-Interstates

\begin{tabular}{||c||c|c|c||}
\hline \hline Truck Class & Mean & Standard Deviation & Coefficient Of Variation \\
\hline \hline TC4 - TC7 & 1.72 & 3.27 & $190.00 \%$ \\
\hline TC8 - TC13 & 3.90 & 3.53 & $91.00 \%$ \\
\hline
\end{tabular}




\section{c) Urban Non-Interstates}

After the analysis for rural sites, similar analysis was conducted for urban sites. Table 4.23 shows the weight factors and Table 4.24 shows the weighted average growth rates for the classification groups on urban non-Interstate highways.

Table 4.23 - Weight Factors for Single and Multi-Unit Truck Classes - Urban Non-Interstates

\begin{tabular}{|c|c|c||}
\hline \hline \multirow{2}{*}{ Site } & \multicolumn{2}{|c|}{ Truck Class } \\
\cline { 2 - 3 } & TC4- TC7 & TC8 - TC13 \\
\hline \hline $\mathbf{3 4}$ & 0.37 & 0.351 \\
\hline $\mathbf{3 6}$ & 0.246 & 0.449 \\
\hline $\mathbf{3 7}$ & 0.151 & 0.085 \\
\hline $\mathbf{3 8}$ & 0.091 & 0.059 \\
\hline $\mathbf{4 0}$ & 0.143 & 0.056 \\
\hline
\end{tabular}

Table 4.24 Weighted Average Growth Rate (urban non-intestates)

\begin{tabular}{|c||c|}
\hline Truck Class & Weighted Average Growth Rate \\
\hline \hline TC4 - TC7 & $3.26 \%$ \\
\hline TC8 - TC13 & $3.31 \%$ \\
\hline
\end{tabular}

The weighted average growth rates obtained for the urban category are in the range of $2 \%$ to $4 \%$ growth value that is generally used by the USDOT at non-Interstate highways in US. Hence, these growth rates are reasonable to further estimate the AADTT. Another point observed here is that the growth rate for heavy truck classification is higher than the light or single-unit truck group. 


\section{Precision Analysis}

Precision analysis was conducted based on the annual average growth rates for urban sites from Table 4.16. The results for the analysis are shown in Table 4.25

Table 4.25 - Coefficient of Variation (CV) for analysis in Each Truck Group (Single/Multi-Unit) - Urban Non-Interstates

\begin{tabular}{||c||c|c|c||}
\hline \hline Truck Class & Mean & Standard Deviation & Coefficient Of Variation \\
\hline \hline TC4 - TC7 & 2.34 & 2.72 & $116.00 \%$ \\
\hline TC8 - TC13 & 3.78 & 0.95 & $25.00 \%$ \\
\hline
\end{tabular}

Negative growth rate observed at Site 38 led the coefficient of variation to increase for single and multi-unit axles. Further, this led to increase in standard deviation value. 


\subsubsection{Linear Regression Analysis using Yearly Average of AADTT}

\subsubsection{Analysis for Sites on Non-Interstate Highways in WV}

Linear regression analysis was conducted using the yearly average of AADTT for all sites. In other words, AADTT's at all sites for the same year were averaged. Nine averaged AADTT's, from 1995 to 2003 were obtained for this study. These values were plotted to determine the slope and the growth rate.

\section{a) All Non-Interstates}

AADTT's for all sites were plotted against time period; the linear trend using the yearly average of AADTT's is shown in Figure 4.1.

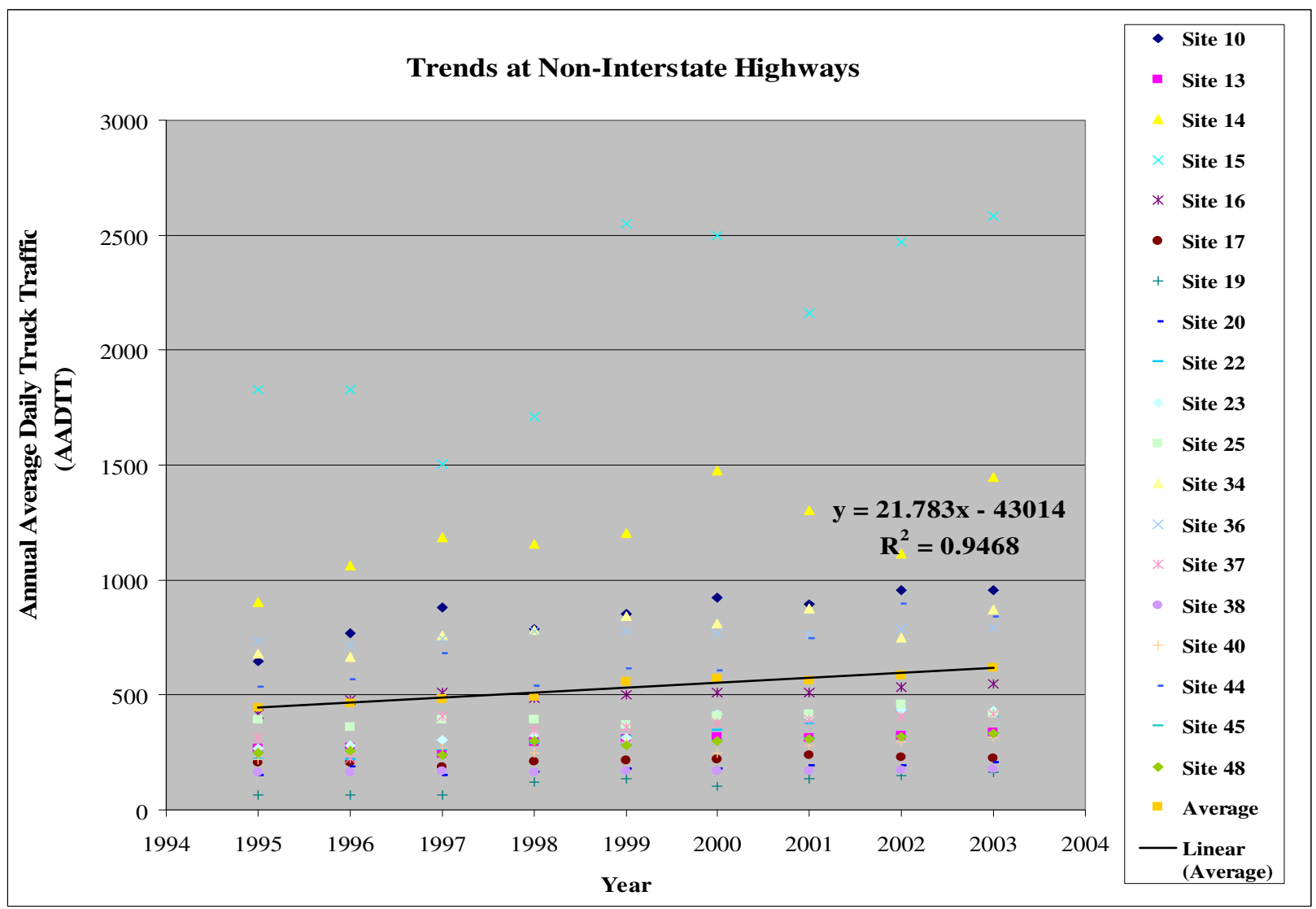

Figure 4.1 Trends at Non-Interstate Highways 


$$
A A D T T=(21.783 \times \text { year })-43014
$$

\begin{tabular}{|c||c|c|c|}
\hline Slope & Intercept & Estimate 2003 & Overall Growth Rate \\
\hline \hline 21.783 & -43014 & 617 & $3.50 \%$ \\
\hline
\end{tabular}

The overall growth rate is within the range of $2 \%-4 \%$ and based on the high value of coefficient of regression (near to 1.00); the above model is reliable and could be used to estimate future truck traffic on non-Interstate highways in West Virginia.

\section{b) Rural Non-Interstates}

Similar to the above analysis, linear regression models were developed separately for rural non-Interstate highways. Figure 4.2 shows the trends at rural sites.

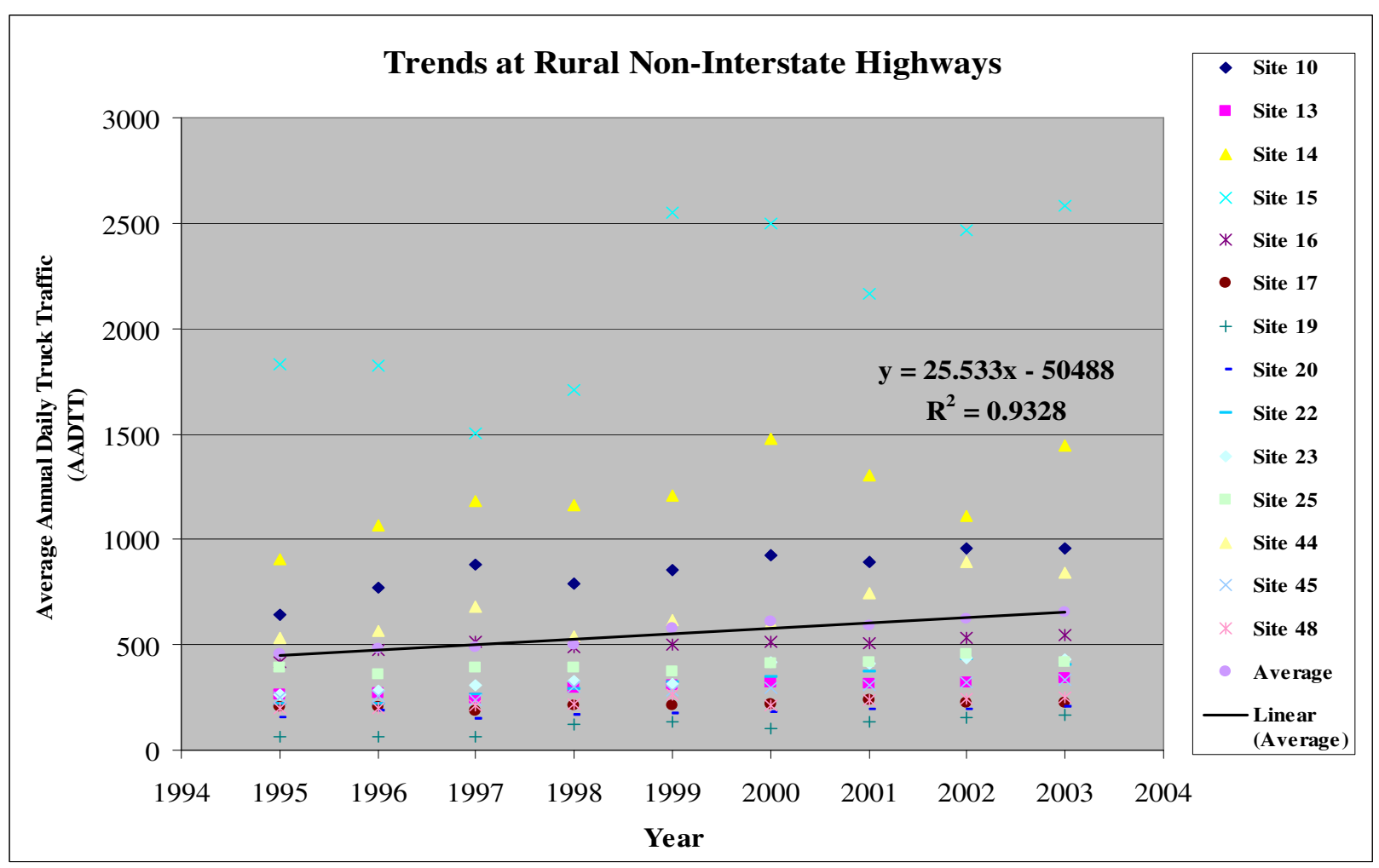

Figure 4.2 Trends at Rural Non-Interstate Highways 


$$
A A D T T=(25.533 \times \text { year })-50488
$$

(Equation 4.2)

\begin{tabular}{|c||c|c|c||}
\hline \hline Slope & Intercept & Estimate 2003 & Overall Growth Rate \\
\hline \hline 25.533 & -50488 & 653 & $3.90 \%$ \\
\hline
\end{tabular}

\section{c) Urban Non-Interstates}

Also linear regression models were developed separately for urban non-Interstate highways. Figure 4.3 shows the trends at urban sites.

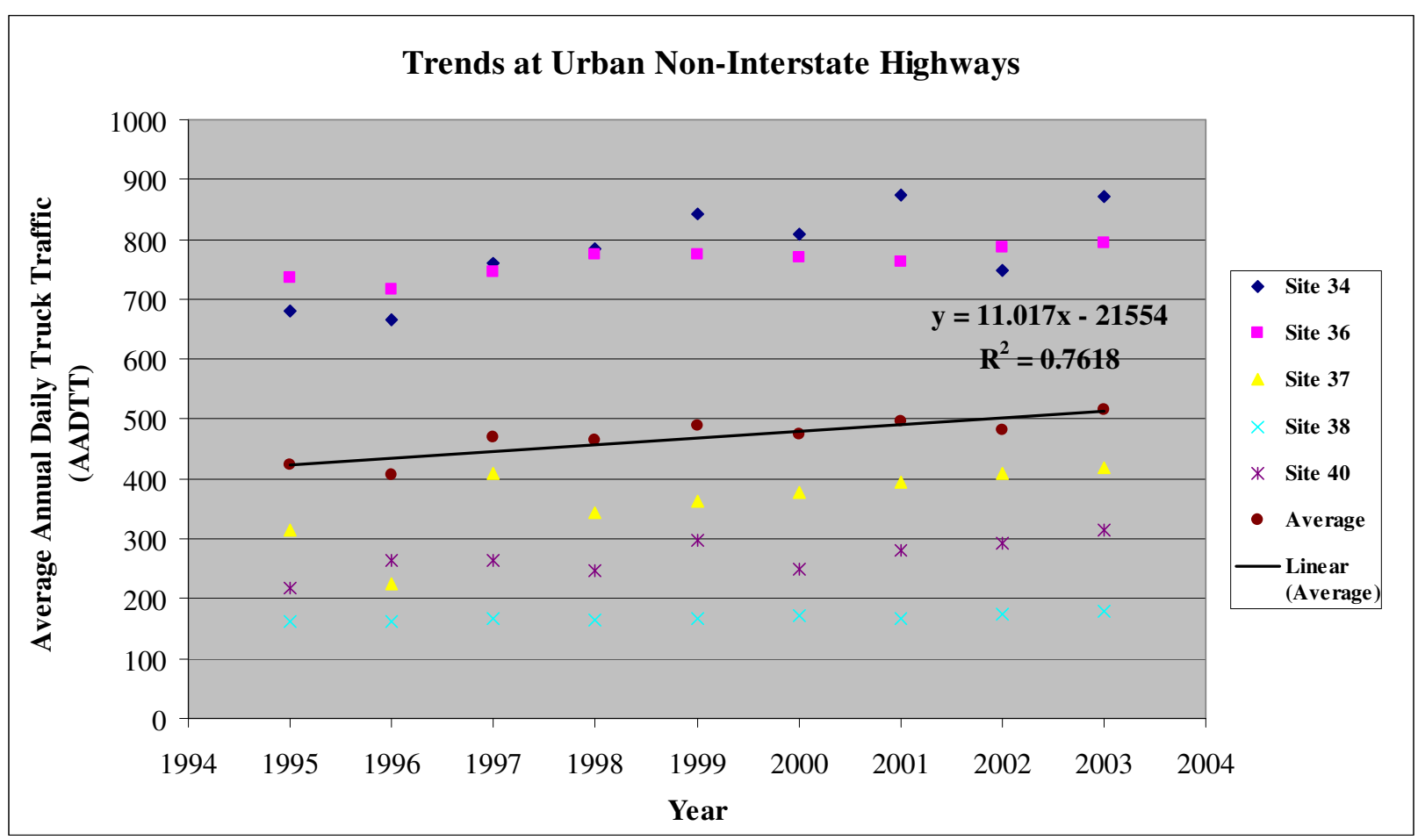

Figure 4.3 Trends at Urban Non-Interstate Highways

$$
A A D T T=(11.017 \times \text { year })-21554
$$

(Equation 4.3)

\begin{tabular}{|c||c|c|c||}
\hline \hline Slope & Intercept & Estimate 2003 & Overall Growth Rate \\
\hline \hline 11.017 & -21554 & 515 & $2.10 \%$ \\
\hline
\end{tabular}


The overall growth rates estimated using yearly average of AADTT at rural and urban non-Interstate highways are $3.90 \%$ and $2.10 \%$ respectively. The models for the same are shown by Equation 4.2 and Equation 4.3. Similar to the estimated growth rate at non-Interstate highways, growth rates at rural and urban sites are within the range of $2 \%$ to $4 \%$ and hence the models could be relied upon for estimating the future truck traffic or AADTT. 


\subsubsection{Analysis for Each Truck Classification}

After the analysis for sites, similar analysis was conducted for each truck classification. Within a truck class, AADTT's in all the required sites for the same year were averaged. Therefore, nine averaged values of AADTT were obtained for each class and were analyzed to find the regression models and growth rates for all truck classes based on all sites, rural and urban categories, as well as for single and multi-unit axle groups. The results are shown in the tables below.

\section{a) All Non-Interstates}

Table 4.26 - Linear Regression Models, Growth Rates and Coefficients of Regression $\left(\mathbf{R}^{2}\right)$

Values for Each Truck Classification - All Non-Interstate Highways

\begin{tabular}{||c|c|c|c||}
\hline Truck Class & Model & $\begin{array}{c}\text { Overall Growth } \\
\text { Rate }\end{array}$ & $\mathbf{R}^{\mathbf{2}}$ \\
\hline \hline TC4 & $\mathrm{y}=1.2833 \mathrm{x}-2552.4$ & $6.00 \%$ & 0.78 \\
\hline TC5 & $\mathrm{y}=3.1333 \mathrm{x}-6180.3$ & $3.00 \%$ & 0.87 \\
\hline TC6 & $\mathrm{y}=0.2667 \mathrm{x}-477.84$ & - & 0.07 \\
\hline TC7 & $\mathrm{y}=-0.0667 \mathrm{x}+142.82$ & $-1.00 \%$ & 0.03 \\
\hline TC8 & $\mathrm{y}=0.6333 \mathrm{x}-1225.6$ & $1.00 \%$ & 0.52 \\
\hline TC9 & $\mathrm{y}=12.017 \mathrm{x}-23859$ & $6.00 \%$ & 0.71 \\
\hline TC10 & $\mathrm{y}=2.1333 \mathrm{x}-4250.1$ & $10.00 \%$ & 0.77 \\
\hline TC11 & $\mathrm{y}=\mathrm{x}-1986.8$ & $7.00 \%$ & 0.67 \\
\hline TC12 & $\mathrm{y}=0.1833 \mathrm{x}-365.15$ & $9.00 \%$ & 0.50 \\
\hline TC13 & $\mathrm{y}=0.6833 \mathrm{x}-1361.8$ & $14.00 \%$ & 0.77 \\
\hline
\end{tabular}

In this case, very low coefficients of regression are observed for truck classes TC6 and TC7. This is due to the zero growth rate observed for truck class TC6 and negative growth rate for truck class TC7. Therefore, these models may not be reliable for estimation of future growth rates on non-Interstate highways in West Virginia. 


\section{Analysis by Grouping Truck Classes}

Similar analysis was performed based on grouping of truck classes for single and multi-unit groups. In this case, the average of AADTT obtained for individual truck classes for the same year were added in a group and the values obtained were analyzed to get regression models, overall growth rates and coefficients of regression for single and multi-unit truck groups.

Table 4.27 - Linear Regression Models, Growth Rates and Coefficients of Regression $\left(\mathbf{R}^{2}\right)$ Values for Each Truck Classification - (single and multi-unit) All Non-Interstates

\begin{tabular}{||c||c|c|c||}
\hline \hline Truck Class & Model & $\begin{array}{c}\text { Overall Growth } \\
\text { Rate }\end{array}$ & $\mathbf{R}^{2}$ \\
\hline \hline TC4 - TC7 & $\mathrm{y}=4.6167 \mathrm{x}-9067.7$ & $2.50 \%$ & 0.88 \\
\hline TC8 - TC13 & $\mathrm{y}=16.65 \mathrm{x}-33048$ & $5.60 \%$ & 0.77 \\
\hline
\end{tabular}

There is not much impact of the negative growth rates from truck classes TC6 and TC7. Due to this better coefficients of regression were observed. 


\section{b) Rural Non-Interstates}

Table 4.28 shows low coefficients of regression for truck classes TC6, TC7, TC8, and TC12. Zero growth rates are observed for classes TC6 and TC8. Therefore, this model may not be reliable to estimate the truck traffic volumes.

Table 4.28 - Linear Regression Models, Growth Rates and Coefficients of Regression $\left(\mathbf{R}^{2}\right)$

Values for Each Truck Classification - Rural Non-Interstate Highways

\begin{tabular}{||c|c|c|c||}
\hline Truck Class & Model & $\begin{array}{c}\text { Overall Growth } \\
\text { Rate }\end{array}$ & $\mathbf{R}^{\mathbf{2}}$ \\
\hline \hline TC4 & $\mathrm{y}=1.0833 \mathrm{x}-2154.5$ & $6.00 \%$ & 0.89 \\
\hline TC5 & $\mathrm{y}=2.8667 \mathrm{x}-5659.9$ & $3.00 \%$ & 0.76 \\
\hline TC6 & $\mathrm{y}=-0.1833 \mathrm{x}+420.71$ & - & 0.03 \\
\hline TC7 & $\mathrm{y}=-0.3333 \mathrm{x}+677$ & $-3.00 \%$ & 0.42 \\
\hline TC8 & $\mathrm{y}=0.0667 \mathrm{x}-91.044$ & - & 0.01 \\
\hline TC9 & $\mathrm{y}=16.133 \mathrm{x}-32051$ & $6.00 \%$ & 0.70 \\
\hline TC10 & $\mathrm{y}=2.2333 \mathrm{x}-4449.7$ & $10.00 \%$ & 0.70 \\
\hline TC11 & $\mathrm{y}=1.5167 \mathrm{x}-3014.9$ & $8.00 \%$ & 0.58 \\
\hline TC12 & $\mathrm{y}=0.1167 \mathrm{x}-231.22$ & $6.00 \%$ & 0.20 \\
\hline TC13 & $\mathrm{y}=0.95 \mathrm{x}-1894.2$ & $16.00 \%$ & 0.70 \\
\hline
\end{tabular}

\section{Analysis by Grouping Truck Classes}

Table 4.29 shows single unit truck group is more reliable with an overall growth rate of $2.00 \%$ even though it includes truck classes TC6 and TC7 that had low coefficients of regression values from Table 4.28 . 
Table 4.29 - Linear Regression Models, Growth Rates and Coefficients of Regression $\left(\mathbf{R}^{\mathbf{2}}\right)$

Values for Each Truck Classification - (single and multi-unit) Rural Non-Interstates

\begin{tabular}{||c||c|c|c||}
\hline \hline Truck Class & Model & $\begin{array}{c}\text { Overall Growth } \\
\text { Rate }\end{array}$ & $\mathbf{R}^{2}$ \\
\hline \hline TC4 - TC7 & $\mathrm{y}=3.4333 \mathrm{x}-6716.7$ & $2.00 \%$ & 0.77 \\
\hline TC8 - TC13 & $\mathrm{y}=21.017 \mathrm{x}-41732$ & $5.90 \%$ & 0.74 \\
\hline
\end{tabular}

\section{c) Urban Non-Interstates}

Low coefficients of regression are observed for sites TC6, TC7, TC9 and TC13. No values are shown for classes TC11 and TC12. The reason for this is either no trucks or very few trucks were observed at these sites in that particular class which may not be sufficient enough to design a model or calculate the growth rates.

Table 4.30 - Linear Regression Models, Growth Rates and Coefficients of Regression $\left(\mathbf{R}^{2}\right)$ Values for Each Truck Classification - Urban Non-Interstate Highways

\begin{tabular}{||c|c|c|c||}
\hline \hline Truck Class & Model & $\begin{array}{c}\text { Overall Growth } \\
\text { Rate }\end{array}$ & $\mathbf{R}^{2}$ \\
\hline \hline TC4 & $\mathrm{y}=1.6 \mathrm{x}-3181.1$ & $6.00 \%$ & 0.50 \\
\hline TC5 & $\mathrm{y}=3.9333 \mathrm{x}-7744.4$ & $3.00 \%$ & 0.59 \\
\hline TC6 & $\mathrm{y}=1.4667 \mathrm{x}-2874.1$ & $2.00 \%$ & 0.22 \\
\hline TC7 & $\mathrm{y}=0.55 \mathrm{x}-1093.3$ & $5.00 \%$ & 0.44 \\
\hline TC8 & $\mathrm{y}=2.5 \mathrm{x}-4962.3$ & $5.00 \%$ & 0.76 \\
\hline TC9 & $\mathrm{y}=0.65 \mathrm{x}-1240$ & $1.00 \%$ & 0.29 \\
\hline TC10 & $\mathrm{y}=1.6333 \mathrm{x}-3251.4$ & $8.00 \%$ & 0.70 \\
\hline TC11 & - & - & - \\
\hline TC12 & - & - & - \\
\hline TC13 & $\mathrm{y}=0.0667 \mathrm{x}-131.04$ & $4.00 \%$ & 0.04 \\
\hline
\end{tabular}




\section{$\underline{\text { Analysis by Grouping Truck Classes }}$}

Based on coefficient of regression values, the models derived seem to be reliable to estimate the truck traffic volumes in their respective groups.

Table 4.31 - Linear Regression Models, Growth Rates and Coefficients of Regression $\left(\mathbf{R}^{2}\right)$

Values for Each Truck Classification - (single and multi-unit) Urban Non-Interstates

\begin{tabular}{||c||c|c|c||}
\hline \hline Truck Class & Model & $\begin{array}{c}\text { Overall Growth } \\
\text { Rate }\end{array}$ & $\mathbf{R}^{2}$ \\
\hline \hline TC4 - TC7 & $\mathrm{y}=7.55 \mathrm{x}-14893$ & $3.20 \%$ & 0.81 \\
\hline TC8 - TC13 & $\mathrm{y}=4.6167 \mathrm{x}-9117.5$ & $3.30 \%$ & 0.74 \\
\hline
\end{tabular}

Overall conclusions from the analysis based on Yearly Average of AADTT are described below:

$>$ The most reliable growth rates were predicted for sites on urban non-Interstate highways.

Truck classes TC6 and TC7 resulted in poor coefficients of regression in both the urban and rural categories. Confirmable reasons could not be made for this due to limited source of data. 
Zero growth rates were observed for truck class TC6 in all non-Interstate categories, TC6 and TC8 in rural category and TC11 and TC12 in urban category. The reason for this is that either no trucks or very few trucks were observed at the sites in that particular class and which may not be sufficient to design a model or calculate the growth rates.

$>$ Similar growth rates were observed in all non-Interstate categories and rural category.

\subsection{Growth Factor Method}

The most recent traffic counts are important to understand traffic patterns. Also, the annual average growth rate depends on the most recent traffic count. Hence, current growth rates were estimated for every site and each truck classification. The current growth rate for this project used the AADTT from the two most recent years with one year as the optimum gap between them. The results for the analysis are shown below. The analysis based on truck class and truck groups is reported in Appendix (C). 


\subsubsection{Analysis for Sites}

\section{a) All Non-Interstates}

Based on the growth factor methodology in Chapter 3, truck traffic growth rates, weight factors and weighted average growth rate were estimated for all non-Interstate highways. Table 4.32 shows the results.

Table 4.32 - Weighted Average Growth Rate - All Non-Interstates

\begin{tabular}{|c|c|c|c|c|c|}
\hline Route & Class & SITE & $\begin{array}{c}\text { Sum of trucks in } \\
\text { analyzed two years }\end{array}$ & $\begin{array}{c}\text { Annual Average } \\
\text { Growth Rate }\end{array}$ & Weight/Site \\
\hline \hline US 60 & Rural & 10 & 1852 & $3.00 \%$ & 0.083 \\
\hline WV 152 & Rural & 13 & 641 & $1.00 \%$ & 0.029 \\
\hline US 33 & Rural & 14 & 2922 & $-1.00 \%$ & 0.131 \\
\hline US 35 & Rural & 15 & 4745 & $9.00 \%$ & 0.212 \\
\hline US 52 & Rural & 16 & 1056 & $4.00 \%$ & 0.047 \\
\hline US 119 & Rural & 17 & 464 & $-2.00 \%$ & 0.021 \\
\hline CO 21 & Rural & 19 & 302 & $9.00 \%$ & 0.014 \\
\hline US 220 & Rural & 20 & 396 & $4.00 \%$ & 0.018 \\
\hline US 19 & Rural & 22 & 626 & $9.00 \%$ & 0.028 \\
\hline US 19 & Rural & 23 & 841 & $3.00 \%$ & 0.038 \\
\hline US 60 & Rural & 25 & 787 & $3.00 \%$ & 0.035 \\
\hline WV 25 & Urban & 34 & 1746 & $1.00 \%$ & 0.078 \\
\hline US 60 & Urban & 36 & 1555 & $2.00 \%$ & 0.070 \\
\hline US 11 & Urban & 37 & 780 & $4.00 \%$ & 0.035 \\
\hline WV 61 & Urban & 38 & 346 & $3.00 \%$ & 0.015 \\
\hline WV 114 & Urban & 40 & 596 & $6.00 \%$ & 0.027 \\
\hline WV 94 & Rural & 44 & 1583 & $6.00 \%$ & 0.071 \\
\hline WV 7 & Rural & 45 & 629 & $4.00 \%$ & 0.028 \\
\hline WV 20 & Rural & 48 & 487 & $4.00 \%$ & 0.022 \\
\hline \hline
\end{tabular}

\begin{tabular}{|l|c|}
\hline Mean & $3.80 \%$ \\
\hline Standard Deviation & $3.10 \%$ \\
\hline Coefficient of Variation & $81.60 \%$ \\
\hline
\end{tabular}

\begin{tabular}{|l|l|}
\hline \hline $\begin{array}{l}\text { Weighted Average } \\
\text { Growth Rate }\end{array}$ & $4.00 \%$ \\
\hline
\end{tabular}


The weighted average growth rate and the coefficient of variation obtained in the Table 4.32 are higher than that obtained in the linear regression analysis. This may be due to the large difference in AADTT between the two years considered for analysis.

\section{b) Rural Non-Interstates}

The weighted average growth rate and the coefficient of regression in the above table are higher than those obtained in the linear regression analysis.

Table 4.33 - Weighted Average Growth Rate - Rural Non-Interstates

\begin{tabular}{|c|c|c|c|c|c|}
\hline Route & Class & SITE & $\begin{array}{c}\text { Sum of trucks in } \\
\text { analyzed two years }\end{array}$ & $\begin{array}{c}\text { Annual Average } \\
\text { Growth Rate }\end{array}$ & Weight/Site \\
\hline \hline US 60 & Rural & 10 & 1852 & $3.00 \%$ & 0.107 \\
\hline WV 152 & Rural & 13 & 641 & $1.00 \%$ & 0.037 \\
\hline US 33 & Rural & 14 & 2922 & $-1.00 \%$ & 0.169 \\
\hline US 35 & Rural & 15 & 4745 & $9.00 \%$ & 0.274 \\
\hline US 52 & Rural & 16 & 1056 & $4.00 \%$ & 0.061 \\
\hline US 119 & Rural & 17 & 464 & $-2.00 \%$ & 0.027 \\
\hline CO 21 & Rural & 19 & 302 & $9.00 \%$ & 0.017 \\
\hline US 220 & Rural & 20 & 396 & $4.00 \%$ & 0.023 \\
\hline US 19 & Rural & 22 & 626 & $9.00 \%$ & 0.036 \\
\hline US 19 & Rural & 23 & 841 & $3.00 \%$ & 0.049 \\
\hline US 60 & Rural & 25 & 787 & $3.00 \%$ & 0.045 \\
\hline WV 94 & Rural & 44 & 1583 & $6.00 \%$ & 0.091 \\
\hline WV 7 & Rural & 45 & 629 & $4.00 \%$ & 0.036 \\
\hline WV 20 & Rural & 48 & 487 & $4.00 \%$ & 0.028 \\
\hline
\end{tabular}

\begin{tabular}{|l|c|}
\hline Mean & $4.00 \%$ \\
\hline Standard Deviation & $3.40 \%$ \\
\hline Coefficient of Variation & $85.00 \%$ \\
\hline
\end{tabular}

\section{Weighted Average}

Growth Rate 


\section{c) Urban Non-Interstates}

The weighted average growth rate in the above table is higher than that obtained in the linear regression analysis; however, the CV value in both the analysis has a slight variation.

Table 4.34 - Weighted Average Growth Rate - Urban Non-Interstates

\begin{tabular}{||c|c|c|c|c|c||}
\hline Route & Class & SITE & $\begin{array}{c}\text { Sum of trucks in } \\
\text { analyzed two years }\end{array}$ & $\begin{array}{c}\text { Annual Average } \\
\text { Growth Rate }\end{array}$ & Weight/Site \\
\hline \hline WV 25 & Urban & 34 & 1746 & $1.00 \%$ & 0.348 \\
\hline US 60 & Urban & 36 & 1555 & $2.00 \%$ & 0.31 \\
\hline US 11 & Urban & 37 & 780 & $4.00 \%$ & 0.155 \\
\hline WV 61 & Urban & 38 & 346 & $3.00 \%$ & 0.069 \\
\hline WV 114 & Urban & 40 & 596 & $6.00 \%$ & 0.119 \\
\hline
\end{tabular}

\begin{tabular}{|l|c|}
\hline Mean & $3.20 \%$ \\
\hline Standard Deviation & $1.90 \%$ \\
\hline Coefficient of Variation & $59.40 \%$ \\
\hline
\end{tabular}

Weighted Average Growth Rate 
4.3 Comparison among the resulted Annual Average Growth Rates by different Methods

\subsubsection{Annual Average Growth Rate for All, Rural and Urban Non-Interstate Highways}

Table 4.35 shows that the growth rate at rural non-Interstate highways is increasing at a higher rate than at urban non-Interstate highways. Also, the annual average growth rates in all three analyses ranges between $2.00 \%$ and $4.00 \%$. Therefore, overall growth rate for non-Interstate highways in WestVirginia could be taken as 3.50\%.

Table 4.35 - Comparison of Annual Average Growth Rates

\begin{tabular}{||c||c|c|c||}
\hline \multicolumn{1}{||}{} & \multicolumn{3}{|c||}{ Average Growth Rate for Daily Truck Traffic } \\
\cline { 2 - 4 } & $\begin{array}{c}\text { Weighted Average } \\
\text { (linear regression) }\end{array}$ & $\begin{array}{c}\text { Yearly Average } \\
\text { (linear regression) }\end{array}$ & Growth Factor \\
\hline \hline All & $3.44 \%$ & $3.50 \%$ & $4.00 \%$ \\
\hline Rural & $3.84 \%$ & $3.90 \%$ & $4.20 \%$ \\
\hline Urban & $2.09 \%$ & $2.10 \%$ & $2.40 \%$ \\
\hline
\end{tabular}

It can also be observed that the growth rates by growth factor method are higher than the growth rates by linear regression analysis. 


\subsubsection{Comparison by Each Truck Classification}

The annual growth rates for each truck classification based on all, rural and urban non-Interstate categories were compared to finalize a reliable method to estimate the truck traffic volumes on non-Interstate highways in West Virginia. The comparison of the results is shown in Table 4.36

Table 4.36 - Comparison of Annual Average Growth Rates - All Non-Interstate Highways

\begin{tabular}{||c||c|c|c||}
\hline \multirow{2}{*}{ All } & \multicolumn{3}{c||}{ Average Growth Rate for Daily Truck Traffic } \\
\cline { 2 - 4 } & $\begin{array}{c}\text { Weighted Average } \\
\text { (linear regression) }\end{array}$ & $\begin{array}{c}\text { Yearly Average } \\
\text { (linear regression) }\end{array}$ & Growth Factor \\
\hline \hline TC4 & $4.92 \%$ & $6.00 \%$ & $13.80 \%$ \\
\hline TC5 & $2.63 \%$ & $3.00 \%$ & $1.90 \%$ \\
\hline TC6 & $-0.40 \%$ & - & $-2.40 \%$ \\
\hline TC7 & $-4.52 \%$ & $-1.00 \%$ & $12.50 \%$ \\
\hline TC8 & $0.05 \%$ & $1.00 \%$ & $3.80 \%$ \\
\hline TC9 & $5.17 \%$ & $6.00 \%$ & $-2.30 \%$ \\
\hline TC10 & $8.85 \%$ & $10.00 \%$ & - \\
\hline TC11 & - & $7.00 \%$ & $-0.60 \%$ \\
\hline TC12 & - & $9.00 \%$ & $14.00 \%$ \\
\hline TC13 & $14.37 \%$ & & \\
\hline \hline
\end{tabular}

The most stable growth rate for non-Interstate highways in West Virginia was observed for truck class TC5 (two-axle single unit trucks including camping and recreational vehicles) with an overall growth rate of about $3.00 \%$. 
In comparison to all three methods, considerable growth rates are seen for truck classes TC4 and TC5 with an average growth rate of about 3.00\%. All other truck classes show wide disparity in growth rates calculated by different methods.

Table 4.37 - Comparison of Annual Average Growth Rates - Rural Non-Interstates

\begin{tabular}{||c||c|c|c||}
\hline \multirow{2}{*}{\multicolumn{1}{|c||}{ Rural }} & \multicolumn{3}{c|}{ Average Growth Rate for Daily Truck Traffic } \\
\cline { 2 - 4 } & $\begin{array}{c}\text { Weighted Average } \\
\text { (linear regression) }\end{array}$ & $\begin{array}{c}\text { Yearly Average } \\
\text { (linear regression) }\end{array}$ & Growth Factor \\
\hline \hline \multirow{2}{*}{ TC4 } & $4.89 \%$ & $6.00 \%$ & $1.30 \%$ \\
\hline TC5 & $2.30 \%$ & $3.00 \%$ & $1.80 \%$ \\
\hline TC6 & $-1.38 \%$ & - & $-3.90 \%$ \\
\hline TC7 & $-6.37 \%$ & $-3.00 \%$ & $9.60 \%$ \\
\hline TC8 & $-1.38 \%$ & - & $-3.50 \%$ \\
\hline TC9 & $5.64 \%$ & $6.00 \%$ & $-4.30 \%$ \\
\hline TC10 & $9.43 \%$ & $10.00 \%$ & - \\
\hline TC11 & - & $8.00 \%$ & $0.50 \%$ \\
\hline TC12 & - & $6.00 \%$ & - \\
\hline TC13 & $15.94 \%$ & $16.00 \%$ & \\
\hline
\end{tabular}


From the Table 4.38, it is clear that the better growth rates are seen for truck classes TC5 and TC6, when calculated by all three methods. Negative growth rates are observed for truck classes TC9 and TC13 calculated by growth factor method. This is due to the large variation in overall truck volumes at each site in the urban category.

Table 4.38 - Comparison of Annual Average Growth Rates - Urban Non-Interstates

\begin{tabular}{||c||c|c|c||}
\hline \multirow{2}{*}{ Urban } & \multicolumn{3}{|c||}{ Average Growth Rate for Daily Truck Traffic } \\
\cline { 2 - 4 } & $\begin{array}{c}\text { Weighted Average } \\
\text { (linear regression) }\end{array}$ & $\begin{array}{c}\text { Yearly Average } \\
\text { (linear regression) }\end{array}$ & Growth Factor \\
\hline \hline \multirow{2}{*}{ TC4 } & $4.93 \%$ & $6.00 \%$ & $36.00 \%$ \\
\hline \multirow{2}{*}{ TC5 } & $3.18 \%$ & $3.00 \%$ & $1.90 \%$ \\
\hline TC6 & $2.17 \%$ & $2.00 \%$ & $2.70 \%$ \\
\hline TC7 & $4.21 \%$ & $5.00 \%$ & $22.10 \%$ \\
\hline TC8 & $4.79 \%$ & $5.00 \%$ & $-1.50 \%$ \\
\hline TC9 & $0.74 \%$ & $1.00 \%$ & $3.90 \%$ \\
\hline TC10 & $7.10 \%$ & $8.00 \%$ & $-8.50 \%$ \\
\hline TC11 & - & - & \\
\hline TC12 & - & - & \\
\hline TC13 & $4.28 \%$ & $4.00 \%$ & \\
\hline
\end{tabular}




\subsubsection{Comparison Based on Truck Groups (Single/Multi-Unit)}

The growth rates determined based on truck classification groups were compared for all, rural and urban non-Interstate highways. Two groups were classified as TC4-TC7 with single-unit trucks and TC8-TC13 with multi-unit or heavy truck vehicles. The comparisons of the results are shown in the following tables.

Table 4.39 - Comparison of Annual Average Growth Rates - All Non-Interstate Highways

\begin{tabular}{|c||c|c|c||}
\hline \multirow{2}{*}{ All } & \multicolumn{3}{|c|}{ Average Growth Rate for Daily Truck Traffic } \\
\cline { 2 - 4 } & $\begin{array}{c}\text { Weighted Average } \\
\text { (linear regression) }\end{array}$ & $\begin{array}{c}\text { Yearly Average } \\
\text { (linear regression) }\end{array}$ & Growth Factor \\
\hline \hline TC4 - TC7 & $1.98 \%$ & $2.50 \%$ & $5.00 \%$ \\
\hline TC8 - TC13 & $5.17 \%$ & $5.60 \%$ & $8.00 \%$ \\
\hline
\end{tabular}

From the above table, it is evident that stable growth rates are observed for singleunit trucks on non-Interstate highways in WV. The growth rate for the same could be established as $2.50 \%$.

Also Table 4.40 shows that multi-unit trucks are increasing at higher rate than single-unit trucks. The overall growth rate for single-unit trucks could be estimated as $2.00 \%$.

Table 4.40 - Comparison of Annual Average Growth Rates - Rural Non-Interstates

\begin{tabular}{||c||c|c|c||}
\hline \multirow{2}{*}{ Rural } & \multicolumn{3}{|c||}{ Average Growth Rate for Daily Truck Traffic } \\
\cline { 2 - 4 } & $\begin{array}{c}\text { Weighted Average } \\
\text { (linear regression) }\end{array}$ & $\begin{array}{c}\text { Yearly Average } \\
\text { (linear regression) }\end{array}$ & Growth Factor \\
\hline \hline TC4 - TC7 & $1.32 \%$ & $2.00 \%$ & $4.00 \%$ \\
\hline TC8 - TC13 & $5.42 \%$ & $5.90 \%$ & $9.00 \%$ \\
\hline
\end{tabular}


Table 4.41 - Comparison of Annual Average Growth Rates - Urban Non-Interstates

\begin{tabular}{||c||c|c|c||}
\hline \multirow{2}{*}{ Urban } & \multicolumn{3}{|c||}{ Average Growth Rate for Daily Truck Traffic } \\
\cline { 2 - 4 } & $\begin{array}{c}\text { Weighted Average } \\
\text { (linear regression) }\end{array}$ & $\begin{array}{c}\text { Yearly Average } \\
\text { (linear regression) }\end{array}$ & Growth Factor \\
\hline \hline TC4 - TC7 & $3.26 \%$ & $3.20 \%$ & $5.00 \%$ \\
\hline TC8 - TC13 & $3.31 \%$ & $3.30 \%$ & $5.00 \%$ \\
\hline
\end{tabular}

Growth rates are observed to be similar in both truck groups by each method for urban non-Interstate highways. Based on all three methods, the overall growth rate can be estimated as $3.50 \%$. 


\section{CHAPTER 5}

\section{CONCLUSIONS AND RECOMMENDATIONS}

\subsection{Conclusions}

In most of the states truck traffic forecasting is often treated as a part of total traffic volume forecasting. In this study, statistical models were developed to forecast truck traffic volumes by estimating growth rates for non-Interstate highways in West Virginia. Theoretical workings for each method were explored based on its capabilities, advantages and disadvantages. Data collected by the West Virginia Permanent Automatic Traffic Recorders from 1995 to 2003, was used to derive the models. The collected data was tested for errors and the discrepancies were removed based on the confidence interval calculated from the mean and the standard deviation. The processed data was then used to develop models and predict growth rates.

Based on comparison of results obtained by using different techniques, it can be concluded that the linear regression technique is more reliable for forecasting AADTT on non-Interstate highways in West Virginia. Regression analysis including socioeconomic factors usually account for major forces that drive truck traffic growth. Also the complete use of the data available makes regression models, the stronger and reliable predictors of growth rates. They provide a consistent forecasting framework across multiple jurisdictions. Therefore, the linear regression analysis is considered to be the best forecasting technique for this study. The following table compares the different forecasting methods that were useful for this study. 
Table 5.1 Comparing Different Forecasting Methods

\begin{tabular}{|c|c|c|c|c|c|}
\hline Methods & $\begin{array}{c}\text { Four } \\
\text { Area* }\end{array}$ & $\begin{array}{c}\text { County } \\
\text { Level }\end{array}$ & $\begin{array}{c}\text { Passenger } \\
\text { vs. Truck Travel }\end{array}$ & $\begin{array}{c}\text { Socioeconomic } \\
\text { Variables }\end{array}$ & $\begin{array}{c}\text { Land } \\
\text { Use }\end{array}$ \\
\hline Regression Analysis & $\mathrm{X}$ & $\mathrm{X}$ & $\mathrm{X}$ & $\mathrm{X}$ & \\
\hline $\begin{array}{c}\text { Growth Factor } \\
\text { Method }\end{array}$ & $\mathrm{X}$ & $\mathrm{X}$ & $\mathrm{X}$ & & \\
\hline $\begin{array}{c}\text { Socioeconomic Data } \\
\text { Based Methods }\end{array}$ & & $\mathrm{X}$ & $\mathrm{X}$ & $\mathrm{X}$ & \\
\hline
\end{tabular}

* Urban Interstate, Urban Non-Interstate, Rural Interstate, and Rural Non- Interstate.

(Feng Liu and Robert G. Kaiser)

Socioeconomic data based methods do not rely on the characteristics of the roadways and also do not produce forecasts by area groups. Growth factor method, though very popular do not respond to changing socioeconomic conditions over time.

The primary limitation of this study was that some of the data was either missing, or eliminated due to errors. Also, due to the limited data available, socioeconomic factors were not incorporated in deriving the models for this study. This, in turn, had its affect on the results obtained. Hence, the results of this study can be validated by comparing them with the current growth factors used by the West Virginia DOT and the US DOT in their study. Due to changing travel patterns and demographics in West Virginia, these factors can still be used to understand future truck traffic patterns. 
The following are some of the points that were observed from the results.

- Weighted average growth rates from the growth factor method are higher than those from the regression analysis. Also, the values for coefficient of variation are higher for the growth factor method when compared to regression analysis.

- Based on coefficients of variation, truck class 13 is more reliable for all nonInterstate highways in West Virginia. For rural non-Interstates, truck class 13 and at urban non-Interstates, truck class 8 seems to be more reliable.

- Based on coefficients of regression, reliable models were observed from the year average based method, with a value of about 0.9 .

- Heavy vehicle or multi-unit trucks are growing at a higher rate with an average of about $5.00 \%$, than single-unit trucks. About $75 \%$ of the truck traffic on nonInterstates in West Virginia belongs to heavy vehicle category.

- Annual average growth rates from all the three methods used for this study ranged from $2.09 \%$ to $4.20 \%$. An overall growth rate for non-Interstate highways in West Virginia could be established as about 3.50\%. 


\subsection{Recommendations and Further Work}

- Analyzing large amount of data for estimating growth rates can result in more reliable models by reducing the errors and discrepancies.

- In order to improve the quality of count data, it is highly recommended that the permanent count stations be inspected on a regular basis and that regular maintenance be performed.

- For better understanding of truck traffic patterns and the variations in growth rate, it is necessary to supply the various socioeconomic variables that could support the model and should be included in the statistical model development. Also, these variables should be updated periodically.

- The factors obtained have a wide range of applications in transportation planning and designing projects across the state. 


\section{REFERENCES}

American Association of State Highway and Transportation Officials (AASHTO). (1992). Guidelines for traffic data programs, Joint Task Force on Traffic Monitoring Standards, AASHTO, Washington, D.C.

Barrett, Monica L; Graves, Clark; Allen, David L; Pigman, Jerry G; Kentucky Transportation Center; "Analysis of Traffic Growth Rates," Research Report. KTC-0115/SPR213-00-1F, University of Kentucky, August 2001.

Dixon, Michael; "The Effects of Errors in Annual Average Daily Traffic Forecasting: Study of Highways in Rural Idaho," National Institute for Advanced Transportation Technology, Idaho, September 2004.

Freight Impacts on Ohio's Roadway System; by Cambridge Systematics, Inc., March 2002.

Gargett, David; Cosgrove, David; "Predicting Traffic Growth in Australian Cities," Bureau of Transport and Regional Economics, Canberra. Paper for the Australasian Transport Research Forum, 29 September-1 October, Adelaide.

Growing Traffic in Rural America: Safety, Mobility and Economic Challenges in America's Heartland; by The Road Information Program (TRIP), March 2005.

Guidebook on Statewide Travel Forecasting; Federal Highway Administration, Center for Urban Transportation Studies - University of Wisconsin - Milwaukee, March 1999.

Hallmark, Shauna L; Lamptey, Stephen; "Evaluation of Different Methods to Calculate Heavy-Truck VMT," Midwest Transportation Consortium, Project 2002-02., Iowa, December 2004.

Highway Performance Monitoring System Field Manual; Federal Highway Administration, Office of Highway Policy Information, May 2005.

Maring, Gary; "Freight Trends/Issues, Multimodal System Flows and Forecasts, and Policy Implications," USDOT, April 2001. 
Memmott, F. W; NCHRP Report 260: Application of Statewide Freight Demand Forecasting Techniques, TRB, National Research Council, Washington, D.C., 1983.

Mohamad, D., Sinha, K. C., and Kuczek, T. (1998), “An Annual Average Daily Traffic Prediction Model for County Roads," presented at Transportation Research Board, 77th Annual Meeting, January 11-15, 1998, Washington D. C.

Ning Wang; Dr. Hualiang Teng; "VMT Estimation Associated with ITS Data and Maintenance of Loop Detectors", VA, August 2004.

Provo Canyon Traffic Analysis, Utah and Wasatch Counties, by Fehr \& Peers Associates, Inc., August 2000.

Rebovich, Andrew J; “An Evaluation of Statewide Truck Forecasting Methods," College of Engineering and Mineral Resources at West Virginia University, 2004.

Traffic Monitoring Guide; U.S. Department of Transportation, Federal Highway Administration, Office of Highway Policy Information, May 1, 2001.

U.S. Department of Transportation (FHWA HPMS). Federal Highway Administration. Highway Performance Monitoring System, 2005.

U.S. Department of Transportation (USDOT), Federal Highway Administration (FHWA). 2002a. Freight Analysis Framework.

Zhao, Fang; Chung, Soon; "Estimation of Annual Average Daily Traffic in a Florida County Using GIS and Regression," Florida International University. Transportation Research Board, TRB Paper 01-3440. 2001. 


\section{APPENDICES}

\section{APPENDIX A}

\section{$\underline{\text { Linear Regression Models for Each Site according to Truck Classification }}$}

\section{$\underline{\text { Rural Non-Interstate Highways }}$}

\begin{tabular}{|c|c|c|c|c|}
\hline Truck Class & Site10 & Site13 & Site14 & Site15 \\
\hline TC4 & $y=0.35 x-694.43$ & $y=0.9333 x-1856.6$ & $y=0.2833 x-557.61$ & $y=-0.5333 x+1086.6$ \\
\hline TC5 & $y=2.4667 x-4859.1$ & $y=2.1905 x-4296.7$ & $y=2.7 x-5232.7$ & $y=1.6333 x-3168.4$ \\
\hline TC6 & $y=-7.6 x+15278$ & $y=1.0667 x-2096.7$ & $y=2.25 x-4339.3$ & $y=3.0333 x-5972.5$ \\
\hline TC7 & $y=-5.2333 x+10497$ & $y=0.3167 x-629.24$ & $y=1.3183 x-2590.2$ & $y=-0.2833 x+570.05$ \\
\hline TC8 & $y=0.4 x-771.6$ & $y=-1.3 x+2640.1$ & $y=1.2 x-2309.1$ & $y=-14.433 x+28992$ \\
\hline TC9 & $y=0.6833 x-1052.3$ & $y=0.6 x-1163.7$ & $y=21.1 x-41749$ & $y=165.68 x-329720$ \\
\hline TC10 & $y=0.0833 x-163.47$ & $y=0.05 x-93.061$ & $y=0.3333 x-657.11$ & $y=6.8167 x-13598$ \\
\hline TC11 & - & - & - & $y=16.6 x-32990$ \\
\hline TC12 & - & - & - & $y=1.5667 x-3110.2$ \\
\hline TC13 & $y=0.6333 x-1261.8$ & $y=0.3167 x-631.13$ & $y=1.9167 x-3822.6$ & $y=4.2667 x-8513$ \\
\hline
\end{tabular}

\begin{tabular}{|c|c|c|c|c|}
\hline Truck Class & Site16 & Site17 & Site19 & Site20 \\
\hline TC4 & $\mathrm{y}=4.0833 \mathrm{x}-8132.6$ & $\mathrm{y}=0.3833 \mathrm{x}-763.73$ & $\mathrm{y}=6.2667 \mathrm{x}-12512$ & $\mathrm{y}=-0.6167 \mathrm{x}+1236.6$ \\
\hline TC5 & $\mathrm{y}=6.1 \mathrm{x}-12108$ & $\mathrm{y}=1.1167 \mathrm{x}-2178$ & $\mathrm{y}=20.683 \mathrm{x}-41272$ & $\mathrm{y}=0.6833 \mathrm{x}-1342$ \\
\hline TC6 & $\mathrm{y}=-10.033 \mathrm{x}+20147$ & $\mathrm{y}=0.7167 \mathrm{x}-1403.1$ & $\mathrm{y}=0.0333 \mathrm{x}-61.967$ & $\mathrm{y}=0.2167 \mathrm{x}-414.56$ \\
\hline TC7 & $\mathrm{y}=-0.9333 \mathrm{x}+1874.7$ & $\mathrm{y}=0.4167 \mathrm{x}-830.25$ & $\mathrm{y}==-0.017 \mathrm{x}+34.43$ & $\mathrm{y}=-0.5 \mathrm{x}+1004.2$ \\
\hline TC8 & $\mathrm{y}=4.9667 \mathrm{x}-9870.3$ & $\mathrm{y}=1.3167 \mathrm{x}-2606$ & $\mathrm{y}=0.8333 \mathrm{x}-1654.6$ & $\mathrm{y}=0.3 \mathrm{x}-588.48$ \\
\hline TC9 & $\mathrm{y}=0.5833 \mathrm{x}-1104.5$ & $\mathrm{y}=0.2667 \mathrm{x}-516.96$ & $\mathrm{y}=0.0167 \mathrm{x}-28.761$ & $\mathrm{y}=0.3167 \mathrm{x}-603.57$ \\
\hline TC10 & $\mathrm{y}=2.7667 \mathrm{x}-5519.6$ & $\mathrm{y}=0.6333 \mathrm{x}-1252.1$ & $\mathrm{y}=0.05 \mathrm{x}-99.283$ & - \\
\hline TC11 & $\mathrm{y}=2.4 \mathrm{x}-4790.3$ & $\mathrm{y}=0.3667 \mathrm{x}-730.86$ & - & $\mathrm{y}=0.35 \mathrm{x}-698.98$ \\
\hline TC12 & - & - & - & - \\
\hline TC13 & - & - & - & - \\
\hline
\end{tabular}




\begin{tabular}{|c|c|c|c|c|}
\hline Truck Class & Site22 & Site23 & Site25 & Site44 \\
\hline TC4 & $\mathrm{y}=0.2833 \mathrm{x}-564.16$ & $\mathrm{y}=3.0833 \mathrm{x}-6139.5$ & $\mathrm{y}=0.05 \mathrm{x}-98.061$ & $\mathrm{y}=0.4 \mathrm{x}-788.16$ \\
\hline TC5 & $\mathrm{y}=0.2167 \mathrm{x}-403.23$ & $\mathrm{y}=1.7667 \mathrm{x}-3474$ & $\mathrm{y}=0.8833 \mathrm{x}-1675$ & $\mathrm{y}=0.7333 \mathrm{x}-1409$ \\
\hline TC6 & $\mathrm{y}=0.7167 \mathrm{x}-1393.4$ & $\mathrm{y}=0.15 \mathrm{x}-253.41$ & $\mathrm{y}=1.1667 \mathrm{x}-2284.6$ & $\mathrm{y}=4.6 \mathrm{x}-9155.3$ \\
\hline TC7 & $\mathrm{y}=0.6833 \mathrm{x}-1350.3$ & $\mathrm{y}=0.25 \mathrm{x}-492.53$ & $\mathrm{y}=0.3 \mathrm{x}-595.7$ & $\mathrm{y}=0.4667 \mathrm{x}-925.98$ \\
\hline TC8 & $\mathrm{y}=1.4667 \mathrm{x}-2913.8$ & $\mathrm{y}=-0.2167 \mathrm{x}+463.12$ & $\mathrm{y}=1.1333 \mathrm{x}-2222.3$ & $\mathrm{y}=3.6833 \mathrm{x}-7318.2$ \\
\hline TC9 & $\mathrm{y}=22.5 \mathrm{x}-44867$ & $\mathrm{y}=-0.3 \mathrm{x}+654.7$ & $\mathrm{y}=5.8167 \mathrm{x}-11542$ & $\mathrm{y}=8.7667 \mathrm{x}-17435$ \\
\hline TC10 & $\mathrm{y}=0.3 \mathrm{x}-597.92$ & $\mathrm{y}=-0.1167 \mathrm{x}+234.66$ & $\mathrm{y}=0.4 \mathrm{x}-796.82$ & $\mathrm{y}=19.367 \mathrm{x}-38590$ \\
\hline TC11 & - & - & - & - \\
\hline TC12 & - & - & - & - \\
\hline TC13 & $\mathrm{y}=0.2167 \mathrm{x}-431.78$ & $\mathrm{y}=0.4667 \mathrm{x}-930.64$ & $\mathrm{y}=0.2833 \mathrm{x}-563.49$ & $\mathrm{y}=0.7333 \mathrm{x}-1454.3$ \\
\hline
\end{tabular}

\begin{tabular}{|c|c|c|}
\hline Truck Class & Site45 & Site48 \\
\hline TC4 & $\mathrm{y}=0.2667 \mathrm{x}-520.84$ & $\mathrm{y}=0.3 \mathrm{x}-591.37$ \\
\hline TC5 & $\mathrm{y}=0.05 \mathrm{x}-57.394$ & $\mathrm{y}=-1.7167 \mathrm{x}+3486.5$ \\
\hline TC6 & $\mathrm{y}=1.2667 \mathrm{x}-2502.3$ & $\mathrm{y}=0.4167 \mathrm{x}-790.92$ \\
\hline TC7 & $\mathrm{y}=0.1667 \mathrm{x}-328.72$ & $\mathrm{y}=-0.75 \mathrm{x}+1504.7$ \\
\hline TC8 & $\mathrm{y}=0.6667 \mathrm{x}-1305.9$ & $\mathrm{y}=0.2 \mathrm{x}-377.58$ \\
\hline TC9 & $\mathrm{y}=-0.9333 \mathrm{x}+1912.5$ & $\mathrm{y}=0.5667 \mathrm{x}-1098.2$ \\
\hline TC10 & $\mathrm{y}=0.0333 \mathrm{x}-65.411$ & $\mathrm{y}=0.1 \mathrm{x}-198.12$ \\
\hline TC11 & - & - \\
\hline TC12 & - & - \\
\hline TC13 & $\mathrm{y}=0.2667 \mathrm{x}-530.29$ & $\mathrm{y}=0.2 \mathrm{x}-395.8$ \\
\hline
\end{tabular}




\section{Urban Non-Interstate Highways}

\begin{tabular}{|c|c|c|c|}
\hline Truck Class & Site34 & Site36 & Site37 \\
\hline TC4 & $\mathrm{y}=0.9 \mathrm{x}-1776.8$ & $\mathrm{y}=5.5833 \mathrm{x}-11127$ & $\mathrm{y}=1.2167 \mathrm{x}-2417.7$ \\
\hline TC5 & $\mathrm{y}=15.6 \mathrm{x}-30975$ & $\mathrm{y}=-0.47 \mathrm{x}+1039.6$ & $\mathrm{y}=2.6 \mathrm{x}-5092.5$ \\
\hline TC6 & $\mathrm{y}=3.4833 \mathrm{x}-6829.4$ & $\mathrm{y}=1.5667 \mathrm{x}-3042.9$ & $\mathrm{y}=2.1333 \mathrm{x}-4237$ \\
\hline TC7 & $\mathrm{y}=0.3333 \mathrm{x}-662.89$ & $\mathrm{y}=1.3667 \mathrm{x}-2710$ & $\mathrm{y}=\mathrm{x}-1995.2$ \\
\hline TC8 & $\mathrm{y}=3.1667 \mathrm{x}-6267.6$ & $\mathrm{y}=6.4833 \mathrm{x}-12908$ & $\mathrm{y}=\mathrm{x}-1974.1$ \\
\hline TC9 & $\mathrm{y}=3.0167 \mathrm{x}-5909.4$ & $\mathrm{y}=-1.8333 \mathrm{x}+3800.2$ & $\mathrm{y}=1.7833 \mathrm{x}-3544.9$ \\
\hline TC10 & $\mathrm{y}=-0.6667 \mathrm{x}+1336.3$ & $\mathrm{y}=8.1167 \mathrm{x}-16165$ & $\mathrm{y}=0.0167 \mathrm{x}-32.317$ \\
\hline TC11 & - & - & - \\
\hline TC12 & - & - & $\mathrm{y}=-0.05 \mathrm{x}+101.17$ \\
\hline TC13 & $\mathrm{y}=0.35 \mathrm{x}-695.54$ & $\mathrm{y}=-0.0667 \mathrm{x}+135.38$ & \\
\hline
\end{tabular}

\begin{tabular}{|c|c|c|}
\hline Truck Class & Site38 & Site40 \\
\hline TC4 & $\mathrm{y}=-0.1333 \mathrm{x}+267.87$ & $\mathrm{y}=0.4333 \mathrm{x}-851.9$ \\
\hline TC5 & $\mathrm{y}=-1.3333 \mathrm{x}+2740.8$ & $\mathrm{y}=3.0667 \mathrm{x}-6028.4$ \\
\hline TC6 & $\mathrm{y}=-0.4167 \mathrm{x}+846.58$ & $\mathrm{y}=0.7833 \mathrm{x}-1541.2$ \\
\hline TC7 & $\mathrm{y}=0.0667 \mathrm{x}-133.16$ & $\mathrm{y}=-0.0333 \mathrm{x}+68.744$ \\
\hline TC8 & $\mathrm{y}=0.9833 \mathrm{x}-1948.9$ & $\mathrm{y}=0.9333 \mathrm{x}-1845.3$ \\
\hline TC9 & $\mathrm{y}=0.25 \mathrm{x}-486.75$ & $\mathrm{y}=0.0667 \mathrm{x}-124.93$ \\
\hline TC10 & $\mathrm{y}=0.7667 \mathrm{x}-1529.9$ & $\mathrm{y}=0.05 \mathrm{x}-99.172$ \\
\hline TC11 & - & - \\
\hline TC12 & - & $\mathrm{y}=0.2 \mathrm{x}-397.91$ \\
\hline TC13 & $\mathrm{y}=0.15 \mathrm{x}-299.29$ & - \\
\hline
\end{tabular}

Note: ' $\boldsymbol{x}$ ' is the independent variable for Time Period

' $y$ ' is the Annual Average Daily Truck Traffic to be predicted and is dependent on ' $x$ '. 


\section{APPENDIX B}

Annual Average Growth Rates and Weight Factors for Each Truck Classification at Rural and Urban Sites

\section{$\underline{\text { Rural Non-Interstate Highways }}$}

Annual Average Growth Rate

\begin{tabular}{|c|c|c|c|c|c|c|c|c|c|c|c|c|c|c|}
\hline Truck Class & Site10 & Site13 & Site14 & Site15 & Site16 & Site17 & Site19 & Site20 & Site22 & Site23 & Site25 & Site44 & Site45 & Site48 \\
\hline TC4 & $3.89 \%$ & $7.54 \%$ & $2.80 \%$ & $-2.65 \%$ & $11.03 \%$ & $7.60 \%$ & $8.71 \%$ & $-31.00 \%$ & $9.33 \%$ & $9.63 \%$ & $1.67 \%$ & $2.67 \%$ & $2.08 \%$ & $3.00 \%$ \\
\hline TC5 & $2.98 \%$ & $2.41 \%$ & $1.42 \%$ & $1.55 \%$ & $5.13 \%$ & $1.90 \%$ & $9.80 \%$ & $2.52 \%$ & $0.73 \%$ & $2.77 \%$ & $0.88 \%$ & $1.26 \%$ & $0.11 \%$ & $-3.58 \%$ \\
\hline TC6 & $-9.27 \%$ & $2.68 \%$ & $1.32 \%$ & $4.97 \%$ & $-19.67 \%$ & $2.12 \%$ & $0.60 \%$ & $1.10 \%$ & $1.71 \%$ & $0.29 \%$ & $2.49 \%$ & $8.85 \%$ & $3.02 \%$ & $0.95 \%$ \\
\hline TC7 & $-26.15 \%$ & $6.40 \%$ & $2.28 \%$ & $-9.33 \%$ & $-13.29 \%$ & $8.40 \%$ & $-2.00 \%$ & $-16.67 \%$ & $3.40 \%$ & $2.78 \%$ & $6.00 \%$ & $5.22 \%$ & $2.43 \%$ & $-15.00 \%$ \\
\hline TC8 & $1.18 \%$ & $-3.61 \%$ & $1.18 \%$ & $-15.75 \%$ & $7.77 \%$ & $5.06 \%$ & $6.38 \%$ & $2.50 \%$ & $5.88 \%$ & $-0.56 \%$ & $2.71 \%$ & $8.98 \%$ & $2.79 \%$ & $1.18 \%$ \\
\hline TC9 & $0.23 \%$ & $1.58 \%$ & $3.86 \%$ & $7.86 \%$ & $0.95 \%$ & $1.59 \%$ & $0.40 \%$ & $0.86 \%$ & $11.90 \%$ & $-0.56 \%$ & $6.19 \%$ & $4.90 \%$ & $-2.16 \%$ & $1.54 \%$ \\
\hline TC10 & $1.60 \%$ & $0.71 \%$ & $2.75 \%$ & $12.87 \%$ & $9.55 \%$ & $4.50 \%$ & - & - & $15.00 \%$ & $-12.00 \%$ & $13.33 \%$ & $10.53 \%$ & $3.00 \%$ & $1.00 \%$ \\
\hline TC11 & - & - & - & - & - & - & - & - & - & - & - & - & - & - \\
\hline TC12 & - & - & - & - & - & - & - & - & - & - & - & - & - & - \\
\hline TC13 & $10.50 \%$ & $10.67 \%$ & $24.00 \%$ & $13.77 \%$ & $34.29 \%$ & $9.25 \%$ & - & $8.75 \%$ & $22.00 \%$ & $23.50 \%$ & $14.00 \%$ & $9.13 \%$ & $13.50 \%$ & $4.00 \%$ \\
\hline
\end{tabular}




\section{$\underline{\text { Weight Factors }}$}

\begin{tabular}{|c|c|c|c|c|c|c|c|c|c|c|c|c|c|c|}
\hline Truck Class & Site10 & Site13 & Site14 & Site15 & Site16 & Site17 & Site19 & Site20 & Site22 & Site23 & Site25 & Site44 & Site45 & Site48 \\
\hline TC4 & 0.034 & 0.058 & 0.056 & 0.131 & 0.193 & 0.016 & 0.100 & 0.025 & 0.014 & 0.155 & 0.012 & 0.073 & 0.078 & 0.053 \\
\hline TC5 & 0.073 & 0.083 & 0.167 & 0.098 & 0.088 & 0.055 & 0.075 & 0.024 & 0.030 & 0.058 & 0.092 & 0.058 & 0.043 & 0.056 \\
\hline TC6 & 0.113 & 0.047 & 0.209 & 0.120 & 0.119 & 0.039 & 0.006 & 0.024 & 0.052 & 0.061 & 0.063 & 0.053 & 0.039 & 0.055 \\
\hline TC7 & 0.238 & 0.025 & 0.303 & 0.025 & 0.060 & 0.018 & 0.007 & 0.031 & 0.105 & 0.048 & 0.027 & 0.046 & 0.030 & 0.037 \\
\hline TC8 & 0.047 & 0.070 & 0.152 & 0.236 & 0.098 & 0.044 & 0.019 & 0.019 & 0.031 & 0.051 & 0.073 & 0.076 & 0.045 & 0.038 \\
\hline TC9 & 0.112 & 0.013 & 0.154 & 0.530 & 0.022 & 0.006 & 0.002 & 0.011 & 0.040 & 0.020 & 0.031 & 0.032 & 0.017 & 0.012 \\
\hline TC10 & 0.015 & 0.033 & 0.045 & 0.139 & 0.053 & 0.067 & 0.003 & - & 0.009 & 0.007 & 0.013 & 0.601 & 0.006 & 0.009 \\
\hline TC11 & - & - & - & - & - & - & - & - & - & - & - & - & - & - \\
\hline TC12 & - & - & - & - & - & - & - & - & - & - & - & - & - & - \\
\hline TC13 & 0.064 & 0.028 & 0.132 & 0.243 & 0.111 & 0.032 & 0.005 & 0.010 & 0.020 & 0.034 & 0.044 & 0.176 & 0.042 & 0.060 \\
\hline
\end{tabular}

\section{Average Annual Growth Rates for Single and Multi-Unit Trucks}

\begin{tabular}{|c|c|c|c|c|c|c|c|c|c|c|c|c|c|c|}
\hline Truck Class & Site10 & Site13 & Site14 & Site15 & Site16 & Site17 & Site19 & Site20 & Site22 & Site23 & Site25 & Site44 & Site45 & Site48 \\
\hline TC4 - TC7 & $-5.16 \%$ & $3.03 \%$ & $1.53 \%$ & $2.04 \%$ & $-0.36 \%$ & $2.55 \%$ & $9.33 \%$ & $-0.42 \%$ & $2.00 \%$ & $3.34 \%$ & $1.55 \%$ & $4.63 \%$ & $1.65 \%$ & $-1.64 \%$ \\
\hline TC8 - TC13 & $0.47 \%$ & $-0.39 \%$ & $3.65 \%$ & $7.02 \%$ & $6.66 \%$ & $4.23 \%$ & $5.11 \%$ & $1.83 \%$ & $11.28 \%$ & $-0.18 \%$ & $5.16 \%$ & $7.90 \%$ & $0.04 \%$ & $1.78 \%$ \\
\hline
\end{tabular}




\section{Urban Non-Interstate Highways}

Annual Average Growth Rate

\begin{tabular}{||c||c|c|c|c|c||}
\hline Truck Class & Site34 & Site36 & Site37 & Site38 & Site40 \\
\hline \hline TC4 & $4.29 \%$ & $6.27 \%$ & $6.78 \%$ & $-13.00 \%$ & $2.53 \%$ \\
\hline TC5 & $7.61 \%$ & $-0.42 \%$ & $1.95 \%$ & $-1.82 \%$ & $2.58 \%$ \\
\hline TC6 & $2.35 \%$ & $1.65 \%$ & $4.63 \%$ & $-3.23 \%$ & $3.39 \%$ \\
\hline TC7 & $6.60 \%$ & $3.81 \%$ & $8.33 \%$ & - & $-3.00 \%$ \\
\hline TC8 & $5.76 \%$ & $4.76 \%$ & $3.13 \%$ & $4.67 \%$ & $4.04 \%$ \\
\hline TC9 & $2.32 \%$ & $-1.43 \%$ & $5.09 \%$ & $1.79 \%$ & $1.00 \%$ \\
\hline TC10 & $-22.33 \%$ & $8.73 \%$ & $2.00 \%$ & $12.83 \%$ & $5.00 \%$ \\
\hline TC11 & - & - & - & - & - \\
\hline TC12 & - & - & - & - & - \\
\hline TC13 & $8.75 \%$ & $-7.00 \%$ & $-5.00 \%$ & $15.00 \%$ & $10.00 \%$ \\
\hline
\end{tabular}

$\underline{\text { Weight Factors }}$

\begin{tabular}{||c||c|c|c|c|c||}
\hline Truck Class & Site34 & Site36 & Site37 & Site38 & Site40 \\
\hline \hline TC4 & 0.257 & 0.396 & 0.166 & 0.015 & 0.165 \\
\hline TC5 & 0.354 & 0.169 & 0.177 & 0.127 & 0.172 \\
\hline TC6 & 0.464 & 0.308 & 0.095 & 0.047 & 0.085 \\
\hline TC7 & 0.110 & 0.702 & 0.121 & - & 0.067 \\
\hline TC8 & 0.355 & 0.293 & 0.141 & 0.095 & 0.116 \\
\hline TC9 & 0.406 & 0.455 & 0.067 & 0.044 & 0.028 \\
\hline TC10 & 0.053 & 0.882 & 0.015 & 0.039 & 0.011 \\
\hline TC11 & - & - & - & - & - \\
\hline TC12 & - & - & - & - & - \\
\hline TC13 & 0.416 & 0.213 & 0.124 & 0.056 & 0.191 \\
\hline \hline
\end{tabular}

Average Annual Growth Rates for Single and Multi-Unit Trucks

\begin{tabular}{|c||c|c|c|c|c||}
\hline Truck Class & Site34 & Site36 & Site37 & Site38 & Site40 \\
\hline \hline TC4 - TC7 & $5.36 \%$ & $2.41 \%$ & $3.33 \%$ & $-2.07 \%$ & $2.66 \%$ \\
\hline TC8 - TC13 & $2.46 \%$ & $3.56 \%$ & $3.99 \%$ & $5.12 \%$ & $3.79 \%$ \\
\hline
\end{tabular}


APPENDIX C

Growth Factor Method

$\underline{\text { Analysis for Each Truck Classification }}$

\section{All Non-Interstate Highways}

Annual Average Growth Rate

\begin{tabular}{|c|c|c|c|c|c|c|c|c|c|c|c|c|c|c|c|c|c|c|c|}
\hline $\begin{array}{l}\text { Truck } \\
\text { Class }\end{array}$ & Site10 & Site13 & Site14 & Site15 & Site16 & Site17 & Site19 & Site20 & Site22 & Site23 & Site25 & Site34 & Site36 & Site37 & Site38 & Site40 & Site44 & Site45 & Site48 \\
\hline TC4 & $34.20 \%$ & $-6.90 \%$ & $5.40 \%$ & $-2.40 \%$ & $\begin{array}{l}-15.60 \% \\
\end{array}$ & - & - & $-29.30 \%$ & - & $23.40 \%$ & $22.50 \%$ & $-8.30 \%$ & $75.20 \%$ & $2.90 \%$ & - & $2-2.80 \%$ & $3.50 \%$ & - & $19.50 \%$ \\
\hline TC5 & $5.90 \%$ & $-4.10 \%$ & $5.70 \%$ & $8.60 \%$ & $5.00 \%$ & $-1.70 \%$ & - & $-5.10 \%$ & - & $0.80 \%$ & $3.70 \%$ & $-5.00 \%$ & $3.20 \%$ & $10.00 \%$ & $-1.30 \%$ & $7.50 \%$ & $-4.80 \%$ & $2.40 \%$ & $-5.70 \%$ \\
\hline TC6 & $25.60 \%$ & $11.80 \%$ & $2.40 \%$ & $-46.20 \%$ & $-15.80 \%$ & $6.50 \%$ & $11.80 \%$ & $2.60 \%$ & $1.20 \%$ & $5.20 \%$ & $-3.00 \%$ & $3.60 \%$ & $-4.00 \%$ & $19.90 \%$ & $4.10 \%$ & $-4.10 \%$ & $5.20 \%$ & $14.60 \%$ & $4.90 \%$ \\
\hline TC7 & $-4.70 \%$ & $29.10 \%$ & $9.90 \%$ & $22.50 \%$ & $32.30 \%$ & $29.10 \%$ & - & - & $8.50 \%$ & - & - & $29.10 \%$ & $20.00 \%$ & $41.40 \%$ & - & $-42.30 \%$ & $22.50 \%$ & $18.30 \%$ & $29.10 \%$ \\
\hline TC8 & $19.00 \%$ & $-3.90 \%$ & $5.30 \%$ & $-12.20 \%$ & $-3.70 \%$ & $-12.60 \%$ & - & $-3.90 \%$ & $9.10 \%$ & $43.30 \%$ & $3.20 \%$ & $-16.60 \%$ & $61.70 \%$ & $8.90 \%$ & $5.10 \%$ & $13.00 \%$ & $-31.40 \%$ & $-7.40 \%$ & $-24.70 \%$ \\
\hline TC9 & $-3.70 \%$ & $1.30 \%$ & $7.40 \%$ & $18.50 \%$ & $-1.60 \%$ & & $11.80 \%$ & $13.00 \%$ & $9.70 \%$ & $22.50 \%$ & $-1.60 \%$ & $1.20 \%$ & $-10.30 \%$ & $20.80 \%$ & $18.30 \%$ & - & $28.70 \%$ & $-2.20 \%$ & $-2.60 \%$ \\
\hline TC10 & $29.10 \%$ & $-11.80 \%$ & $9.50 \%$ & $19.70 \%$ & $17.50 \%$ & $-9.30 \%$ & $-100.00 \%$ & - & $-18.40 \%$ & - & $-13.40 \%$ & $73.20 \%$ & $-2.60 \%$ & - & $144.90 \%$ & - & $-11.90 \%$ & $-29.30 \%$ & $-42.30 \%$ \\
\hline TC11 & - & - & - & - & - & - & - & - & - & - & - & - & - & - & - & - & - & - & - \\
\hline TC12 & - & - & - & - & - & - & - & - & - & - & - & - & - & - & - & - & - & - & - \\
\hline TC13 & - & $22.50 \%$ & $-21.60 \%$ & $54.40 \%$ & $-20.20 \%$ & $15.50 \%$ & - & $100.00 \%$ & $-29.30 \%$ & - & $-29.30 \%$ & $41.40 \%$ & $-50.00 \%$ & - & - & $-29.30 \%$ & $-47.50 \%$ & $-18.40 \%$ & $-8.70 \%$ \\
\hline
\end{tabular}

* The boxes with no values indicate either no growth rate of that class is observed at that site or no truck traffic is sighted of that particular class 
Weight Factors and Weighted Average Growth Rate

\begin{tabular}{|c|c|c|c|c|c|c|c|c|c|c|c|c|c|c|c|c|c|c|c|c|}
\hline $\begin{array}{l}\text { Truck } \\
\text { Class }\end{array}$ & Site10 & Site13 & Site14 & Site15 & Site16 & Site17 & Site19 & Site20 & Site22 & Site23 & Site25 & Site34 & Site36 & Site37 & Site38 & Site40 & Site44 & Site45 & Site48 & $\begin{array}{c}\text { Weighted } \\
\text { Average } \\
\text { Growth Rate }\end{array}$ \\
\hline TC4 & 0.021 & 0.043 & 0.029 & 0.063 & 0.136 & 0.009 & 0.119 & 0.009 & 0.009 & 0.081 & 0.008 & 0.070 & 0.181 & 0.054 & 0.003 & 0.054 & 0.044 & 0.040 & 0.026 & $13.80 \%$ \\
\hline TC5 & 0.044 & 0.054 & 0.102 & 0.055 & 0.064 & 0.034 & 0.079 & 0.016 & 0.017 & 0.036 & 0.055 & 0.122 & 0.062 & 0.069 & 0.042 & 0.063 & 0.034 & 0.024 & 0.029 & $1.90 \%$ \\
\hline TC6 & 0.060 & 0.032 & 0.151 & 0.123 & 0.055 & 0.029 & 0.004 & 0.018 & 0.037 & 0.045 & 0.044 & 0.129 & 0.089 & 0.035 & 0.011 & 0.022 & 0.045 & 0.033 & 0.038 & $-2.40 \%$ \\
\hline TC7 & 0.111 & 0.021 & 0.279 & 0.013 & 0.029 & 0.021 & 0.005 & 0.016 & 0.097 & 0.047 & 0.026 & 0.021 & 0.161 & 0.047 & 0.003 & 0.011 & 0.039 & 0.032 & 0.021 & $12.50 \%$ \\
\hline TC8 & 0.035 & 0.045 & 0.116 & 0.125 & 0.080 & 0.036 & 0.016 & 0.015 & 0.028 & 0.035 & 0.057 & 0.080 & 0.113 & 0.035 & 0.024 & 0.025 & 0.077 & 0.031 & 0.028 & $3.80 \%$ \\
\hline TC9 & 0.084 & 0.010 & 0.140 & 0.497 & 0.017 & 0.005 & 0.001 & 0.009 & 0.048 & 0.012 & 0.026 & 0.035 & 0.040 & 0.008 & 0.003 & 0.002 & 0.040 & 0.012 & 0.010 & $11.80 \%$ \\
\hline TC10 & 0.009 & 0.018 & 0.025 & 0.104 & 0.058 & 0.036 & 0.001 & - & 0.006 & 0.002 & 0.008 & 0.005 & 0.221 & 0.002 & 0.008 & 0.002 & 0.486 & 0.003 & 0.005 & $-2.30 \%$ \\
\hline TC11 & - & - & - & - & - & - & - & - & - & - & - & - & - & - & - & - & - & - & - & - \\
\hline TC12 & - & - & - & - & - & - & - & - & - & - & - & - & - & - & - & - & - & - & - & - \\
\hline TC13 & 0.060 & 0.025 & 0.106 & 0.221 & 0.090 & 0.035 & - & 0.025 & 0.015 & 0.020 & 0.030 & 0.030 & 0.025 & 0.010 & 0.010 & 0.030 & 0.186 & 0.025 & 0.055 & $-0.60 \%$ \\
\hline
\end{tabular}

\section{$\underline{\text { Precision Analysis }}$}

\begin{tabular}{||c||c|c|c||}
\hline $\begin{array}{c}\text { Truck } \\
\text { Class }\end{array}$ & Mean & $\begin{array}{c}\text { Standard } \\
\text { Deviation }\end{array}$ & $\begin{array}{c}\text { Coefficient of } \\
\text { Variation }\end{array}$ \\
\hline \hline TC4 & 0.09 & 0.26 & $289.00 \%$ \\
\hline TC5 & 0.01 & 0.05 & $500.00 \%$ \\
\hline TC6 & 0.02 & 0.15 & $750.00 \%$ \\
\hline TC7 & 0.17 & 0.21 & $124.00 \%$ \\
\hline TC8 & 0.03 & 0.22 & $733.00 \%$ \\
\hline TC9 & 0.08 & 0.11 & $138.00 \%$ \\
\hline TC10 & 0.04 & 0.54 & $1350.00 \%$ \\
\hline TC11 & - & - & - \\
\hline TC12 & - & - & - \\
\hline TC13 & -0.01 & 0.43 & $-4300.00 \%$ \\
\hline \hline
\end{tabular}


Rural Non-Interstate Highways

\section{Annual Average Growth Rate}

\begin{tabular}{|c|c|c|c|c|c|c|c|c|c|c|c|c|c|c|}
\hline Truck Class & Site10 & Site13 & Site14 & Site15 & Site16 & Site17 & Site19 & Site20 & Site22 & Site23 & Site25 & Site44 & Site45 & Site48 \\
\hline TC4 & $34.20 \%$ & $-6.90 \%$ & $5.40 \%$ & $-2.40 \%$ & $-15.60 \%$ & 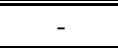 & - & $-29.30 \%$ & 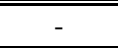 & $23.40 \%$ & $22.50 \%$ & $3.50 \%$ & 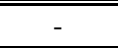 & $19.50 \%$ \\
\hline TC5 & $5.90 \%$ & $-4.10 \%$ & $5.70 \%$ & $8.60 \%$ & $5.00 \%$ & $-1.70 \%$ & - & $-5.10 \%$ & - & $0.80 \%$ & $3.70 \%$ & $-4.80 \%$ & $2.40 \%$ & $-5.70 \%$ \\
\hline TC6 & $25.60 \%$ & $11.80 \%$ & $2.40 \%$ & $-46.20 \%$ & $-15.80 \%$ & $6.50 \%$ & $11.80 \%$ & $2.60 \%$ & $1.20 \%$ & $5.20 \%$ & $-3.00 \%$ & $5.20 \%$ & $14.60 \%$ & $4.90 \%$ \\
\hline TC7 & $-4.70 \%$ & $29.10 \%$ & $9.90 \%$ & $22.50 \%$ & $32.30 \%$ & $29.10 \%$ & - & - & $8.50 \%$ & - & - & $22.50 \%$ & $18.30 \%$ & $29.10 \%$ \\
\hline TC8 & $19.00 \%$ & $-3.90 \%$ & $5.30 \%$ & $-12.20 \%$ & $-3.70 \%$ & $-12.60 \%$ & - & $-3.90 \%$ & $9.10 \%$ & $43.30 \%$ & $3.20 \%$ & $-31.40 \%$ & $-7.40 \%$ & $-24.70 \%$ \\
\hline TC9 & $-3.70 \%$ & $1.30 \%$ & $7.40 \%$ & $18.50 \%$ & $-1.60 \%$ & - & $11.80 \%$ & $13.00 \%$ & $9.70 \%$ & $22.50 \%$ & $-1.60 \%$ & $28.70 \%$ & $-2.20 \%$ & $-2.60 \%$ \\
\hline TC10 & $29.10 \%$ & $-11.80 \%$ & $9.50 \%$ & $19.70 \%$ & $17.50 \%$ & $-9.30 \%$ & $-100.00 \%$ & - & $-18.40 \%$ & - & $-13.40 \%$ & $-11.90 \%$ & $-29.30 \%$ & $-42.30 \%$ \\
\hline TC11 & - & - & - & - & - & - & - & - & - & - & - & - & - & - \\
\hline TC12 & - & - & - & - & - & - & - & - & - & - & - & - & - & - \\
\hline TC13 & - & $22.50 \%$ & $-21.60 \%$ & $54.40 \%$ & $-20.20 \%$ & $15.50 \%$ & - & $100.00 \%$ & $-29.30 \%$ & - & $-29.30 \%$ & $-47.50 \%$ & $-18.40 \%$ & $-8.70 \%$ \\
\hline
\end{tabular}

\section{Weight Factors and Weighted Average Growth Rate}

\begin{tabular}{||c||c|c|c|c|c|c|c|c|c|c|c|c|c|c|c||}
\hline \hline $\begin{array}{c}\text { Truck } \\
\text { Class }\end{array}$ & Site10 & Site13 & Site14 & Site15 & Site16 & Site17 & Site19 & Site20 & Site22 & Site23 & Site25 & Site44 & Site45 & Site48 & $\begin{array}{c}\text { Weighted } \\
\text { Average } \\
\text { Growth Rate }\end{array}$ \\
\hline \hline TC4 & 0.034 & 0.067 & 0.046 & 0.098 & 0.213 & 0.014 & 0.187 & 0.014 & 0.014 & 0.127 & 0.012 & 0.070 & 0.062 & 0.041 & $1.30 \%$ \\
\hline TC5 & 0.069 & 0.084 & 0.158 & 0.085 & 0.100 & 0.053 & 0.123 & 0.025 & 0.026 & 0.056 & 0.085 & 0.054 & 0.038 & 0.045 & $1.80 \%$ \\
\hline TC6 & 0.085 & 0.045 & 0.211 & 0.172 & 0.078 & 0.040 & 0.006 & 0.025 & 0.052 & 0.063 & 0.061 & 0.063 & 0.047 & 0.053 & $-3.90 \%$ \\
\hline TC7 & 0.146 & 0.028 & 0.368 & 0.017 & 0.038 & 0.028 & 0.007 & 0.021 & 0.128 & 0.063 & 0.035 & 0.052 & 0.042 & 0.028 & $9.60 \%$ \\
\hline TC8 & 0.048 & 0.062 & 0.161 & 0.173 & 0.110 & 0.050 & 0.022 & 0.021 & 0.038 & 0.048 & 0.079 & 0.106 & 0.043 & 0.039 & $-3.50 \%$ \\
\hline TC9 & 0.092 & 0.011 & 0.154 & 0.545 & 0.019 & 0.005 & 0.001 & 0.010 & 0.052 & 0.014 & 0.029 & 0.043 & 0.013 & 0.011 & $13.00 \%$ \\
\hline TC10 & 0.012 & 0.024 & 0.033 & 0.136 & 0.076 & 0.047 & 0.002 & - & 0.008 & 0.003 & 0.011 & 0.638 & 0.005 & 0.006 & $-4.30 \%$ \\
\hline TC11 & - & - & - & - & - & - & - & - & - & - & - & - & - & - & - \\
\hline TC12 & - & - & - & - & - & - & - & - & - & - & - & - & - & - & - \\
\hline TC13 & 0.067 & 0.028 & 0.118 & 0.247 & 0.101 & 0.039 & - & 0.028 & 0.017 & 0.022 & 0.034 & 0.208 & 0.028 & 0.062 & $0.50 \%$ \\
\hline
\end{tabular}




\section{$\underline{\text { Precision Analysis }}$}

\begin{tabular}{||c||c|c|c||}
\hline $\begin{array}{c}\text { Truck } \\
\text { Class }\end{array}$ & Mean & $\begin{array}{c}\text { Standard } \\
\text { Deviation }\end{array}$ & $\begin{array}{c}\text { Coefficient of } \\
\text { Variation }\end{array}$ \\
\hline \hline TC4 & 0.05 & 0.20 & $400.00 \%$ \\
\hline TC5 & 0.01 & 0.05 & $500.00 \%$ \\
\hline TC6 & 0.02 & 0.17 & $850.00 \%$ \\
\hline TC7 & 0.20 & 0.12 & $60.00 \%$ \\
\hline TC8 & -0.02 & 0.19 & $-950.00 \%$ \\
\hline TC9 & 0.08 & 0.11 & $138.00 \%$ \\
\hline TC10 & -0.13 & 0.34 & $-262.00 \%$ \\
\hline TC11 & - & - & - \\
\hline TC12 & - & - & - \\
\hline TC13 & 0.02 & 0.44 & $2200.00 \%$ \\
\hline \hline
\end{tabular}


Urban Non-Interstate Highways

\section{Annual Average Growth Rate}

\begin{tabular}{||c||c|c|c|c|c||}
\hline Truck Class & Site34 & Site36 & Site37 & Site38 & Site40 \\
\hline \hline TC4 & $-8.30 \%$ & $75.20 \%$ & $2.90 \%$ & - & $-2.80 \%$ \\
\hline TC5 & $-5.00 \%$ & $3.20 \%$ & $10.00 \%$ & $-1.30 \%$ & $7.50 \%$ \\
\hline TC6 & $3.60 \%$ & $-4.00 \%$ & $19.90 \%$ & $4.10 \%$ & $-4.10 \%$ \\
\hline TC7 & $29.10 \%$ & $20.00 \%$ & $41.40 \%$ & - & $-42.30 \%$ \\
\hline TC8 & $-16.60 \%$ & $61.70 \%$ & $8.90 \%$ & $5.10 \%$ & $13.00 \%$ \\
\hline TC9 & $1.20 \%$ & $-10.30 \%$ & $20.80 \%$ & $18.30 \%$ & - \\
\hline TC10 & $73.20 \%$ & $-2.60 \%$ & - & $144.90 \%$ & - \\
\hline TC11 & - & - & - & - & - \\
\hline TC12 & - & - & - & - & - \\
\hline TC13 & $41.40 \%$ & $-50.00 \%$ & - & - & $-29.30 \%$ \\
\hline
\end{tabular}

Weight Factors and Weighted Average Growth Rate

\begin{tabular}{||c||c|c|c|c|c|c||}
\hline \hline $\begin{array}{c}\text { Truck } \\
\text { Class }\end{array}$ & Site34 & Site36 & Site37 & Site38 & Site40 & $\begin{array}{c}\text { Weighted } \\
\text { Average } \\
\text { Growth Rate }\end{array}$ \\
\hline \hline TC4 & 0.195 & 0.500 & 0.148 & 0.008 & 0.148 & $36.00 \%$ \\
\hline TC5 & 0.342 & 0.173 & 0.192 & 0.117 & 0.176 & $1.90 \%$ \\
\hline TC6 & 0.450 & 0.312 & 0.123 & 0.039 & 0.076 & $2.70 \%$ \\
\hline TC7 & 0.087 & 0.663 & 0.196 & 0.011 & 0.043 & $22.10 \%$ \\
\hline TC8 & 0.290 & 0.407 & 0.128 & 0.087 & 0.089 & $23.00 \%$ \\
\hline TC9 & 0.401 & 0.448 & 0.092 & 0.037 & 0.022 & $-1.50 \%$ \\
\hline TC10 & 0.019 & 0.927 & 0.010 & 0.034 & 0.010 & $3.90 \%$ \\
\hline TC11 & - & - & - & - & - & - \\
\hline TC12 & - & - & - & - & - & - \\
\hline TC13 & 0.286 & 0.238 & 0.095 & 0.095 & 0.286 & $-8.50 \%$ \\
\hline
\end{tabular}

\section{$\underline{\text { Precision Analysis }}$}

\begin{tabular}{||c||c|c|c||}
\hline $\begin{array}{c}\text { Truck } \\
\text { Class }\end{array}$ & Mean & $\begin{array}{c}\text { Standard } \\
\text { Deviation }\end{array}$ & $\begin{array}{c}\text { Coefficient of } \\
\text { Variation }\end{array}$ \\
\hline \hline TC4 & 0.17 & 0.39 & $229.00 \%$ \\
\hline TC5 & 0.03 & 0.06 & $200.00 \%$ \\
\hline TC6 & 0.04 & 0.10 & $250.00 \%$ \\
\hline TC7 & 0.12 & 0.37 & $308.00 \%$ \\
\hline TC8 & 0.14 & 0.29 & $207.00 \%$ \\
\hline TC9 & 0.08 & 0.15 & $188.00 \%$ \\
\hline TC10 & 0.72 & 0.74 & $103.00 \%$ \\
\hline TC11 & - & - & - \\
\hline TC12 & - & - & - \\
\hline TC13 & -0.13 & 0.48 & $-369.00 \%$ \\
\hline \hline
\end{tabular}


Grouping of Truck Class (TC4-TC7, TC8-TC13) - All Non-Interstates

Annual Average Growth Rates for Single and Multi- Weight Factors for Single and Multi-Unit Truck

Unit Truck Classes - All Non-Interstates

\begin{tabular}{|c|c|c|}
\hline \multirow{2}{*}{ Site } & \multicolumn{2}{|c|}{ Truck Class } \\
\hline & TC4 - TC7 & TC8 - TC13 \\
\hline 10 & $12.60 \%$ & $-1.60 \%$ \\
\hline 13 & - & $-1.70 \%$ \\
\hline 14 & $4.90 \%$ & $6.60 \%$ \\
\hline 15 & $-23.50 \%$ & $15.70 \%$ \\
\hline 16 & $-4.80 \%$ & $-0.90 \%$ \\
\hline 17 & $2.10 \%$ & $-7.30 \%$ \\
\hline 19 & $71.20 \%$ & - \\
\hline 20 & $-3.60 \%$ & $11.00 \%$ \\
\hline 22 & $2.20 \%$ & $8.90 \%$ \\
\hline 23 & $5.90 \%$ & $28.70 \%$ \\
\hline 25 & $1.70 \%$ & $-1.00 \%$ \\
\hline 34 & $-1.80 \%$ & $-4.20 \%$ \\
\hline 36 & $12.50 \%$ & $7.10 \%$ \\
\hline 37 & $12.50 \%$ & $14.10 \%$ \\
\hline 38 & - & $16.40 \%$ \\
\hline 40 & $3.60 \%$ & $4.90 \%$ \\
\hline 44 & $1.10 \%$ & $-5.50 \%$ \\
\hline 45 & $7.30 \%$ & $-5.30 \%$ \\
\hline 48 & $1.40 \%$ & $-12.30 \%$ \\
\hline
\end{tabular}

Classes - All Non-Interstates

\begin{tabular}{|c|c|c|}
\hline \multirow{2}{*}{ Site } & \multicolumn{2}{|c|}{ Truck Class } \\
\hline & TC4 - TC7 & TC8 - TC13 \\
\hline 10 & 0.052 & 0.065 \\
\hline 13 & 0.044 & 0.016 \\
\hline 14 & 0.122 & 0.119 \\
\hline 15 & 0.076 & 0.426 \\
\hline 16 & 0.067 & 0.031 \\
\hline 17 & 0.029 & 0.013 \\
\hline 19 & 0.043 & 0.003 \\
\hline 20 & 0.016 & 0.009 \\
\hline 22 & 0.028 & 0.038 \\
\hline 23 & 0.044 & 0.015 \\
\hline 25 & 0.045 & 0.028 \\
\hline 34 & 0.115 & 0.038 \\
\hline 36 & 0.089 & 0.064 \\
\hline 37 & 0.056 & 0.012 \\
\hline 38 & 0.026 & 0.007 \\
\hline 40 & 0.046 & 0.006 \\
\hline 44 & 0.040 & 0.083 \\
\hline 45 & 0.030 & 0.014 \\
\hline 48 & 0.031 & 0.013 \\
\hline
\end{tabular}

\section{Weighted Average Growth (all)}

\begin{tabular}{|c|c||}
\hline Truck Class & $\begin{array}{c}\text { Weighted Average } \\
\text { Growth Rate }\end{array}$ \\
\hline \hline TC4 - TC7 & $5.00 \%$ \\
\hline TC8 - TC13 & $8.00 \%$ \\
\hline
\end{tabular}

Precision Analysis (all)

\begin{tabular}{|c|c|c|c||}
\hline Truck Class & Mean & $\begin{array}{c}\text { Standard } \\
\text { Deviation }\end{array}$ & $\begin{array}{c}\text { Coefficient of } \\
\text { Variation }\end{array}$ \\
\hline \hline TC4 - TC7 & 0.06 & 0.19 & $317.00 \%$ \\
\hline TC8 - TC13 & 0.04 & 0.10 & $250.00 \%$ \\
\hline
\end{tabular}




\section{Grouping of Truck Class (TC4-TC7, TC8-TC13) - Rural Non-Interstates}

Annual Average Growth Rates for Single and Multi- Weight Factors for Single and Multi-Unit Truck

Unit Truck Classes - Rural Non-Interstates

\begin{tabular}{|c|c|c|}
\hline \multirow{2}{*}{ Site } & \multicolumn{2}{|c|}{ Truck Class } \\
\hline & TC4 - TC7 & TC8 - TC13 \\
\hline 10 & $12.60 \%$ & $-1.60 \%$ \\
\hline 13 & - & $-1.70 \%$ \\
\hline 14 & $4.90 \%$ & $6.60 \%$ \\
\hline 15 & $-23.50 \%$ & $15.70 \%$ \\
\hline 16 & $-4.80 \%$ & $-0.90 \%$ \\
\hline 17 & $2.10 \%$ & $-7.30 \%$ \\
\hline 19 & $71.20 \%$ & - \\
\hline 20 & $-3.60 \%$ & $11.00 \%$ \\
\hline 22 & $2.20 \%$ & $8.90 \%$ \\
\hline 23 & $5.90 \%$ & $28.70 \%$ \\
\hline 25 & $1.70 \%$ & $-1.00 \%$ \\
\hline 44 & $1.10 \%$ & $-5.50 \%$ \\
\hline 45 & $7.30 \%$ & $-5.30 \%$ \\
\hline 48 & $1.40 \%$ & $-12.30 \%$ \\
\hline
\end{tabular}

Classes - Rural Non-Interstates

\begin{tabular}{|c|c|c|}
\hline \multirow{2}{*}{ Site } & \multicolumn{2}{|c|}{ Truck Class } \\
\cline { 2 - 3 } & TC4- TC7 & TC8 - TC13 \\
\hline $\mathbf{1 0}$ & 0.077 & 0.074 \\
\hline $\mathbf{1 3}$ & 0.067 & 0.019 \\
\hline $\mathbf{1 4}$ & 0.183 & 0.136 \\
\hline $\mathbf{1 5}$ & 0.114 & 0.488 \\
\hline $\mathbf{1 6}$ & 0.100 & 0.035 \\
\hline $\mathbf{1 7}$ & 0.043 & 0.014 \\
\hline $\mathbf{1 9}$ & 0.065 & 0.004 \\
\hline $\mathbf{2 0}$ & 0.024 & 0.010 \\
\hline $\mathbf{2 2}$ & 0.042 & 0.043 \\
\hline $\mathbf{2 3}$ & 0.066 & 0.017 \\
\hline $\mathbf{2 5}$ & 0.068 & 0.032 \\
\hline $\mathbf{4 4}$ & 0.059 & 0.095 \\
\hline $\mathbf{4 5}$ & 0.044 & 0.016 \\
\hline $\mathbf{4 8}$ & 0.047 & 0.015 \\
\hline
\end{tabular}

Weighted Average Growth (Rural)

\begin{tabular}{||c||c||}
\hline Truck Class & $\begin{array}{c}\text { Weighted Average } \\
\text { Growth Rate }\end{array}$ \\
\hline \hline TC4 - TC7 & $4.00 \%$ \\
\hline TC8 - TC13 & $9.00 \%$ \\
\hline
\end{tabular}

Precision Analysis (Rural)

\begin{tabular}{|c||c|c|c||}
\hline Truck Class & Mean & $\begin{array}{c}\text { Standard } \\
\text { Deviation }\end{array}$ & $\begin{array}{c}\text { Coefficient of } \\
\text { Variation }\end{array}$ \\
\hline \hline TC4 - TC7 & 0.06 & 0.21 & $350.00 \%$ \\
\hline TC8 - TC13 & 0.03 & 0.11 & $367.00 \%$ \\
\hline
\end{tabular}




\section{Grouping of Truck Class (TC4-TC7, TC8-TC13) - Urban Non-Interstates}

Annual Average Growth Rates for Single and Multi- Weight Factors for Single and Multi-Unit Truck

Unit Truck Classes - Urban Non-Interstates

\begin{tabular}{|c||c|c|}
\hline \multirow{2}{*}{ Site } & \multicolumn{2}{|c|}{ Truck Class } \\
\cline { 2 - 3 } & TC4- TC7 & TC8- TC13 \\
\hline \multirow{3}{*}{34} & $-1.80 \%$ & $-4.20 \%$ \\
\hline $\mathbf{3 6}$ & $12.50 \%$ & $7.10 \%$ \\
\hline $\mathbf{3 7}$ & $12.50 \%$ & $14.10 \%$ \\
\hline $\mathbf{3 8}$ & - & $16.40 \%$ \\
\hline $\mathbf{4 0}$ & $3.60 \%$ & $4.90 \%$ \\
\hline
\end{tabular}

Classes - Urban Non-Interstates

\begin{tabular}{|c|c|c|}
\hline \multirow{2}{*}{ Site } & \multicolumn{2}{|c|}{ Truck Class } \\
\cline { 2 - 3 } & TC4- TC7 & TC8 - TC13 \\
\hline $\mathbf{3 4}$ & 0.347 & 0.301 \\
\hline $\mathbf{3 6}$ & 0.268 & 0.505 \\
\hline $\mathbf{3 7}$ & 0.168 & 0.092 \\
\hline $\mathbf{3 8}$ & 0.079 & 0.055 \\
\hline $\mathbf{4 0}$ & 0.139 & 0.047 \\
\hline
\end{tabular}

Weighted Average Growth (Urban)

\begin{tabular}{||c||c||}
\hline Truck Class & $\begin{array}{c}\text { Weighted Average } \\
\text { Growth Rate }\end{array}$ \\
\hline \hline TC4 - TC7 & $5.00 \%$ \\
\hline TC8 - TC13 & $5.00 \%$ \\
\hline
\end{tabular}

Precision Analysis (Urban)

\begin{tabular}{|c|c||c|c||}
\hline Truck Class & Mean & $\begin{array}{c}\text { Standard } \\
\text { Deviation }\end{array}$ & $\begin{array}{c}\text { Coefficient of } \\
\text { Variation }\end{array}$ \\
\hline \hline TC4 - TC7 & 0.05 & 0.07 & $140.00 \%$ \\
\hline TC8 - TC13 & 0.08 & 0.08 & $100.00 \%$ \\
\hline
\end{tabular}

